Illinois State University

ISU ReD: Research and eData

Theses and Dissertations

3-7-2017

\title{
Colorblind Policies And The Discourses That Uphold Them: The Social Construction Of Bullying
}

Kathleen M. O'Brien

Illinois State University, kobrien@ilstu.edu

Follow this and additional works at: https://ir.library.illinoisstate.edu/etd

Part of the Education Commons

\section{Recommended Citation}

O'Brien, Kathleen M., "Colorblind Policies And The Discourses That Uphold Them: The Social Construction Of Bullying" (2017). Theses and Dissertations. 830.

https://ir.library.illinoisstate.edu/etd/830

This Dissertation is brought to you for free and open access by ISU ReD: Research and eData. It has been accepted for inclusion in Theses and Dissertations by an authorized administrator of ISU ReD: Research and eData. For more information, please contact ISUReD@ilstu.edu. 


\title{
COLORBLIND POLICIES AND THE DISCOURSES THAT UPHOLD THEM: \\ THE SOCIAL CONSTRUCTION OF BULLYING
}

\author{
Kathleen O’Brien
}

\section{Pages}

This research explores the relationship between the social construction of bullying and race in K-12 schools using Crenshaw's (1991) theory of intersectionality. The central research questions are: In what ways is the bullying discourse connected to race and racialized discourses in PK-12 settings? How do bullying discourses and policies offer protection to some students while portraying/positioning others as bullies? In what ways do bullying discourses and policies privilege and afford institutional protection for some students while marginalizing others? How do the participants explicitly name race or use coded racial language when discussing their experiences and perceptions of bullying? Twenty high school seniors were interviewed. Twelve participants attend an alternative high school because they have been expelled from or pushed out of mainstream schooling. They are primarily students of color from low-income backgrounds. The other eight students attend a college-preparatory high school where they must have high grades and few behavioral infractions. They are mostly white, middle-class or wealthy students. Critical discourse analysis was used to analyze the data. Findings include that students of color and white students from low-income backgrounds are multiply-marginalized through a criminalization process when they are not protected when they are bullied, when they defend themselves when bullied, by being labeled bullies, and through discipline related to bullying. While newer school bullying policies include protection of various vulnerable groups, including 
students of color, the policies are meaningless unless enacted in such a way that actually protects students and interrupts the criminalization process.

KEYWORDS: Intersectionality, Bullying, Marginalization, Criminalization of Black students 
COLORBLIND POLICIES AND THE DISCOURSES THAT UPHOLD THEM:

THE SOCIAL CONSTRUCTION OF BULLYING

\author{
KATHLEEN O'BRIEN
}

A Dissertation Submitted in Partial

Fulfillment of the Requirements

for the Degree of

DOCTOR OF PHILOSOPHY

Department of Educational Administration and Foundations

ILLINOIS STATE UNIVERSITY 
(C) 2017 Kathleen O’Brien 
COLORBLIND POLICIES AND THE DISCOURSES THAT UPHOLD THEM:

THE SOCIAL CONSTRUCTION OF BULLYING

\author{
KATHLEEN O'BRIEN
}

COMMITTEE MEMBERS:

Beth Hatt, Chair

Pamela Hoff

Dianne Renn

Terry Husband 


\section{ACKNOWLEDGMENTS}

This work is dedicated to the children and young adults who shared their stories in this research and to other students who have suffered in similar ways. Their lives have been stolen from them in countless ways by a system and individuals within this system that normalize the sacrificing of children and young adults. Their humanity went unrecognized, their voices were ignored, and their pleas for help were dismissed. Our country requires them to be in a public sphere, Monday through Friday, where their basic human needs and right to be safe were

violated. Not only were they victims of the atrocities told throughout their stories, but then through being pathologized and blamed for this inhumane treatment by their teachers, their administrators, and the system which is pervaded by whiteness and white supremacy.

I share the following quotes because they capture the essence of the ways the bullying discourse has marginalized and deeply affected the students in this study.

The society has transmitted their war to these students. Taken their pathology and passed it on. Their pathological greed and have shifted it to them [the students]_James Baldwin

Of course, the mind can rationalize fighting back...but the heart, the heart would never understand. Then you would be divided in yourself, the heart and the mind, and the war would be inside you-Dali Lama

Society's problems have been shifted onto the most vulnerable in society-marginalized children in schools. The students have little choice but to try to deal with the fallout of that which has been forced upon them-how to finish school and how to reckon the dysfunction that has been placed on them.

K. O. 


\section{CONTENTS}

Page

ACKNOWLEDGMENTS

TABLES Di - vi

FIGURES Nii

CHAPTER I: INTRODUCTION 1

Introduction of the Study 1

$\begin{array}{ll}\text { Significance of the Study } & 4\end{array}$

$\begin{array}{ll}\text { Conceptual Framework } & 10\end{array}$

$\begin{array}{ll}\text { Intersectionality } & 13\end{array}$

$\begin{array}{ll}\text { Intersectionality and Identity } & 17\end{array}$

African American Learners and Identity 18

CHAPTER II: LITERATURE REVIEW 21

The History of Race and Schooling $\quad 21$

“Scientific” Racism as Deficit Thinking 24

$\begin{array}{ll}\text { Schools and Hegemony } & 26\end{array}$

Normalization of Whiteness $\quad 32$

Normalization of Whiteness in Schools $\quad 36$

$\begin{array}{ll}\text { Colorblindness } & 40\end{array}$

CHAPTER III: METHODOLOGY

$\begin{array}{ll}\text { Purpose and Overview } & 45\end{array}$

Methodology and Epistemology 46

$\begin{array}{ll}\text { Kind of study } & 51\end{array}$ 
$\begin{array}{ll}\text { Researcher Positionality } & 54\end{array}$

$\begin{array}{ll}\text { Validity/Trustworthiness } & 62\end{array}$

Consideration of Ethical Issues/Reciprocity 63

$\begin{array}{ll}\text { Data Collection } & 64\end{array}$

$\begin{array}{ll}\text { Site selection } & 64\end{array}$

$\begin{array}{ll}\text { Participants } & 64\end{array}$

Academy Preparatory High School recruitment of participants 65

Safe Alternative High School recruitment of participants 65

$\begin{array}{lr}\text { CHAPTER IV: CONTEXT } & 68\end{array}$

$\begin{array}{lr}\text { Safe Alternative School Climate } & 68\end{array}$

Safe Alternative Participants' Stories $\quad 69$

$\begin{array}{ll}\text { Derrick } & 70\end{array}$

$\begin{array}{ll}\text { Max } & 71\end{array}$

$\begin{array}{ll}\text { Aniah } & 72\end{array}$

$\begin{array}{ll}\text { Colton } & 72\end{array}$

$\begin{array}{ll}\text { Jesus } & 73\end{array}$

$\begin{array}{ll}\text { Brittany and Michelle } & 74\end{array}$

$\begin{array}{ll}\text { Kayla and Maya } & 75\end{array}$

$\begin{array}{ll}\text { Precious } & 76\end{array}$

$\begin{array}{ll}\text { Terriana } & 77\end{array}$

$\begin{array}{ll}\text { Robert } & 78\end{array}$

$\begin{array}{ll}\text { Academy Preparatory } & 79\end{array}$ 
$\begin{array}{lr}\text { Academy Preparatory Participants' Stories } & 80\end{array}$

$\begin{array}{lr}\text { Hope } & 80\end{array}$

$\begin{array}{ll}\text { Tim } & 82\end{array}$

$\begin{array}{lr}\text { Heather } & 83\end{array}$

$\begin{array}{lr}\text { Ashley } & 85\end{array}$

$\begin{array}{ll}\text { Cameron } & 86\end{array}$

$\begin{array}{ll}\text { Gill } & 87\end{array}$

$\begin{array}{lr}\text { Richey } & 88\end{array}$

$\begin{array}{ll}\text { Larry } & 88\end{array}$

CHAPTER V: DATA ANALYSIS POLICY AND INTERVIEWS 90

$\begin{array}{lr}\text { Overview } & 90\end{array}$

$\begin{array}{lr}\text { Discourse Analysis } & 90\end{array}$

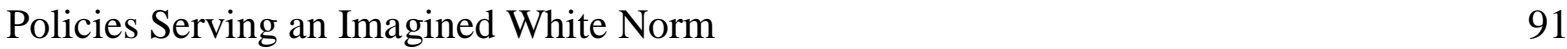

The Discourses Surrounding the Policies 92

Creating Perceptions of Schools—-The Spinning of Stories 94

What the Policies Say—Words and Rules 98

$\begin{array}{ll}\text { Student interviews: What policies do and their lived meaning } & 105\end{array}$

$\begin{array}{ll}\text { Central themes } & 108\end{array}$

$\begin{array}{ll}\text { Consequences of being unprotected. } & 108\end{array}$

Consequences of students protecting or defending themselves. 117

Who is the bully? 118

Consequences of difference, normativity, and hegemony. 121

Consequences of the ways schools are complicit in bullying. 125 
Individual students.

CHAPTER VI: FINDINGS

Bullying Discourse and Race

Overall Findings

Multiple Marginalization

Outlaw emotions.

Hegemony, Whiteness, and Policy

Institutionalized bullying

Implications

Heuristic Moments

Different Approaches

Recommendations

Future Research

Masculinity

166

Girls and Women of Color

REFERENCES 


\section{TABLES}

Table $\quad$ Page

1. Student Data 


\section{FIGURES}

Figure $\quad$ Page

1. Schools and hegemony 28

2. School policy and whiteness 139 


\section{CHAPTER I: INTRODUCTION}

\section{Introduction of the Study}

The discourse about bullying in schools has largely been framed within a colorblind ideology. Little attention has been given to the ways the social construction of bullying and the implementation of anti-bullying policies may influence students differently based upon their racial and ethnic identities. The purpose of this study is to explore the racialized social construction of bullying discourses in PK-12 schools and the ways the student populations are affected by bullying discourses by interviewing high school students. Participants include 12 students who have been expelled from mainstream schooling, and attend an alternative high school, and eight students who attend an elite, college-preparatory high school. The absence of such research is problematic because the dominating culture defines bullying and decides policies for schools, and students of color are disproportionately disciplined, suspended, and expelled from PK-12 institutions (Carter, Skiba, Arredondo, \& Pollock, 2014; Ferguson, 2001; Noguera, 2009; Skiba, Arredondo, \& Rausch, 2014; Webb-Johnson, 2002). Furthermore, while there are many studies that provide statistical data on bullying, fewer studies capture students' lived experiences and analyze them through the lens of critical discourse.

This study is significant because little is known about the relationship between the social construction of bullying and race. Anti-bullying policies may influence students differently based upon their racial and ethnic identities. Bullying has been examined primarily through positivist lenses which further discounts voices of people of color through colorblind research. The research fails to look at how policies and discourses informing them are colorblind and then how these policies and discourses affect students of color. Post-positivist qualitative studies on bullying have not focused on aspects of racism embedded within discourses and policies of 
bullying but instead provide perceptions devoid of racial meanings and status in the contexts of schools.

Bullying discourses in PK-12 institutions inform policies that shape trajectories of students' lives in and out of school, and educational policies in general "assume[s] and defend[s] white supremacy through the priorities it sets, the beneficiaries that it privileges, and the outcomes that it produces" (Gillborn, 2005, p. 498). Bullying policies, and those who create them, have the power to grant or remove access to education through disciplinary actions like suspension, expulsion, and in some cases criminal sentences (Carter, Skiba, Arredondo, \& Pollock, 2014). Considering that students of color are disproportionately disciplined, suspended, and expelled (Carter, Skiba, Arredondo, \& Pollock, 2014; Webb-Johnson, 2002) for similar or the same behaviors as white students, students of color may be thought to exhibit bullying behavior in the same ways they are perceived to misbehave more often and because of this, they may not be offered the same level of protection as white students. In other words, the colorblind practices, policies, and discourses surrounding bullying may marginalize students of color in multiple ways. They may create opportunities for students of color to be bullied due to the misperception that they are the bullies, and therefore go unprotected. More frequent and harsher punishment leads to removal from the classroom environment and academics. Studies show that the less time students spend in the classroom receiving instruction, the more disengaged from school they will be, the further they will lag behind their peers academically, and the more they will develop identities counter to those of high-achieving students (Gregory, Skiba, \& Noguera, 2010). School policies are typically created to serve a "mythical norm" and neglect to consider students even moderately on the margins. 
This study will explore how students of color are affected by existing bullying policies. By exploring these topics, I will encourage productive discourse around bullying and the unique ways students of color are affected by them. I also intend to challenge the hegemonic practices in schools concerning discipline steeped in deficit thinking.

My research will address the following questions:

1. In what ways is bullying discourse connected to race and racialized discourses in PK-12 settings?

a. How do bullying discourses and policies offer protection to some students while portraying/positioning others as bullies?

b. In what ways do bullying discourses and policies privilege and afford institutional protection for some students while marginalizing others?

c. How do the participants explicitly name race or use coded racial language when discussing their experiences and perceptions of bullying?

The research questions address various aspects of the bullying discourse and seek to build knowledge and clarity around the ways they affect students of color in PK-12. Qualitative methods utilizing discourse analysis will be used to conduct the research. Qualitative methods, "offer greater possibilities for the use of alternative frameworks, co-construction of multiple realities and experience, and knowledge that can lead to improved educational opportunities for African Americans," (Tillman, 2002, p. 5). While there have been a number of qualitative studies on bullying, some which looked at race and ethnicity, they, too, neglect to unravel the ways colorblind policies and practices affect students of color. Solórzano \& Yosso (2002) affirm it is, "crucial to focus on the intersections of oppression because storytelling is racialized, gendered, and classed and these stories affect racialized, gendered, and classed communities" (p. 31). The nuances of this discourse can only be discovered through in-depth conversations with students who have recently been immersed in and to some degree lived these discourses. 
Ethnographic studies "enrich and make more complex" (p. 33) because culture or identity "are just the kind of contextual factor[s] that [are] likely to undermine successful implementation of any intervention" (Brown, 2005, p. 33). A more relevant story is told through the lenses of constructivism and critical race methodologies because, "Qualitative research methods are used to understand some social phenomena from perspectives of those involved, to contextualize issues in their particular socio-cultural-political milieu, and sometimes to transform or change social conditions" (Glesne, 2006, p. 4). Ethnography is a way to center students' voices and perceptions especially when the students are marginalized and their voices are frequently silenced the most in any discourse and absent from most research studies (Glesne, 2006). As Brown (2005) puts it, "ethnography clarifies the nuanced, contextualized processes that operate in schools and classrooms - particularly those inhabited by students of color" (p. 33).

This study examines, through the lens of intersectionality, the ways various student populations are marginalized while other are privileged. Previous research on the topic of bullying has not addressed race in this way, but instead has used positivist methodologies which tend to silence student voice and not capture the lived experiences of students historically marginalized and marginalized in school settings. In this next section, I will outline and frame some general literature on bullying and connect it with literature on the ways students of color are marginalized through discipline. I will also unpack how schools frame the bullying problem as an individual student problem without reflecting upon the ways bullying is institutionalized.

\section{Significance of the Study}

Two significant events in 1999, the Columbine shooting and the outcome of a lawsuit stating schools could be held liable for continued sexual harassment against students, led to more than 120 bills passing between 1999 and 2010 either initiating or amending anti-bullying policies 
in 49 of 50 states (Cornell \& Limber, 2015). Prior to these pivotal events that forced schools into responding, Holben and Zirkel (2014) note a sharp increase in anti-bullying litigation starting in 1990. While some of these cases were high-profile, bullying resulting in suicide or a life-altering disability, there may be even more lawsuits initiated but settled outside of court when the schools do not have strong cases (Holben \& Zirkel, 2014). Holben and Zirkel (2014) conclude that, "the increasing frequency but persisting pro-district outcomes of bullying liability litigation confirms that bullying continues to be a serious issue for K-12 schools and that the solutions should not be based on sensationalized or hyperbolic threats of liability" (p. 328). From their analysis of case law over a twenty-year period of bullying in public schools, they also contend that while legislation has its place, "the solution primarily rests on the educational mission and expertise of K-12 schools" in part because schools cannot realistically handle more legislation and lack of enforcement of enacted policies (Holben \& Zirkel, 2014, p. 328).

The stakes seem to be becoming increasing higher as some students, when repeatedly bullied and not protected, attempt to protect themselves by bringing weapons to school. Only quite recently, some school districts are turning away from zero-tolerance policies and towards restorative justice practices because zero-tolerance policies, which criminalize many minor and highly subjective behaviors, have not demonstrated effectiveness in terms of reducing undesired behavior. However, newly rewritten policies forcing schools to collect data on discipline by demographic groups and protect formerly unprotected student populations from being bullied, may not do what they imply (Gillborn, 2005).

"Pipeline to prison" is a term commonly referred to in discussions related to zerotolerance policies because the effects of the policies provide a direct path to incarceration resulting in the greater pattern and phenomenon of institutional racism. Berlowitz, Frye, and Jette 
(2015) surmised from their research that teachers and administrators view zero-tolerance policies as their only alternative when it comes to bullying because they believe in cultural deficit explanations (Bonilla-Silva, 2006) for interpretations of behaviors. Over reliance on extreme and harsh punishments that have life-long consequences for students stemming from beliefs in cultural deficit is an equity issue with deep roots that goes overlooked and unexamined.

Over the past forty years discourses around bullying have expanded and taken on new and nuanced meanings (Walton, 2005a). Bullying discourses in PK-12 schools are mired in rhetoric of "common sense" and "fairness" that rely on the authority and judgment of the administration (Walton, 2005a). Mitchell and Borg (2013) argue that a more ecological perspective of bullying is needed to avoid the "assumed nature of truth embedded in many of the terms and concepts surrounding discussions of bullying" (p. 146). "What is best" for students is defined in terms of "normalcy," and the media reinforces "what is best" for schools and students also through notions of "common sense" and "traditional values" (Mills \& Keddie, 2010). Berger and Luckmann (1996) explain that "objective reality" most likely substantiates the racial/cultural hierarchy of domination. Institutions serve as socializing agents of accepted values and beliefs in which they become the norm or the standard for all within a society. The values and beliefs are perpetuated, reinforced, and recreated through language and knowledge. Webb-Johnson (2002) points out that when behaviors deviate from "the norm" in a school environment, students of color are referred at disproportionate rates to special education, labeled, and diagnosed as disordered. Perceptions of behavior by the mostly white, middle-class teachers and administrators are laden with deficit thinking (Valencia, 2010; Solórzano \& Solórzano, 1995), dysconscious racism (King, 1991), unconscious bias (Moule, 2009), and colorblindness (Thompson, 1998), which can likely lead to students of color being portrayed as bullies. 
Other problematic, but more general features of the bullying discourse, revolve around narrow definitions around victim, aggressor, and bystander. Reductionist ways of defining notions around bullying make it easy for schools to locate the blame among individuals and focus on specific behaviors (Walton, 2005a). Individualizing the problem removes the focus from how bullying plays out on systematic and institutional levels and the ways bullying is socially and culturally constructed (Mitchell \& Borg, 2013). Mitchell and Borg (2013) include Jacobson's (2010) argument that bullying is a "narration of the cultures within which it exists, mirroring the dividing practices of schools and the hierarchies that exist within schools" (p. 149). Furthermore, Jacobson (2010) contends that schools are complicit in bullying and offer spaces for it to be enacted due to discourses of normalization and comparison resulting in social power hierarchies in which some people count while others do not. When the focus is on "fixing" individuals who "have much choice" about their behavior, schools are "off the hook" and relieved of responsibility for their role in reproducing inequity and institutionalized oppression. By locating the problem within individuals, discourses around bullying serve as a way for schools to deflect attention away from inequitable outcomes in general. While the school may produce momentous inequitable academic and discipline outcomes, implementing a bully prevention program sends a well-received message of caring and student protection to the public. Walton (2005a) highlights these benefits by sharing the following quote by Ronnie Casella (2001):

For schools, violence prevention programs meet several unique needs. They attempt to prevent violence. They give mostly high-achieving students the opportunity to join a team or club (such as a peer mediation team or a student support team) that looks good on college applications. Finally, they enable schools to say that they are doing something 
about violence.... Most strategies are fundamentally similar and are either based on judicial processes or educational processes, or a mixture of the two. In essence, most are...spinoffs of national "get tough" policies, or, in the case of educational programs, variations on the theme of behavior modification. (p. 27)

These differences are further complicated when some working class and low-income families mistrust institutional authority (Lareau, 1989) because of their negative experiences with them. Mitchell and Borg (2013) in their comprehensive international review of the literature on bullying problematize definitions of bullying because the meanings around bullying as understood cross-culturally and inter-culturally are different. Nevertheless, perceptions as defined by the dominating, white-middle class inform policies around bullying for all students. There may be a level of awareness of how this system works for and against students. Students of color might rely less on authority figures in their environment to resolve conflicts because these policies have not served them or offered protection, or as Rigby and Bagshaw (2003) found, students involved in bullying, as either the aggressor or the victim, tend to trust institutional authority less and doubt their teachers' abilities to be fair in helping them resolve conflict. It is also possible that punishments are harsher and more frequent for students of color as they are across the board in disciplinary practices (Carter, Skiba, Arredondo, \& Pollock, 2014; Webb-Johnson, 2002). On the other hand, white students might trust institutional authority and turn to them more often for help in resolving conflicts because they are aware on some level that they are protected by these policies. There is a notable silence of voices of students of color as not represented in the bullying discourse as evidenced by the literature demonstrating a need for "complexity and depth of the lived experience of all people associated with schools who may be involved in bullying incidents" (Mitchell \& Borg, 2013, p. 152). 
If the needs of students of color are not being met by bullying programming, because the social construction and meaning of bullying is construed by the dominating culture alone, then the discourse has the effect of reifying institutionalized racism. The discourses are in effect doing the opposite of what they claim to be doing through paradoxical "white talk": protecting white children at the expense of children of color (Applebaum, 2010). Solórzano and Yosso (2001) explain that educational institutions can "operate in contradictory ways, with the potential to oppress and marginalize coexisting with the potential to emancipate and empower" (p. 479). Similar to the way Bonilla-Silva (2002) reveals how "semantic moves" shroud racism keeping the speaker sounding socially acceptable even to him or herself; discourses around bullying, schools, prevention and intervention programs engage in contemporary race talk. Barbara Applebaum (2010) points out that whiteness is protected by claims of morality and the danger in this "either/or" or "good/bad" way of thinking about white people is that it comforts them into complicity and deflects from the real issue of daily dehumanizing treatment of people of color. Lensmire (2010) brings light to this conflictual state with a poignant quote by Ralph Ellison (1993/95):

the white American seeks to resolve the dilemma arising between his democratic beliefs and certain antidemocratic practices, between his acceptance of the sacred democratic belief that all men are created equal and his treatment of every tenth man as though he were not ... Perhaps the object of the stereotype is not so much to crush the Negro as to console the white man.

Ellison's quote shines light on the schism between the democratic principle of equality and the behaviors that are not consistent with this principle. He also points out that perhaps the most 
troubling aspect is that this dynamic consoles white consciousness into complicity through creation and maintenance of stereotype.

In sum, although there is much literature on bullying and bullying prevention programming in schools, it continues to become an even greater problem. The bullying discourse has centered the bullying problem on an individual level rather than examining and acting on what institutions do or do not do to create and maintain environments where bullying thrives. For students who are multiply-marginalized, they are not offered protection and in some cases they are criminalized pipelining them to prison. Many definitions and policies surrounding the bullying discourse are based in white-middle class norms and serve this population while excluding students of color and white students from working-class backgrounds. Furthermore, the policies are enacted primarily by white-middle class teachers and administrators who lack cultural competence, critical consciousness, and engage in deficit thinking when students do not present as having academic knowledge and school-norm based behaviors. In this next section, I will define and explain the theory of intersectionality which I use as a lens through which to analyze the way power plays out through bullying in school settings by providing examples of laws and policies that marginalize women of color.

\section{Conceptual Framework}

I draw on Kimberlé Crenshaw’s (1991) theory of intersectionality as a framework to examine the ways bullying discourses and their resulting policies fail students of color by not examining the way identity politics affect them. More specifically, I will consider the complex convergence of social, economic, and political influences in schools including racial formation and informed identities in terms of race, ethnicity, class, gender, perceived ability, inclusion/exclusion, and opportunity (Hill-Collins, 2015). Another intention of this research and 
the use of intersectionality as a framework is to disrupt notions of heterogeneous violence to avoid its reoccurrence (Hill-Collins \& Bilge, 2016). Crenshaw's theory of intersectionality explicates the ways laws and policies ignore the needs of people who are institutionally oppressed by multiple systems. The way racism itself is legally conceptualized is part of the problem because it does not emphasize outcome, just intent:

the dominant legal conception of racism as a discrete and identifiable act of "prejudice based on skin color" placed virtually the entire range of everyday social practices in America - social practices developed and maintained throughout the period of formal American apartheid - beyond the scope of critical examination or legal remediation (Crenshaw, Gotanda, Peller, \& Thomas, 1995, p. xv)

In her article Mapping the Margins: Intersectionality, Identity Politics, and Violence Against Women of Color, Crenshaw shows how women of color who are victims of violence are further victimized when laws and the discourses surrounding them are grounded in singular aspects of their identity and offer little protection or support. For example, laws and violence intervention programs meant to protect and assist all women, ignore the compounded needs of women of color that are a result of racism such as economic marginalization and housing discrimination. This lack of protection is a form of whiteness and exemplifies, "the set of assumptions, privileges, and benefits that accompany the status of being White" as well as a form of property that is "affirmed, legitimated, and protected by the law" (Harris, 1993, p. 1713).

Audrey Thompson (1998) argues similarly that "most women have to work with 'reallived' conditions that bear little resemblance to the choice-laden circumstances posited for the moral individual in mainstream ethical theories" which are "likely to be referenced implicitly to 
a White, middle-class ethic of domestic well-being" (p. 529). Because the compounded needs of women of color are neglected, women of color are left unprotected and in some cases further marginalized because it makes their situations worse. I argue that students of color are marginalized in similar ways in regard to bullying policies when those who define and choose policies fail to consider the effects of institutionalized racism. Moreover, by neglecting to examine the ways institutionalized racism operates and shapes bullying discourses, students of color are not offered the same protection as white students.

The way intersectionality may play out in school bullying discourses is that families of color experiencing the economic effects of racism in housing and employment have little choice over where they can live and, in effect, where their children attend school. More times than not, the less money families have the greater the likelihood their children will have to attend impoverished schools in terms of resources and staff (Ayers \& Ayers, 2011; Darling-Hammond, 2010; Loewen, 2005). These are two major ways racism is perpetuated in a very systematic way. Another way racism is embedded systemically is through the imposition of dominating culture in school curriculum and social interaction patterns (Delpit; 1998; King, 1991; Ladson-Billings, 1995). Curriculum and behavioral expectations that are familiar and relevant to only some children, privilege some students over others. Furthermore, there is much data showing that students of color are disciplined and punished at higher rates than white students (Skiba, Arredondo, \& Rausch, 2014). Students of color may be thought to exhibit bullying behavior in the same ways they are perceived to misbehave more often. Because they are more likely to be viewed as a perpetrator rather than a victim, not only will they be punished more frequently, they will receive less protection when they are the victim. In other words, the colorblind ideology 
present in the bullying discourse may add an additional layer of racism making it even more difficult for students of color to receive education and participate in schooling.

\section{Intersectionality}

Crenshaw's (1991) theory of intersectionality developed out of a need to address racist and sexist legal practices as well as feminist practices in relation to theory and politics, but has continued to evolve and be applied to many other areas and variations of marginalization (Carbado, Crenshaw, Mays, \& Tomlinson, 2013). Intersectionality expounds the ways laws, policies, and institutional practices neglect to consider the needs of people who are oppressed by multiple systems, and fail them by not including measures that meet the particular needs involved with their situated identities (Crenshaw, 1991). Hill-Collins and Bilge (2016) provide the following as a way to think about intersectionality:

a way of understanding and analyzing the complexity in the world, in people, and in human experiences. The events and conditions of social and political life and the self can seldom be understood as shaped by one factor. They are generally shaped by many factors in diverse and mutually influencing ways. When it comes to social inequality, people's lives and the organization of power in a given society are better understood as being shaped not by a single axis of social division, be it race or gender or class, but by many axes that work together and influence each other. Intersectionality as an analytic tool gives people better access to the complexity of the world and of themselves. (p. 2)

In this "reciprocally constructing phenomena" (Hill-Collins \& Bilge, 2015, p. 1) subordination occurs when the resistance strategies used by one group negate the legitimacy of the other group, exacerbating and multiplying subordination due to these conflicting political agendas (Crenshaw, 1991). Laws and policies often do not even recognize and include the full spectrum or depth of 
the racism or sexism involved. Thompson (2003) illuminates this further, "Concealed in the liberal feminist insistence on sameness is an implicit deficit account" as "women who deviate from the norm set by privileged men are seen as lesser" (p. 24). Nash (2008) explains that intersectionality is meant to disrupt race and gender binaries allowing for the rendering of identity in all its complexities, provide a language that represents non-homogeneity among women and among Black people, and bring to focus the ways "multiply-marginalized" women have been affected.

Audre Lorde (1984) clarifies "white women ignore their built-in privilege of whiteness and define women in terms of their own experience alone, then women of Color become 'other,' the outsider whose experience and tradition is too 'alien' to comprehend" (p. 117). Seeing Black women and women of color as whole, means acknowledging the real differences and would mean doing something to remedy this. Lorde further argues that there is vested interest for white women in not seeing the differences. However, the interest is mostly based on an illusion because while patriarchy offers white women more "rewards" for buying into it, they are empty and false. The fantasy is based in an illusion of sharing power and they are still operating as subordinates which they are reminded of in cases of rape or when a man gets the sought after job. Thompson (2003) provides an example of this on a societal level: "liberal analysis and solutions to women's oppression are shortsighted, for they represent the mistreatment of women as an aberration in the system rather than as a function of the system" (p. 30). Furthermore, poor women are portrayed as “innocent victims of men's irresponsibility” and while this may serve the purpose of gaining sympathy and then perhaps a bit of access, "it does so at the cost of failing to challenge deeply held notions about feminine dependence on a male breadwinner" (Thompson, 2003, p. 30). The failure to challenge these notions brings forth discourses around 
the deserving and non-deserving poor which exemplify Crenshaw's point mentioned earlier about conflicting political agendas subordinating others' agendas and needs. Lorde (1984) claims the fantasy of sharing power in patriarchy is less alluring for women of color because they are reminded in their daily, lived experiences that it is only an illusion. Thompson (2003) further explains: "The situation of women of color demands exceptional survival skills and lends itself to oppositional knowledge, it may promote a type of authoritative agency incompatible with white ideals of femininity" (p. 24).

Angela Davis (1981) provides a historical account of the inequality between white and Black women. She describes the history of resistance Black women practiced in the face of this inequality, the interest convergence (Bell, 1995) that occurred over women's rights, followed by the separation that occurred when white women focused instead on gaining rights within their social class. White women's rights were "sold" for a perceived need for protection, and this feminized and infantilized white women in the process. Nash (2014) argues for the continued need to develop and analyze the needs of Black women through the lens of intersectionality in the present because references to either past or future applications further marginalize Black women. The need to do as Nash suggests can be clearly seen when considering the ways marginalizing effects become even more complex when considering the negative depictions and stereotypes that abound about women of color in the media and elsewhere. Crenshaw (1991) provides an example of a news show portraying battered white women as whole people, and then one Black woman with no context and little personifying features. Because of these negative depictions, women of color face the additional burden of having to think about how to deal with stereotypes and the fallout of discriminatory behavior (Nash, 2014). For example, the portrayal 
of Black women as sexualized results in discriminatory treatment within legal realms and other institutions meant to support them (Crenshaw, 1991).

Another example of this is in violence-against women campaigns where the ad will feature a white woman accompanied by a slogan "Violence can happen in any home or to anyone." The implication is: even to white women and now violence against women is an issue for which we should be concerned. Because we, as white people, need an ad to point it out to us, the subtext suggests that we all think it would not be an issue white women would face. The message simultaneously perpetuates the stereotype of violence being associated with women of color and white superiority. A concern of those who create the ad might be to avoid stereotypes but appearing not to stereotype becomes a central concern rather than actually protecting and providing assistance to women of color or eliminating stereotypes altogether. Consequently, the question of why violence against women of color has been overlooked becomes further buried and remains unaddressed which, of course, is the real issue at hand.

Racism and whiteness further victimize women of color who are victims of violence are through colorblind workplaces. Colorblind workplaces in mainstream organizations and movements meant to address the needs of all women frequently do not employ women of color at the same rate as white women. If they do, women of color may choose to opt out because their opinions and perspectives are not valued, and they may experience other forms of dismissal or microaggressions. They may also become increasingly frustrated over the lack of understanding of the difference that race, language barriers, and cultural and ethnic backgrounds make. This is not only a matter of lack of understanding or inequality in the workplace; it is an issue of survival for the women of color who are victims of violence and their actual needs go unmet. 
Similar to the ways colorblind laws and policies designed to protect and serve white women and overlook the marginalizing effects of these policies for women of color, this process occurs in schools as well. Intersectionality developed out a need to address this type of legalized racism that resulted in a violation of human rights for women of color. Intersectionality lends understanding to multifaceted dimensions of society that cannot be explained through one lens and provides insight into the complexity of individualized experience and larger society. In the following section, I specifically address the ways identity and intersectionality work in school settings.

\section{Intersectionality and Identity}

Crenshaw (1991) explains two areas that have been historically challenged: notions around the construction of categories around race and then the material resources granted those categories. In colorblind situations, the construction of the category is ignored altogether which is a way to maintain the status quo. Even if requests around resources are granted, it is done from a position of domination because power involved in the naming of the category remains with the dominating members. In this way identity is constructed by another, by an outsider. The identity categories have very real effects because of the meanings given them and the plethora of disadvantages associated with them.

Next, I will explain how these categories and the meanings ascribed to them can play out in educational settings. As mentioned earlier, intersectionality has been applied to many other areas and fields, "Intersectionality moves not only in relation to shifting subjects, but it moves more broadly as a prism linking and engaging scholarly subfields, research methodologies, and topical inquiries" (Carbado et al., 2013, p. 307). The following will focus on how race intersects with various aspects of student identity. Nash (2014) advocates for, “'more’ intersectionality by 
critiquing current practices of intersectionality that neglect significant structures of domination and by proposing a new intersectionality that centers undertheorized intersections" (p. 49).

Students of color are marginalized in schools similar to the ways Crenshaw (1991) describes women of color being marginalized in legal realms when those who define and choose policies fail to consider the effects of institutionalized racism and the ways identities are constructed in school settings. Moreover, by neglecting to consider the ways institutionalized racism operates, shapes practices, and multiple forms of discrimination converge, students of color are not offered the same opportunities and chances in education as white students. Identity is influenced in school settings and certain aspects of identity are shaped by social experiences and contexts because students may internalize some of these experiences (Baines, 2014). Colorblind ideologies influence most schooling practices and overlook their effects on students of color. Deconstructive theories seek to "denormalize and denaturalize commonsense categories, exposing them as socially constructed and maintained" (Thompson, 2003, p. 20). Making new meanings when "our habits and expectations organize what and how we see" is critical for the "development of new possibilities of perception" (Thompson, 2003, p. 20).

\section{African American Learners and Identity}

Murrell (2009) maintains that academic identity is "a form of social identity in which the learner projects, maintains, and improvises an image of self as a learner" (Murrell, 2009, p. 97). Academic identity is not static existing within binaries, and involves individual choice and agency around purposeful positioning as part of social construction (Foster, 2004; Murrell, 2009). Overlooking agency is a mistake because students develop discursive practices resisting being positioned in negative ways. Murrell (2009) claims: "Black achievement is mediated by the specific forms of social identification experienced by Black youth in the complex 
intersections of racial, economic, gender and class privilege in American society" (p. 98). He contests deficit explanations about African American academic achievement, and argues for the need to understand learners' academic and racial identities through the lens of Black scholarship. He also advocates for this being done by examining and integrating social identification of the cultural contexts of schooling, the individual, social networks, and the larger sociopolitical context. To avoid misunderstanding Black students, Murrell (2009) emphasizes recognizing "the differences between social affiliation and academic commitment as distinct motivations" (p. 96). He recommends that school personnel examine their racialized positionality and recognize the factors in school environments, that is, the context that evokes for African American students, the experience of "being Black" in that particular situation. In other words, Murrell suggests the focus needs to shift to the social context, school structure, and racialized or colorblind discourses rather than the individual.

In sum, Crenshaw (1991) and Thompson (1998) point out the necessity to view laws, policies, and institutionalized practices through a lens that considers the real needs of women of color uninfluenced by popular and normalized narratives such as those found in white feminism. Intersectionality provides an opportunity to deconstruct the marginalizing effects of policies on people belonging to multiple oppressed groups. Oftentimes, public and institutional policies are mired in colorblind rhetoric, leaving people of color exposed to whatever the policy is meant to protect against. The lack of awareness around this is based in "white innocence" and a form of colorblind racism. Colorblind policies violate human rights and put the lives of people of color at further risk all the while obfuscating this reality by explicit statements that claim to protect everyone. 
Similarly, Murrell (2009) expresses the need to look deeper at the real needs and lived experiences of African American learners in educational settings by consulting the literature by African American researchers, and by having schools examine the environment they create and sustain because learners' identities are to some degree affected by school context. In the next section, I will provide the background literature concerning the construction of race, the history of schooling related to racism, and colorblind policies. 


\section{CHAPTER II: LITERATURE REVIEW}

This review of the literature begins with the history of the social construction of race as it relates to the political, economic, and social forces in the U.S. Next, is explaied how schools are the nexus point where these forces meet and reify hegemony, but consistently shift focus from this fact and critiques about it, by problematizing the most vulnerable students. Reification occurs through the normalization of whiteness and colorblind policies that ultimately marginalize students of color by providing them with fewer educational opportunities than white students.

\section{The History of Race and Schooling}

The historical features of race in relation to schooling as driven by political, economic, and social forces, and the ways race has been institutionalized and normalized sets the stage or the context for race and schooling in America. Omi and Winant (1993) explain that history, rather than being thought of as something that already happened, can instead be thought of as an ongoing movement. "Racial formation" and the "socially constructed status of race" continue to reverberate similar to the "big bang" as race-thinking and acting have deep and pervasive effects on identity formation and social organization (Omi \& Winant, 1993, p. 13). The "continuing significance and changing meaning" of race fuel, inform, and shape ideas in our racialized society (Omi \& Winant, 1993, p.8). Leonardo (2004) affirms this process:

Domination is a relation of power that subjects enter into and is forged in the historical process... out of a patterned and enduring treatment of social groups. Ultimately, it is secured through a series of actions...not always transparent to its subjects and objects. (p. 139) 
Gillborn (2005) questions whether, "institutional racism and race inequity are deliberate insofar as (at best) there appears to be a judgement that their eradication is simply not important enough to shape the main tenets of education policy" (p. 499). If it were deemed important enough, the following would occur: "funding urban schools to a realistic level; securing testing regimes that do not unfairly discriminate on racial lines; abandoning selective teaching and grouping; broadening the curriculum; diversifying the teaching force; and genuinely acting on the results of ethnic monitoring" (Gillborn, p. 499). Schools are oppressive institutions that reproduce hierarchies. Farber (1969) implored society to, "stop trying to pass imprisonment off as education" and refers to compulsory schooling as "public internment centers" (p. 43). Woodson (2006) viewed schooling as extremely oppressive reproducing inequality through teaching white superiority and Black inferiority. One of the methods for doing so was by presenting a curriculum either omitting African and African American history altogether or presenting distorted versions of it. Ratteray (1994) reinforces that, "the content of the schooling that African-Americans [were subject to]...was designed to meet the needs of the politically empowered European-Americans" (p. 123). Hoff and Martin (in press) point out that, "The dominating legacies of European colonialism and neo-colonialism are alive and well in the cultural structures of educational institutions" (p. 5), and Ani (1994) refers to European universalism as a weapon. By creating the illusion that all that is white is "good" and "normal" aligns European colonial agendas and interests. Then by employing this rhetoric to force people en masse to conform by weaving it within laws, institutional practices, and ultimately the dominating culture, European universalism itself is a tool of subjugation and control. Conforming is reinforced through rewards in regards to safety, material resources, social approval, and social status that exists on a continuum of being viewed and treated as human. 
Depictions of African Americans and their ancestors as whole and accomplished people were and continue to be left out and stories of racial oppression replace them. Whites, on the other hand, were and are portrayed positively while their history of domination was downplayed. Joyce E. King (2006) refers to the white supremacist version of history as a "child's version" of history, and she cites Baldwin (1996) who describes those who buy into it, as adults who have never grown up because they will not examine their identity. Woodson (2006) believed history to be the mechanism of survival for Black people. Kunjufu (1988) emphasizes a similar point in saying that if Black people knew what their ancestors accomplished; it would be difficult to get them to buy into lies. John Henrik Clarke (2012) made the following comparison: "History is the same to a people as the relationship of a mother to her child" and this is why history has been distorted and part of why white people continue dominating. Knowing one's history is a counterhegemonic practice strongly advocated by both Clarke and Woodson. Myers (1987) delineates the value of knowing African cultural heritage and identity because of the way culture influences the quality of life.

Culture reinforces and reifies taken for granted notions through daily interactions, and this is why schooling is a powerful transmitter of ideas about race. For example, Smith, Yosso, and Solorzano's (2007) study shows that through the hidden curriculum, children learn pathological aversion toward Black men in particular which is reinforced throughout their lives. Ani (1994) affirms that ideological liberation is needed to resist other forms of destruction. Key, to this process, is removing the "piece of the oppressor" from within (Lorde, 1984), and to "come more into touch with our own ancient, non-european consciousness... and to respect those hidden sources of our power from where true knowledge and, therefore, lasting action comes" (p. 37). Furthermore, Murrell (2009) asserts, "Cultural racism in the form of discourse practices- 
the social practices of communication and everyday human interaction which culture is most frequently and deeply expressed—is prevalent in school contexts" (p. 97). Ladson-Billings (1995) stresses, "students must develop a broader sociopolitical consciousness that allows them to critique the cultural norms, values, mores, and institutions that produce and maintain social inequities" (p. 162) as education has the potential to liberate. Without a sociopolitical consciousness, dysconscious racism in white students ensues. King (1991) defines dysconscious racism as, "a distorted way of thinking about race" that assumes white superiority and justifies the "social and economic advantages white people have as a result of subordinating diverse others" (p. 135).

In summary, this section highlights hegemony and schools as indoctrinating and subjugating spaces. Schooling emphasizes Western, white people's accomplishments while eliminating achievements of African people creating a perception of less than through curricular choices and actions. Ladson-Billings and King point out that counter stories or even multiple perspectives of history are not used, but need to be used, in mainstream education. The development of a sociopolitical consciousness in which white supremacy and whiteness can be deconstructed is necessary. In the next section, I will explain deficit thinking and the ways white supremacy, whiteness, and racism permeate schooling and are pervasive by tracking its historic roots which shape perceptions today and newer forms of racism.

\section{"Scientific" Racism as Deficit Thinking}

Europeans historically reinforced white supremacy through "scientific racism." During the $18^{\text {th }}$ century, variations of "scientific racism" developed and continued through the $19^{\text {th }}$ century which strengthened white superiority and solidified justification for slavery. Scientific racism became more important when the medical field contributed to these theories (Watkins, 
2001). Eugenics rose in the mid-nineteenth century alongside of Black education (Smedley \& Smedley, 2005). Seldon (2000) traces the eugenics movement in the U.S. in the first half of the $20^{\text {th }}$ century and ties it into curriculum development. The value of considering this research is to look at current discourses in education, which Selden (2000) refers to as "curricular selective tradition," and the ways they have their roots in the eugenics movements. Eugenics is similar to constructions surrounding race and deficit thinking (Valencia, 2010) by assigning arbitrary categories to people, based in and reified through pseudoscience claiming hereditary determines intelligence, moral character, non-genetically related diseases, and are aligned with or driven by political and economic forces used to influence policies.

Dogma and narratives popularized in the late 20s and 30s at social functions such as exhibits and fairs is disturbingly similar to sentiments found in current media depictions related to race or codes for race. Some of these include the cost of prisoners to society and the many ways more affluent members of society carry the financial burden of those less well off with implications that poor people are genetically flawed (Aitken, 1915; Allen, 2003; Seldon, 2000). Another way this storyline was manipulated to portray immigrants and African Americans as flawed was by comparing their literacy rates with those who had formal education while omitting from the story that it was illegal at various points for African Americans to receive formal education (Seldon, 2000). In other words, literacy learning was "structurally constrained" much like current structural constraints found in education. Blacks, who were not given access to education and suffered the effects of not having access, were then blamed by whites for having low rates of literacy related to lack of intelligence. 


\section{Schools and Hegemony}

"Schools are the hotbed of hegemony," (Hoff, 2013) explains that schooling is an especially powerful transmitter and reinforcing agent of these rules with all their rewards and benefits which are linked to assumptions about truth, authority, and power. David Gillborn (2005) in his examination of educational policy in the UK states the following which is also true of US educational policy:

This critical perspective is based on the recognition that race inequity and racism are central features of the education system. These are not aberrant nor accidental phenomena that will be ironed out in time, they are fundamental characteristics of the system. It is in this sense that education policy is an act of white supremacy. (p. 498)

Figure 1 below serves as a visual representation created to show how aspects of racism and white supremacy are interrelated, supported by and affected by other aspects, and are institutionalized. The processes of racism and white supremacy are much like deficit thinking that Valencia (2010) describes in the way each aspect reinforces and holds in place the other aspects. Below the visual model, I provide an overview of Valencia's (2010) deficit thinking framework. Figure 1 shows historic aspects of racism, how racism is recreated in current discourses about race through schooling, and is reinforced and reproduced politically and economically. History, in this sense, is not linear following conventional timelines (Omi \& Winant, 1993). The socialization in schooling is the nexus where the other aspects come together through the practice of whiteness and are reinforced and reestablished as, "schools [are] a central and significant domain for how students learn about racial matters" (Smith, Yosso, \& Solorzano’s, 2007). In fact, Kailin (2002) cites Kunjufu's (1985) likening of the school model to a plantation model. Culture is enacted and reproduced on every level and cannot be separated as schools are spaces where whiteness and 
racist ideologies are reinforced daily. To show the importance of culture in influencing every level/aspect, culture is placed both in the center and on the outer circle to show the ways it influences and encompasses all the other aspects. The interplay of agency and positioning to counter and resist racism occurs on every level as well, but exists on an individual level or as a counter movement, for the most part, as opposed the structural features of racism which makes racism a system society operates within. 


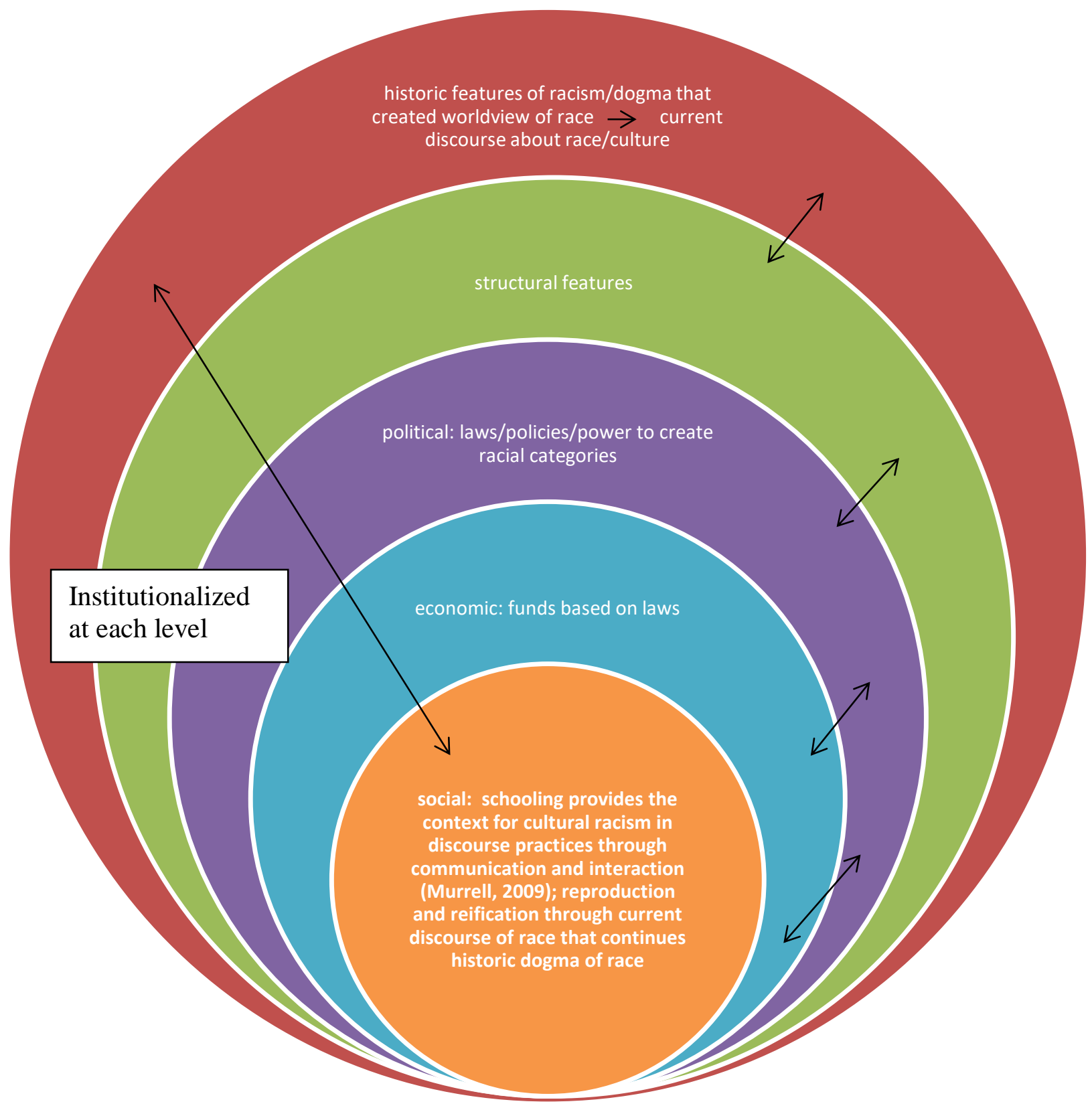

Figure 1. Schools and hegemony 
White supremacy operates within political, economic, and social systems through being institutionalized. As Ansley (1997) characterizes it:

a political, economic, and cultural system in which whites overwhelmingly control power and material resources, conscious and unconscious ideas of white superiority and entitlement are widespread, and relations of white dominance and non-white subordination are daily reenacted across a broad array of institutions and social settings. (p. 592)

Some examples of how this works include lack of access to quality education which results in lack of access to political sovereignty and economic freedom. This is further exacerbated by racism in hiring and the workplace, informal redlining in polluted and toxic environments, lack of access to healthcare, and laws that make it difficult if not impossible to be politically involved on many levels. The justice system limits personal freedom of people of color through the prison-industrial complex, policing, laws, and judicial rulings which Davis (2016) argues is an attempt to deflect attention from systemic racism. The prison-industrial complex and policing could be considered forms of modern-day, legalized lynching which communicates the message to people of color that they are never safe in this society serving as a never-ending threat and social control. The psychological and physical toll this takes on people of color is another way further marginalization occurs resulting in illness and early mortality rates.

To break this down further, political decisions, made by the dominating class determine where children must attend school which also determines the quality of education and amount of resources due to funding. In this "selective tradition" of schooling, the education groups of children receive line up with race and class (Darling-Hammond, 2010). Economically-based 
segregation results in poor quality of teachers, physical environment, and curricular resources (Murrell, 2009). Further, schooling is conducted in a white-middle class linguistic and cultural style. The focus is frequently on "fixing" people of color leaving little room for appropriate pedagogy and communicates white superiority in yet another way. While professing principles of democracy "schooling is a process intended to perpetuate and maintain the society's existing power relations and the institutional structures that support those arrangements," (Shujaa, 1993, p. 15) through indoctrination and subjugation.

Valencia (2010) explains the ways deficit thinking fits together in such a way so as to provide justification for and reinforce various components in a hegemonic society and remove almost all responsibility for schools to change. Blaming the victim locates the problem for school failure in the victims who have the least amount of institutional power in society, usually people of color and those living in poverty. Narratives, such as these "ignore history and structure as they remove social actors from their larger contexts" (Lewis, 2004, p. 5) and maintain that educational outcomes are comparable when they are not. The particular deficiencies used to justify deficit thinking change over time and depend upon the pseudo research du jour. Valencia (2010) deconstructs deficit thinking in a historical context. All of these components describe the ways racial inferiority and superiority have been constructed, reinforced, and maintained politically, economically, and socially throughout history. He outlines six characteristics of deficit thinking:

- blaming the victim: reducing and oversimplifying problems, mistaking association for causation and in doing so locating the origins of a problem within the victims or the people suffering the consequences, and part of justifying blaming the victim is using 
theoretical works out of context to support political agendas making structural changes seem unnecessary;

- oppression: irrational and misinformed beliefs of incompetency about groups of people by those in authority resulting in institutionalized practices or laws that restrict, limit, and deny access to those groups and making it impossible for those groups to move out of their societal positions;

- pseudoscience: flawed data not employing the scientific method and used to provide validity and legitimize deficit ideologies, the research lacks commitment to validating the hypothesis and has huge errors in reasoning;

- temporal changes: shifts in deficit thinking depending upon current research which is characterized by pseudoscience as in the cases of identifying pathological genes in people of color and assigning causes of academic failure to cultural systems of the poor;

- educability: beliefs based in pseudoscience that traits of being uneducatable, lacking intelligence, or culture are transmitted through the individual, gene pool, or social group and enacting these beliefs in prescriptions for interventions for these groups; and

- heterodoxy: push and pull between the dominant and the less dominant groups in society that challenge the taken-for-granted and unquestioned ways in which the society is set up to privilege some at the expense of others. (pp. 7-18)

Findings of pseudoscience are used to support biased, negative views towards people of color, and the deficiencies usually include variations of "limited intellectual abilities, linguistic shortcomings, lack of motivation to learn, and immoral behavior" (Valencia, 2010, p. 7) and are very similar to dogma originally created about race (Smedley \& Smedley, 2011). Other "deficiencies" that have been and continue to be used to justify deficit thinking are "genetics, 
culture and class, and familial socialization" (Valencia, 2010, p. 7). When individual teachers and entire school systems engage in deficit thinking, oppressive systems are reproduced in schools.

Overall, schools are places where economic, political, and social forces that drive white supremacy come together. The history of race can be thought of as not something that occurred in the past, but as something that continues to shape perceptions and have major implications for people of color. Deficit thinking is institutionalized in schools in part through historical narratives and curriculum designed to secure political, economic, and social status of white Americans. This next section will further explain how whiteness operates in schools.

\section{Normalization of Whiteness}

Whiteness is normalized in part by its invisibility, caused by normalization and standardization of whiteness and by the belief by many white people that "white" is not a race. Being white then is removed from all political realms and portrayed as not having advantages associated with it. Presumed universalism of the values of whiteness attempt to make it seem natural, right, and ordained while making anyone "not white" wrong, unnatural, and criminal. Whiteness is executed through control, violence, and oppression, and built on ideologies and myths about desirability, difference, inferiority of people of color, and superiority of whites (Tatum, 1997). Whiteness is reinforced through institutionalization meaning that the people with the most power make decisions about who else can have access to power. The degree of power held by those with the most power means they can perpetrate violence legally for the most part, both physically and psychologically, and use the threat of violence as a social control mechanism. Laws and policies implemented by whites are colorblind, and do not take into account the needs of people of color which in turn makes white people more powerful by 
perpetually putting people of color at a disadvantage. The inverse is true as well, as identities intersecting with white, male, heterosexual, and so forth will compound power and privilege as these systems reinforce one another. Hegemonic practices move in circles reestablishing whiteness.

Whiteness survives by being taught, both explicitly and non-explicitly through generations in families and institutions by simultaneously minimizing and exaggerating differences. "Commonsense" (or as Gillborn (2005) refers to it as "white-sense") is taken for granted notions that become the norm through social, economic, and political rewards and punishments, both material and psychological, for conforming to the norm. Hatt's (2011) smartness research shows how "smartness" is constructed in classrooms by teachers and administrators as well as reinforced through the reward of school artifacts and is aligned with race and class. The invisibility of whiteness serves the people benefitting from it by protecting their interests and by keeping their actions somewhat covert and easier to not argue against.

Fanon (1967) describes “negrification" which exists in relation to whiteness: 1) promotion of negative attitudes towards Black people and Africa; 2) normalization of preference towards white people, Europe, and white culture; 3) white is the norm from which all else is measured which makes it seem as if being white is the only way of being. These notions are reinforced in all forms of the media, social interactions, and school curriculum. Myers (1987) cites Nobles (1986) exemplifying the normalization of whiteness: "The natural consciousness of black people is forced to relate to a reality defined by white consciousness" (p. 72). Hoff and Martin (in press) echo this: "Whiteness is the norm by which everyone is judged and classified" (p. 1). Whiteness is universal and normalized in schools. In other words, what is "normal" is 
white. To further elucidate this notion, I continue with King's conceptualizations of Blackness and whiteness.

Joyce E. King $(2006 ; 2011 ; 2015)$ brings attention to the national and to some degree global collective consciousness of alterity where Blackness and representations of it are conceptualized and represented as inhuman and white as human. This "national myth of Black inferiority" and white superiority rule and inform thinking, shape identity, and exist in direct relation and proportion to one another with "conceptual blackness" being the "alter ego" of "conceptual whiteness" (King, 2006, p. 338). King (2006; 2011) goes on to explicate that within this conceptualization, the (un)worthiness of Black life is central and that Black people and their identities are portrayed and represented on a daily basis by the media, schools, and in political realms in nihilistic terms including lacking a culturally affirming collective identity, as criminal, slaves, second-class citizens, and jobless. King (2011) further describes this parallel relationship:

Following Wynter, I have proposed that this nihilation (e.g., total abjection) of Blackness is inherent in the U.S./Western cultural model of what it means to be human/civilized/worthy of life. Whites also pay a cost for this socially constructed Black/White duality: the attenuation of their own humanity. (p. 351)

In this quote, King points out what is somehow missed by many white people: that the price paid for whiteness is their humanity. Similar to Lorde's (1984) pointing out the empty promise for white women of equality embedded in white patriarchy, white people remain blind to the fact that while they receive more "rewards" than people of color, the price is high, the rewards never match the promise, and they, too, are constantly pitted against one another without a prize that could ever satisfy. Engagement in the culture of white supremacy requires a winner, a loser, no 
prize, and unconscious participation in a wearing battle leaving an insatiable desire that attempts to be met through consuming and further hierarchy building. In this repeating cycle of the culture of white supremacy, participants are chasing a sense of an unattainable sense of worthiness based on the unworthiness of another. As King (2011) describes, superiority/inferiority in part works on a collective level but also on an individual level by creating identities. Gillborn (2005) citing Youdell (2004) explains "her analysis also demonstrates the numerous ways in which certain identities are strengthened and legitimized through countless acts of reiteration and reinforcement" (p. 490).

Whiteness is further normalized and reinforced socially and culturally through repetition, ostracizing those who object, and by pretending it does not exist. Pretending racism and whiteness do not exist, gets whites are "off the hook" by making their actions not about their choices and behavior. By separating imperialism and white supremacy from racism in history lessons, the implication becomes that as long as inclusion exists, racism does not exist. Colorblindness is also exhibited in behaviors that communicate "everyone knows things are supposed to be this way" and "if they do not know, there is something wrong with them." What is spoken explicitly is "we're all equal and the same," but in actuality, great inequality and disparity exist, maintaining tremendous rift in power and resources for survival.

The creation of a binary of "less than" and existing as only in comparison with white, Western culture and its many and shifting meanings was described in this section. White and Western culture is framed as "normal" and "good" while Black and "other than Western" culture is considered deviant. This creation of this perception is institutionalized and then easily perpetuated through institutionalized practices. In the following section, I elucidate the ways 
these notions of "good" and "bad" are associated with white and Black and have been normalized in schools.

\section{Normalization of Whiteness in Schools}

Actions taken in the name of equality and equity are often masked creating the illusion of help or fair treatment, but often deflect attention away from sociopolitical issues by blaming individuals. Furthermore, the "help" is often so little, or actually harmful, that it actually serves to maintain the status quo. Farber (1969) points out that as a society, we are taught to view school as a "favor society grants you" similar to what "sweat shop owners tell their workers" (p. 51 , when in reality school is "a 12 -year course in how to be slaves...obliging and integrating on the surface but resistant underneath" (p. 3). Offers of false generosity, such as reforms, or historically the Hampton experiment, hold within them the very tools and means of whiteness, as the consciousness developed in teachers was similar to the white savior complex present in the teaching force today (Anderson, 1998; Leonardo \& Boas, 2013; Watkins, 2001). School reforms can be covert ways of deflecting from the fact that the same structures that support the status quo remain in place (Shujaa, 1993).

As Woodson (2006) so adamantly points out, the only way to escape the system is through self-determination, that is designing and executing a system solely by people not invested in dominating because any other efforts feeds whiteness practices. Having a $90 \%$ white teaching force who consciously or unconsciously buy into white supremacy, ensures that racial and class systems will ensue (Smith, Yosso, \& Solorzano, 2007). King (2006) makes this clear, "The visionary social struggle that resulted in the 1954 Brown v. Board of Education decision did not take into account the ways ideologically distorted knowledge sustains societal injustice, particularly academic and school knowledge about black history and culture” (p. 337). The 
curriculum reflects white supremacist ideologies and are embedded within schooling on many levels. King (1991) explains that most white people fail "to account for...beliefs and attitudes that have long justified societal oppression and inequity in the form of racial slavery or discrimination," (p. 7) and show deficit thinking about Black people. She further explains that white people have to go through a transformative shift in their worldview to imagine a world without privilege, and it is critical for teachers to "provide an alternative context of meaning within which students can critically analyze the social purpose of schooling” (King, 1991, p. 9). Students need "transformative emotional growth experiences" through self-reflection, in conjunction with "an intellectual understanding of schooling and inequity" (King, 1991, p. 3).

Much of what is transmitted in schools occurs through deep culture, which is not explicit. Unexamined assumptions are especially dangerous in school settings because this is where children are taught what counts as knowledge and what ways of being in the world are acceptable (Hoff \& Martin, in press). Culture possesses "the force and power to direct activity, to mold personalities, and to pattern behavior" (Ani, 1994, p. 5). Leonardo and Broderick (2011) attempt to decenter "the myth of the normal child" by shining light on underlying ideologies and the ways they intersect with whiteness and intellectual ability. Leonardo and Broderick (2011) describe whiteness as an invisible, but very real, hierarchical system of institutionalized privilege that shapeshifts into whatever those who benefit from it need it to be and depends upon the available pseudoscientific discourses. Some students are taught that they are intellectually superior to others, and therefore worthy recipients of privilege and its benefits, while others are taught they are intellectually inferior and not entitled to or worthy of such privileges.

Ferri and Bacon (2011) explain ways whiteness is normalized in school settings beginning in Pre-K. Norming of students based on "school readiness" developmental markers 
begins in early childhood and is a form of "ability tracking" making this process and its trajectory quite powerful. School readiness and "at risk" labeling practices are grounded in deficit thinking and eugenics evidenced by the overrepresentation of poor and ethnically and racially non-majority students with special education labels. Psychometric testing adds credence to this sorting and absolves schools of accountability of student failure as "the field must continue to produce the problem it was created to serve...to justify its existence" (Ferri \& Bacon, 2011, p. 139) and then "addresses student need" through the false generosity of early childhood programs. Standardized testing and Response to Intervention (RtI) screenings further sort students by comparing students to one another and ranking them. Ranking seems more real the greater the differences are between students. In fact, ranking is based on students doing poorly. Stiggins (2014) argues this is the main function of assessment currently rather than supporting learning, and it forces students "to compete for an artificial scarcity of success" (Stiggins, p. 40). Shujaa (1993) further illuminates how this works:

Structural conditions are the 'institutionalized arrangements of human life'. The influence of society's structural conditions on an individual's achievement expectations is cumulative. Schooling exerts an influence on members' achievement expectations through policies (e.g., tracking and testing), reward systems (e.g., grading and awarding credentials), and patterns of human interaction (e.g., social inclusion and exclusion) that reinforce and are reinforced by society's structural conditions. (p. 17)

Schools are structured in such a way to support achievement of those who enter school with cultural capital that matches that of the institution, or "norms that act as a form of currency in the social realm" (Winkle-Wagner, 2010, p 5). Then schools continue to support achievement of only those students achieving at the highest levels (Valenzuela, 1999). Only the students who 
are able to "keep up" will have access to and accumulate academic artifacts (grades, certificates, honors' courses, and diplomas) needed for economic gain. In this vicious cycle, teachers and schools reproduce failure for some students by communicating to students their intelligence and abilities are fixed and their potential predetermined and by doing little to interrupt it. In other words, schools are mirrors of capitalist systems, those who start out with the most privilege often end up with the most privilege meaning schools are designed so only some students will achieve success.

Whiteness is standardized and normalized in schools making it difficult to pinpoint the process, the unearned privilege, and making it difficult to work against. Schools act as gatekeeping entities that sort and label students mirroring societal hierarchies in terms of race and class. Much of the socialization that occurs happens at the level of deep culture standardizing and normalizing whiteness in a hidden way. Rewards in the form of grades and honors coursework that leads to access to institutions of higher education, degrees and ultimately economic leverage are granted to students whose culture matches that of the institution while those whose culture does not match are portrayed as deviant and deficit. These rewards are aligned with race and class but disguised by meritocracy narratives. In this next section, I will show how colorblind racism fits into the schooling process, supports the normalization of whiteness, and how colorblind policies take inequity and inequality to another level.

Jumping through hoops of whiteness has been normalized in schools and associated with very real rewards that result in survival on multiple levels. This section named various ways structures in schools racialize students and provide less access to education and its associated rewards. Culture is an especially insidious way of transmitting racism and white supremacy because it is often taken for granted and therefore difficult to see and sometimes name. 
Intricately tied to these practices is colorblind racism which I explain the tenets of and some of colorblind school practices below.

\section{Colorblindness}

Colorblind ideologies maintain that race does not matter in order to conceal how much it really does matter. Concealing this knowledge allows white people to avoid confronting the racial realities they live in, their own racist ideas, and deracialize happenings in their surroundings (Crenshaw, 1991). Lewis (2001) explains in her ethnography, while working in white schools, she found much colorblind "race talk" which "masked an underlying reality of racialized practices and understandings" (p. 781). Thompson (1999) defines colorblindness as the "refusal to see race" and as a doctrine held by most white Americans. This implies that there is a "we" that shares a common experience, but this claim to "blindness" and "innocence" seeks to avoid acknowledging differences in power and disparity. Schools are places where whiteness is normalized and normalization is strengthened through colorblind discourses, policies put in place, and the enacting of those policies. Normalization of whiteness makes asking why white people have more privilege and power irrelevant. Lisa Delpit (1998) explains how inexplicit norms in classrooms favor white students by design and portray racial "others" as problems. In many areas of schooling, such as curriculum, the needs of students of color are not considered or met (Ladson-Billings, 1995) unless a purposeful institutional effort is made to ensure equitable outcomes. Joyce E. King (2006) poses the question: "Is equal access to a faulty curriculum justice?" (p. 337) as the curriculum is informed by white supremacy. She exposes the flawed logic and assumptions embedded in colorblind processes which are by overlooking race and the consequences of the content of the curriculum, but by exposing each student to it equally, the colorblind way of defining "equality" equates with justice. The effects of colorblind racism are 
exhibited in the following quote written about England's schools, but it applies to US schools as well:

The evidence suggests that, despite a rhetoric of standards for all, education policy in England is actively involved in the defence, legitimation and extension of white supremacy. The assumptions which feed, and are strengthened by, this regime are not overtly discriminatory but their effects are empirically verifiable and materially real in every meaningful sense. Shaped by long established cultural, economic and historical structures of racial domination, the continued promotion of policies and practices that are known to be racially divisive testifies to a tacit intentionality in the system. The racist outcomes of contemporary policy may not be coldly calculated but they are far from accidental. (Gillborn, 2005, p. xx)

Audrey Thompson (2003) discusses colorblindness as being a hallmark of socialization theory as it seeks to ignore or minimize differences in order to achieve equality. One problem with this idea is that it claims to remove categories, but the meanings assigned the categories and their effects remain including inequality in life chances (Lewis, 2004). Another problem is that it measures or defines "equality" in terms of the most privileged members, and so an idea of "other" is created and only exists in relation to the most privileged in society. In doing so, this "other" is normalized and judged against those with the most power. Since supposedly equality has been achieved, when "others" do not "measure up" they get blamed (Lewis, 2004). Because the "other" is imagined and hypothetical, real needs and real strengths are not taken into consideration from the perspectives of the actual people the injustice affects. The "solution" to addressing the inequality comes from the standpoint of the same source that allowed or created the environment of for inequality to exist in the first place. Those privileged members have now 
come up with a "solution," but the "solution" is really a way to maintain the status quo because it does not meet real-life needs. Narratives are created and maintained to justify racial disparity. Objections to the narratives or circumstances are condemned, considered inappropriate and deceitful by those with the most power. White spaces that demand "race" to not be mentioned is the dominating force reinforcing domination by declaring that "objections to racism are not allowed" (Leonardo \& Porter, 2010).

Blau (2003) describes the ways the economy and liberalism are intricately tied to and aid in reinforcing and reproducing racism, demonstrating the interest convergence (Bell, 1995) present:

Liberalism has become an ideology, a defense used by white Americans to maintain their dominance. However, social values are never static, and I argue that neoliberalism...is not compatible with contemporary economic and social conditions. The New Economy encourages less hierarchical authority but more contingency, informality, and in-group preferences. Therefore, existing racial privileges and inequalities are easily reproduced and reinforced. (p. xiv)

The interest convergence (Bell, 1995) present is similar to the interest convergence that was present when racism was invented-dehumanizing others and profiting from it while making it co-exist with "values" of Christianity. This "pseudo-humanism," as Leonardo and Porter (2010) cite Césaire as calling it, exploited groups of people are depicted as less than human and then all these practices are "brushed under the rug" making it seem not only normal but natural.

Eduardo Bonilla-Silva (2006) developed a framework for explaining colorblindness as the newest form of racism. In short, colorblind ideology provides ways for communicating a stance centered in individualism while overlooking inequality. Bonilla-Silva's three-part 
framework looks at ways principles of liberalism hide inequality embedded in rhetoric of logic and morals. Liberalism uses political ideals such as "equal opportunity" to reinforce that everybody has the same opportunities making addressing inequality unnecessary, even harmful, and unfair. Economic liberalism maintains that each individual has choices that lead to their situation and overlooks the effects of racism in limiting choices and opportunities. One way all of this is normalized is through language and discourses that say the opposite of what they mean. In order to decipher what is really going on, it requires learning a language of opposite meanings. This "rational" approach to describing issues of race can on the surface sound "practical" and "fair," but it ignores all the aspects that could actually address institutionalized racism. Naturalization is used to explain racism in segregation practices and preferences for one's own race, and is used to reinforce the myth of nonracialism by purporting "all groups have these preferences." Cultural racism is the third frame Bonilla-Silva names as part of the colorblind framework. These include discourses and metanarratives based on stereotypes that rely on cultural rather than biological reasons for deficits which is a form of new racism and provides justifications for inequalities.

Colorblind ideologies privilege white people, maintain the status quo, and allow whites to remain complicit and "innocent" in the atmosphere of inequality by downplaying the effects of racial categories and their associated status. This also occurs through the silencing of voices that object, policies that reinforce inequity, and mainstream narratives that describe people of color as flawed and to blame for inequities and inequality. Narratives of meritocracy and policies built around them, make real and concrete their effects by providing economic and political rewards.

Colorblind racism is one way racism and white supremacy has morphed or shapeshifted to shift the narrative away from denying human rights to people of color. Many of its tenets deny 
racism exists and praise equality and many people believe this ideology to be true because the United States espouses these values. It really is the same old narrative dressed up serving dominating white supremacists. In the next chapter, I speak to why I chose my methods and why the lent themselves to understanding the type of information and understanding I sought. In Chapter 3, I will provide the purpose and overview of my research, discuss the methodology and epistemology as it relates to the study, my positionality, and data analysis. 


\section{CHAPTER III: METHODOLOGY \\ Purpose and Overview}

The discourse about bullying in schools has largely been framed within a colorblind ideology. Little attention has been given to the ways the social construction of bullying and the implementation of anti-bullying policies may influence students differently based upon their racial and ethnic identities. The purpose of this study is to explore the ways PK-12 student populations are affected by bullying discourses by interviewing 16 high school students, 8 who have been expelled from mainstream schooling, and attend an alternative high school, and 8 students who attend an elite, college-preparatory high school.

Research and discussions about the ways bullying discourses in PK-12 affect students of color are mostly absent from the research, and students of color are disproportionately disciplined, suspended, expelled from PK-12 institutions (Carter, Skiba, Arredondo, \& Pollock, 2014; Ferguson, 2001; Noguera, 2009; Skiba, Arredondo, \& Rausch, 2014; Webb-Johnson, 2002), and directly or indirectly identified as bullies. The absence of such research is problematic because the dominating culture defines bullying and decides policies for schools. In effect, white administrators and policymakers choose which students are protected by policies and which students are portrayed as bullies. Definitions of violence by those with the most power are extremely problematic because their definitions will support the status quo (Leonardo \& Porter, 2010). "Peace and order" as described by Angela Davis (1998) defined by white people means violence for people of color in white, colorblind designated spaces (Leonardo \& Porter, 2010). Studies revealing the "intersection between culture, identity, and school-based and family cultures" are needed (Brown, 2005, p. 33). While there are many studies that provide statistical 
data on bullying, fewer studies capture students' lived experiences and analyze them through the lens of critical discourse.

My research will address the following questions:

1. In what ways is bullying discourse connected to race and racialized discourses in k-12 settings?

a. How do bullying discourses and policies offer protection to some students while portraying/positioning others as bullies?

b. In what ways do bullying discourses and policies privilege and afford institutional protection for some students while marginalizing others?

c. How do the participants explicitly name race or use coded racial language When discussing their experiences and perceptions of bullying?

\section{Methodology and Epistemology}

In this section, I highlight and then build off of Gerald Walton's research as he is one of the few researchers to contest the hegemony present in the bullying discourse by pointing out the positivist and post-positivist notions of science and truth in bullying research. Then I will suggest methodologies better suited to address and analyze the complexities of bullying in light of what Walton (2005b) frames as extremely problematic with the hope of reconceptualizing these notions. Bullying is conceptualized, Walton (2005b) asserts, "Through the lens of scientism, bullying has become defined, objectified, categorized, and psychologized....and framed in discourse that implies objectivity, rationality, and scientific validation, apparently divorced from ideological underpinnings" (p. 57). Positivist notions of "Truth" and science are similar to, if not embedded within, the structures of whiteness as they seek to dominate and normalize by claiming there is one objective reality and they have access to it (Solórzano \& Yosso, 2002). The methodologies themselves are colorblind in not considering the effects of race because as Leonardo and Porter (2010) state "our imagination is itself racial" (p. 153), and therefore these problems that race creates cannot be solved outside of race. These positivist notions have allowed discourses around bullying to become a feature of whiteness. Bullying rhetoric works 
along the same lines of whiteness: proclaiming the principles of liberalism and at the same time allowing violent spaces to be created, groups of students to be scapegoated, and then coming up with new and better profitable interventions.

Most research on bullying quantifies human action and develops typologies associated with criminality and good/bad (Walton, 2005a) without looking at any the ways the meanings around and the status of race plays into bullying in school settings. In fact, the research on bullying almost exclusively finds solutions that rest solely on students changing their behavior without considering the sociopolitical environment of schools, social oppression, or political factors. Some of the strategies have been zero-tolerance policies which essentially moves violence that started in school elsewhere (Walton, 2005a). Most bullying research does not address that schools are places that set the stage for violence with hierarchies, educational militarism, traditional discipline based in control, and epistemology based in whiteness - a competition for scarce resources (Noddings, 1992; Walton, 2005a).

Epistemologies and methodologies that have informed bullying policies and intervention programs are colorblind "downplaying the intercentricity of race and racism in the discourse tell[ing] majoritarian stories about the insignificance of race and the notion that racism is something in the past" (Solórzano \& Yosso, 2002, p. 32). Positivist methodologies in the bullying discourse neglect the complex effects of racism on students of color, resistance strategies, and the ways they are already marginalized because of racism. Resistance to white hegemony defined as violence by hegemonic definitions results in students of color being called bullies (Leonardo \& Porter, 2010). Some of the research hints at class distinctions, low socioeconomic status, and "good" and "bad" homes, and there is little discussion of how these homes are usually defined in terms of Eurocentric, middle-class standards (Walton, 2005a). 
Positivist methods also do not consider what happens when the mostly white administration, teachers, and students define bullies and perceive bullying behaviors through their own cultural lenses of white superiority, normativity, and deficit thinking. They fail to include the ways schools privilege white students, construct identities, perceptions, support individualism and competition, and produce and reproduce social hierarchies around race and class. What is more, they do not look at the ways bullying prevention programs and policies developed from positivist research, reified through claims of "scientific" method and truth, are affecting students of color. In these ways, the bullying discourse results in literal and psychic violence for students of color (Leonardo \& Porter, 2010).

What is observed and measured in positivist methodologies is supposedly an objective description, but it is really researchers recapitulating how whiteness plays out in schools. In other words, the research is showing what is happening devoid of any context or meaning, making it colorblind research. Coming from a belief that "fixed reality exists external to people that can be measured and apprehended with some degree of accuracy" (Glesne, 2006, p. 6) does not account for or explain that people have very different experiences. Furthermore, it grants a "god-like" authority to those that lay claim to knowing this reality and by defining what counts as science, marginalizes other methodologies (Gordon, 1990; Solórzano \& Yosso, 2002). Neutral claims of objectivity in science mixed with power are frightening because it means that the people with power have so little understanding of their positionality, that their actions will most likely serve only them and others who can serve them. Peshkin (1998) asserts: "When their subjectivity remains unconscious, they insinuate rather than knowingly clarify their personal stakes" (p. 17). Positivists' claims that humans can turn off their subjectivity, their preferences, their biases at will and proclaim what is best for everyone else is rooted in the logic of Christianity and white 
benevolence, "the golden rule," and is synonymous with savior complexes. Because of the way authority and "truth" are intertwined, when the dominating culture enacts and practices discourses around a topic, that discourse becomes the hegemonic discourse and has the most power to affect groups of people on a mass level because rules and laws are based on them. When hegemonic discourses are institutionalized as practices and enacted in schools through policies, pedagogy, and ultimately access, as well as in the justice system, the effects are seen in court rulings, prison sentences, policing practices, and are an endpoint to many forms of freedom.

Colorblind policies and practices when examined through a positivist lens might show that there are patterns of violence, discord, conflict, high dropout rates and low achievement for some students, but the "intersecting patterns of racism" are overlooked (Crenshaw, 1991, p. 1243) telling only a partial story. Research used in this way is what Valencia (2010) would refer to as pseudo research as it lends credence to deficit thinking through colorblind lenses (Solórzano \& Yosso, 2002). It supports systems of hegemony, racism, and deficit thinking because it only tells the story of the outcomes without considering the "why," and the outcomes then justify criminalizing treatment, provide "explanation" for the way things are, and "explain" the circumstances of people of color.

A more relevant story is told through the lenses of constructivism and critical race methodologies because, "Qualitative research methods are used to understand some social phenomena from perspectives of those involved, to contextualize issues in their particular sociocultural-political milieu, and sometimes to transform or change social conditions" (Glesne, 2006, p. 4). Participant voice is particularly important in studies of marginalized populations because it is often these marginalized voices that have been silenced and need to be understood in order to 
actually understand problems (Caplan \& Ford, 2014). Nash (2008) makes a similar point, "For intersectional theorists, marginalized subjects have an epistemic advantage, a particular perspective that scholars should consider, if not adopt, when crafting a normative vision of a just society" (p. 3). Furthermore, Brown (2005) emphasizes that the Federal Government is very invested in finding interventions "that work" and can be generalized to other settings. However, as shown throughout the discussion on bullying, colorblind interventions do not work for students of color.

To understand students of color appropriately and not grossly misinterpret, research by scholars of color needs to be used (Murrell, 2009; Tillman, 2002) especially because their research tends to be marginalized and not acted upon (Gordon, 1990). Methodologies need to at least be consistent with worldviews of the people being studied or the worldviews that influenced their practices and culture (Tillman, 2006). Myers (1987) discusses how the Western worldview tends to fragment and decontextualize. Constructivist and critical race methodologies, on the other hand, utilize more holistic approaches in seeking to center silenced voices, emphasizing storytelling, narratives, counter-storytelling, revealing complex systems, and their interrelatedness. In fact, Tillman (2002) recommends using culturally congruent and "culturally sensitive research approaches [because] they both recognize ethnicity and position culture as central to the research process" (p. 3). Tillman (2002) also advocates for this method because it is a way for Black people to know "cultural and historical contexts of their lives" and culturally sensitive approaches avoid "attempts to portray Black people and Black culture(s) by persons who have limited knowledge of Black life" and "lead to inaccurate generalizations" (p. 4). Qualitative methods “offer greater possibilities for the use of alternative frameworks, coconstruction of multiple realities and experience, and knowledge that can lead to improved 
educational opportunities for African Americans" (Tillman, 2002, p. 5). Tillman also mentions Kershaw's (1992) Afrocentric emancipatory methodology which considers the nuances of the historical and cultural real-lived experiences of Black people in America in contrast to colorblind, positivist research methodologies. Later, Tillman (2006) offered Asante's framework based in Afrocentricism as it challenges Eurocentric notions of objectivity and authority in science and simultaneously provides methods for co-constructing knowledge with participants and challenging one's own positionality. Tillman's framework advocates for culturally nurturing practices such as culturally congruent methods, like those found in qualitative research, and data analysis that puts integrity and the community's well-being first, and practices that avoid dominance including theoretical dominance.

\section{Kind of study}

This study will explore the perceptions and experiences related to bullying of both white students and students of color through interviews and analyze the interview data using Crenshaw's (1991) theory of intersectionality to examine the way identity politics influences and shapes their experiences and perceptions. This is a qualitative study centering the voices, experiences, and understandings of students of color around bullying discourses seeking to capture students' lived experiences and analyze them through the lens of critical discourse. It will also focus on how race intersects with various aspects of student identity and how students of color are affected by existing bullying policies. Colorblind ideologies, influencing most schooling practices, overlook these identities, their effects, and then affect students of color in ways not considered. The intersection of race, as it intersects or relates to victimization in bullying and being portrayed as a bully, may create an additional level of victimization that will 
be explored. Drawing on critical race methodologies advocated by Solórzano \& Yosso (2002) this research will generate what they describe as:

A narrative that tells another person's story can reveal experiences with and responses to racism and sexism as told in a third person voice. This type of counter-narrative usually offers biographical analysis of the experiences of a person of color, again in relation to U.S. institutions and in a sociohistorical context. (p. 33)

This research will also look for patterns, practices, discourses, and social constructions of bullying to reveal some of the ways colorblind discourses have informed white students' perceptions. White students' responses may include colorblind discourses, race talk, and coded words for race. The data will be analyzed for disciplinary patterns, perceived safety and feelings of being protected by policies, and comfort and trust in reaching out to authorities.

Older high school students are an ideal student population to interview because they have been immersed in bullying discourses for twelve years. The research sites have been chosen because of the anticipated contrast in experiences of the students. The alternative school houses primarily students of color, living in poverty who have not been "successful" in mainstream systems of schooling, while the university affiliated, college-preparation high school caters to middle-to-upper class white students. A requirement of the college prep high school is lack of disciplinary referral, and the students at the alternative school have been expelled. Interview questions will be used to gather data. This data will be analyzed using discourse analysis because of the way authority and "truth" is intertwined and normalized. The data will be analyzed for participants' worldviews, ideologies, systems of thought, and expressions of agency or lack thereof as related to aspects of situated identity. Perceptions, enactments, and definitions of 
bullying are represented through language, and are embedded within these discourses and exist as hidden power and assumptions. These overlooked power structures and assumptions are what inform rules, policies, and the ways decisions are made that affect students and may privilege some student groups while harming others. The data will also be analyzed for themes related to discourse produced over time; the social, economic, and political climate; what was said and what was left out; location of challenges and assigned power; explanations and understandings of incidents and interactions; and interpretations and taken for granted notions (Applebaum, 2010). Discourses as social language and other types of symbolic exchanges are constructed by the users of language at the nexus of a particular culture, time, and place and because they are socially constructed and used amongst individuals and groups of people, are imbued with degrees of power.

\section{Contributions of Pilot Study}

I conducted a pilot study by interviewing one African American male who was a sophomore in college and plans to become a police officer. The pilot data mirrored research in that bullying discourses are defined very narrowly: one bully, one victim. This participant emphasized that bullying cannot happen without an audience and/or the involvement of other students and very much had to do with social identity groups (i.e., athletes, popular, class [own desirable possessions and clothing], "thugs/gangster," "students who don't care about anything"). However, he also emphatically explained that schools, teachers, and bullying propaganda (i.e., bullying prevention month commercials) paint the picture that bullying is a one-on-one act of aggression that is solved by telling an authority figure. This participant even identified that defining bullying in this way was a means for authority figures in schools to "wash their hands of the issue," so to speak, and "call it a day." His perceptions are consistent 
with the research about how schools are creating/perpetuating these hierarchical environments, they address bullying but it is meaningless, and bullies are depicted as an individual. While he did not mention race, he did describe class a playing a large role in bullying as in the ways possessions were equated with popularity. He further asserted that social media is instrumental in bullying now, and that is an aspect I did not delve into in my conceptual framework because I was focused on deconstructing the discourses in schools. This may be an important aspect of how bullying plays out that I need to build questions around in the future.

In sum, many studies that examine bullying are colorblind in the sense that they use positivist methods that do not examine real, lived experiences of people of color. Context not only matters when trying to forefront silenced voices, it is paramount to the research. Dominating groups will only learn about oppression and marginalization by listening to the voices of those who have experienced it. In this next section, I share my positionality as a researcher, my working against my whiteness, my experiences as a teacher, and my interest in conducting this study.

\section{Researcher Positionality}

Entering data collection, I was aware of a strong, negative bias towards students at Academy Prep because I had been in extracurricular settings with students and their families from this school. I experienced them as white liberals, having a sense of entitlement, and had heard some of them making derogatory remarks about people. These experiences reminded me of people I had worked with at private schools made up of mostly wealthy, white families. I also assumed that many would be like white students in Social Foundations courses I taught in the way that there would be a lot of white talk. Instead, I found that the students were able to "say the right thing" in terms of race, sexuality, and present a positive image of their school even 
though some of what they described contradicted this positive image put forth. While talking about race without really mentioning it is a form of white talk, but it was different from the more explicit objections I was accustomed to when teaching Social Foundations.

The danger of my preconceived notions is that I would interpret and analyze the data based on my biases and overlook critical aspects of the data to tell the bullying story. I journaled about my biases because I wanted to be more open to what the students were sharing instead of being wrapped up in my own preconceived notions. I sat down and wrote about these negative biases, processed them, and was able to get myself to a place of open mindedness about the students as opposed to having these expectations. I went into meeting these students with a different outlook than before I worked against my preconceived notions.

I had a positive bias towards students I expected to interview at Safe Alternative because I had worked with them in the past. I appreciated their straightforward, and what I would describe as a down-to-earth approach. I mostly held positive bias towards students at SA because I expected them to be similar to students I have worked with in the past at a community college in developmental reading. Because I have read and worked extensively within educational and social systems, I understand how power works and these systems are set up to reinforce privilege and marginalize. I was aware and paid attention to how power was at play in both school settings. The main focus of my teaching has evolved over the years to work against these systems. My positive bias was also related preference for environments with racial, ethnic, linguistic, and socioeconomic diversity. Various types of diversity provide a rich learning environment because of the multiple perspectives. The students I have worked with in the past who have been marginalized tend to be critical thinkers and are willing to challenge the status quo, and the fact that they had not fared well in school is something I always found telling. 
I realize now, being white and female, has afforded me a host of privilege I was unaware of in terms of safety, protection, and real-lived absence of assault or potential assault. I wish I had understood this much more in depth before entering this research. I was unable to reflect upon that which I was unaware of, but I was able to go back to the data analysis considering this new information and awareness and apply it to what Black females shared in their stories.

I was aware and concerned that SA students might not feel comfortable talking with me because I could be perceived as a teacher and I am white, a member of groups they may not trust. I appreciated when they disclosed as much as they did, and I was relieved when they expressed that the interview itself was beneficial to them and that they enjoyed it. Most of the students of color did not bring up race, and this is most likely due to me being white. One SA, who is white, did make racially loaded comments, and I am confident he felt comfortable in doing so due to our shared race.

Carter (2003) describes a researcher stance that values people over process and values people over the rewards of the academy, keeping truth telling (as much as that is possible) in the forefront at all times. Carter (2003) also cites Collins (2000, p. 186) stating that a "rearticulated consciousness" absent of hierarchical power relationships with the researcher as an authority is vital. What Carter (2003) noted can be expanded upon and applied to one's consciousness as a researcher considering their multiple identities, roles, subjectivities, biases, and power as a researcher. By placing in the forefront people, research, and the practices involved, the research can have a humanizing effect and outcomes. While teaching racially, ethnically, culturally, and economically diverse students in PK-16, a similar consciousness was required to ensure students' strengths and assets were acknowledged and supported rather than robotically embodying dogma flowing through me as a teacher or forcing them into boxes to meet my own agenda. Part of my 
consciousness involved not recapitulating the dogma, but seeking and enacting pedagogy that supported my students. This conscious-initiating process began when taking coursework that highlighted inequities and culturally relevant pedagogy. I have continued to read, study, examine my privilege and ways I have internalized habits of whiteness, learn from my students, and, most importantly, change my pedagogical practice to reflect equitable and humanizing pedagogy. I drew on the experience of teaching to constantly keep in the forefront the sensitivity, respect, and humanizing effect needed in this research.

In my attempt to follow this line of consciousness and awareness of self and my perceptions, I know that my interpretations and understandings will be influenced by the social identity groups to which I belong even as I work against them — white in America, culturally middle-class with white, middle-class schooling as a white, hetero, cis-female, Standard English speaking, member of the academy, and researcher. To work against my biases, my blind spots, I used active listening and checked my understandings and interpretations with my participants. However, to avoid placing undue burden upon them to explain areas and experiences that I am unfamiliar with or simply will never fully understand because of my privilege and lived experiences, I also relied heavily on the literature and what I learned through my coursework to understand participants' responses. The best I can do while working against my unconscious bias, is to consistently challenge myself to become aware of it by questioning perceptions and interpretations that arise, read and listen to perspectives I will not have naturally or own my own, and to reach towards the most humanizing way of viewing people with whom I do not share lived experiences.

My interest in the topic stems from many different experiences, my personal values, and perspectives. It is inhumane to make children attend school and make them invisible or set them 
up to fail under the guise of education. Schools as a nexus of white hegemony carrying out the larger sociopolitical agenda of genocide and exploitation of black and brown bodies, is a heinous crime which is especially insidious because it is so arbitrary and pervasive. Interest parties maintain power through an elusive dominating narrative that has manipulated the masses into believing lies seeking to keep racial narratives complex, invisible, and backwards. As a teacher, I have found the exploitative systems reveal themselves in the educational system which simply mirrors greater society.

My experience of teaching in diverse settings first in early elementary school and then in developmental reading in community college, I viewed "full circle" the reproduction of lack of opportunity stemming from the effects of poverty, institutional racism and discrimination, and the lack of culturally sustaining pedagogies as students of color and students living in poverty were commonly viewed in deficit ways. These educational settings and their climates limited students' educational opportunity through disproportionately placing certain students in special education, removing them from the classroom thus limiting their instructional exposure due to disciplinary reasons, and providing them with less challenging curriculum and related opportunities. Much of the reasoning driving these teacher and administrative behaviors were based on deficit perspectives, the failure to see strengths of the students, blaming the divide between students and teachers on an elusive "cultural factor," the failure to bridge home to school knowledge, and a strong resistance to employing culturally sustaining pedagogy. Even more disheartening, than the schooling cycle just described is when I recently taught two years of Social Foundations of Education courses to mostly white, middle-class preservice teachers. Most had no understanding of how institutionalized oppression works, had not begun the work of unpacking their privilege, or had any idea that racism still existed. One semester of engaging, to 
the limited degree to which most were willing, would unfortunately not go far in creating equitable atmospheres in their future classrooms. Knowing from my own experience, building critical consciousness is daily, life-long work linked to many unconscious processes that is never finished.

The actual or perceived social identity groups to which I belong most likely made the white, middle-class female students I interviewed more comfortable and respond in a more trusting, confidential way because they may be used to confiding to some degree to their parents and other authorities that seem and look like me. On the other hand, participants of color most likely and understandably may have been less trusting of me because I am white, a perceived authority figure, and receive benefits daily just for being white. Ethnic and cultural differences may be obstacles as well. There is much I may have missed when hearing stories of Black young women due to my privilege and protection afforded me as a white female. I will always have blind spots that I try to work against by listening and reading. Being white is an asset in forging relationships with white participants, and most likely an obstacle in building relationships with participants of color.

Because of my experiences and social identity groups to which I belong, it was difficult for me to imagine having to defend myself physically in a school setting. When young women described this, I realized there was a whole other layer to threat and violence that some of the young women had to endure that I had not considered. Although there were white teenagers who fought physically in my high school, my being white and perceivably from middle-class has protected me from a level of physical threat women of color or working-class women are not privy to, most likely. I am confident that I received more protection from teachers and officials and probably expected that protection. After reading Andrea J. Ritchie's book on police violence 
against Black women and women of color, I am now certain that I, as a white woman, have been afforded much less threat to my safety in terms of physical and sexual assault, as white girls and women are perceived as more innocent, in need of and deserving of protection. This lens definitely influenced and limited the ways I heard stories from the Black young women I interviewed. Ritchie's research assisted me in analyzing Black women's stories, to flesh out this lack of vulnerability I was afforded but blind to, in many ways in the data.

Another experience that was foreign to me, but I do not know that I can attribute it solely to race, ethnicity, or cultural-group affiliation, is the degree of familial support and sense of responsibility to one's family some of the students expressed. I have learned from the literature and from scholars of color that familial ties are strong and collectivist among people of color more so than among white families. While I do come from a more individualistic culture, I am also surprised when hearing white people speak of their family ties and degree of support as well. However, the familial strengths spoken of by African American students I interviewed at SA seem in alignment with the ways African Americans I have spoken with or listened to speak of their familial ties, and it is different from those of white people I have listened to and definitely in contrast with my own personal experiences. The familial ties expressed by the African American young women seemed to be their strength in getting through these horrendous experiences and situations put upon them by schools.

I will continue to use my being white and my continuing journey to deconstruct my own whiteness, and to better understand both institutional whiteness and the whiteness of participants. It is my intention to consciously use my experience with whiteness to work against it as a researcher, and it is my hope that through this research, my behavior, and my interactions with other white people to bring consciousness and awareness around what whiteness is and what 
white people need to do lessen the burden of it for people of color-beginning with ourselves and extending out to institutions.

Being in the role of researcher/interviewer puts me a position of power because I am asking questions and will have ultimate control of the data. As Tierney (1995) describes there is a real danger in imposing one's worldview upon others and in viewing ourselves as researchers who are scientific, all-knowing and all-seeing. Being in this position with uncritical habits of mind has led to gross misinterpretations of data that has hurt others. Tierney (1995) quotes Giroux (1993): "educators [write] from [and without] deconstructing their own linguistic privilege, and reproduces a populist elitism that serves to deskill educators rather than empower them" (p. 383). To guard against this, I will practice self-awareness through extensive journaling, reading literature on whiteness to bring about awareness of how I might be reproducing whiteness through my research. I will also be mindful that I am co-constructing this research with my participants, being mindful not to overshadow their voices, experiences, with white or academic authority.

As I engage in this work of examining how whiteness plays out in bullying discourses, I examine where elements of this lie in my consciousness and use that understanding to better understand how this works on a societal and institutional level. I attempt to enact the vigilance and hyper self-awareness Applebaum (2010) calls for "that recognizes the dangers of presuming that one can transcend racist systems when one attempts to work to challenge racist systems" (Applebaum, 2010, p. 20). To put another way, the danger looms large while critiquing a system, believing that I can stand outside of it and relinquish my complicity. The illusion that I am "done with my work" is so attractive, that I have to ride the wave of doing this work and knowing I never will "arrive" and, in fact, that delusion is what is at the heart of Applebaum's (2010) 
argument and title of her book Being Good, Being White. Applebaum (2010) further explains this idea through Ahmed's assertion that to be against something is to be in relationship with it and therein is the danger of believing if I am against something; I am not it. I also recognize my power and privilege in doing this dissertation work from the schooling I received, the opportunities awarded my parents just by being white which lead up to my being in this Ph.D. program, conducting this research with participants, including the privilege that allows me to sit back and reflect upon all of this.

In this section, I described my personal journey through the research: my biases entering data collection, my background experience, my identity and privilege, and my work against whiteness. I reflected upon who I am and how that potentially affected my data collection and my interpretation of the data. In the following section, I discuss the trustworthiness and validity of the data, ethics, and reciprocity.

\section{Validity/Trustworthiness}

I built trustworthiness by following what Glesne (2006) suggests, based on the work of Hollway and Jefferson (2000), which is to ask four critical questions about one's research:

1) What do you notice?

2) Why do you notice what you notice?

3) How can you interpret what you notice?

4) How can you know that your interpretation is the 'right' one? (p. 166)

I kept extensive reflective journals detailing my feelings, thoughts, and impressions before, during and after interviewing students. I tried to make myself aware of what I expected to find so I would not be blind to what actually happened in interviews. Then I paid special attention to what stood out to me as important and reflected upon why this was so to "seek out my 
subjectivity" (Peshkin, 1998). By engaging in negative case analysis, I examined my data for negative evidence and do my best to offer explanations and understanding (Glesne, 1999).

Further, I have created credibility and support for findings by interspersing my data with research from scholars who have explored and conducted related studies. In other words, I have couched the data in scholarly literature. I created a document that is descriptive, interpretive, theoretical, and evaluative (Maxwell, 1992). In doing so, my goal has been deep understanding (Wolcott, 1990). Finally, I provided a "rich, thick description" of the data which "allows the reader to enter the research context" (Glesne, 1999, p. 32).

\section{Consideration of Ethical Issues/Reciprocity}

Reciprocity is defined as a process of sharing, an exchange of responsiveness that creates a sense of community (Glesne, 2006). To address reciprocity, I created a space for respondents' stories and voice through presence and active listening. Because students chose to speak to me about bullying, it provided them with the opportunity to share their viewpoints on a topic they have strong feelings and opinions about, and, most importantly—being and feeling heard. Through this process, they may have gained clarity and understanding about their experiences, ideas, and feelings. I listened well and expressed much gratitude for their willingness to speak with me, share their thoughts, time, and deeply personal experiences. I gave respondents gift cards for their time, and to express appreciation for the value of their time and energy put forth in engaging in conversation. Some participants may benefit by reflecting upon how bullying has or has not affected their lives. Through reflecting it may also bring about insights related to fairness practices for various groups of students. Gaining an awareness of the ways some students are treated more fairly than others can be a catalyst for taking action in one's own life. IRB approval 
will also be sought and established to ensure ethical guidelines are followed to protect participants and their rights.

After broadly considering ethical concerns related to participants and the research, I now go into explaining in detail my data collection process, including how I selected the sites, the participants, and how the process of recruitment of participants played out.

\section{Data Collection}

\section{Site selection}

I selected each site because I believed it would provide a rich comparison due to the difference in student demographics. The alternative school (Safe Academy, SA) serves students who have been pushed out of mainstream educational settings related to behavioral or other issues. In some cases, they opted to attend the alternative school for various reasons, but again this indicates they felt pushed out of or unsafe at the schools they were attending. The college preparatory high school (Academy Preparatory, AP) represents the polar opposite in terms of student population and demographics in regards to race, class, and either personal issues or issues related to discipline. The students at the college preparatory school, in fact, need to have a strong academic record and few if any behavioral infractions.

\section{Participants}

The principals at each high school had suggestions for interviewing students. While I initially intended to solely use the snowballing technique, instead I followed the principals' suggestions. The principal at the alternative school, Safe Alternative (SA), suggested interviewing high school females who just graduated, and then asking them who they recommend I interview next. The principal at the college preparatory, Academy Preparatory 
(AP), school suggested I send out an email to all high school seniors because the students are used to volunteering since it is a laboratory school. Her reasoning was that in this way, I will be able to recruit students who "have something to say" about bullying.

\section{Academy Preparatory High School recruitment of participants}

After providing the principal at AP with the recruitment email to be sent out to the seniors at AP, I did not receive one response from the student body of approximately 200 students. Two weeks later, I contacted the principal and asked if she would send out an email to all the grade levels, and if I still did not receive any responses, I could possibly sit in on some classes and ask students if they were interested in participating. The principal did not respond to either of my suggestions, but said she had a plan. To my surprise, I began receiving email

responses from students' parents. Rather than interviewing students who decided on their own to interview, their decision might be influenced by their parents or at least filtered through their parents. I did receive a few emails directly from some of the seniors. I am not sure who the principal sent the emails out to or in what ways they were filtered. I interviewed a total of eight students from AP. Two students of color — one who identified as Eskimo/Inuit but "mostly white," one student who identified as African American, and six white students. I made efforts to contact and interview more students of color through connections, but the students did not contact me.

\section{Safe Alternative High School recruitment of participants}

One of my professors was leading a parenting class at SA. She suggested that I sit in and talk to students about my research to see if any might be interested in participating. I interviewed four students from this initial group. After these four interviews, I contacted the principal to ask if he could give me the names of students who he thought might be interested in participating. I 
interviewed four students he introduced me to. Afterwards, I stopped in on the parenting class, and there were a number of students I had not yet interviewed who were also interested in doing the interview. They wrote down their names and contact information. I did not end up interviewing all these students as some did not respond when I contacted them, but I did interview four of them. I interviewed a total of thirteen students at SA because once word spread, more students were interested in telling their stories. One student's data I did not include because he had one-word responses. The students I interviewed at SA were very engaged in telling their stories and sharing their perceptions. Perhaps because their voices have been silenced to such a degree, they wanted to tell their stories. I interviewed ten students of color and two white students at SA.

The interviews for both schools took place either at their schools or the public libraries over a two-month period. The interviews varied in length depending upon what and how much the participants had to share relevant to the questions. The students who had stories of bullying were very eager to share their stories while the students who had not experienced bullying or witnessed it, had less to say and these interviews were as brief as twenty minutes. The longest interview lasted three hours and was completed over a two-day period because the student had other obligations and time restrictions.

The interviews were semi-structured to allow aspects of the discourse to surface that I may not have considered. They were structured to the degree that I asked each student the same questions pertaining to experiences with the bullying discourse. Not all the interviews followed the interview questions in order, but instead became conversations where it was more natural to not impose my agenda on the interview, and rather to ask questions of areas we had not discussed in a lull period. Students also at times answered questions before they were asked 
because the topic happened to be connected to one of the stories they were telling. I will provide brief descriptions of each high school to provide context for participants' stories and to give the reader a feel for the overall social climate at each school. 


\section{CHAPTER IV: CONTEXT}

\section{Safe Alternative School Climate}

Safe Alternative serves students from the school districts of the town they are located within as well as more rurally located schools that the regional office of education governs. Students who attend SA have been expelled sometimes permanently and sometimes temporarily. Students can choose to attend SA when they do not feel safe at their home schools. At times, as is mentioned in the students' stories, they are given the "option" to attend. This can look like counselors or principals "suggesting" or "offering" SA as an option, but this is often after the school personnel do not know what to do with the students or how to help them. The students who took this option, usually were at such a point of desperation and frustration, that they and their parents were more than happy to make this transfer.

Even though the space the school and students occupy is small, the space is utilized well. Their classrooms are brightly colored, decorated with messages related to inclusivity, filled with technology, and consist of many small, private rooms for meetings and tutoring to occur. Many of the spaces reflect environments most conducive to collaboration, creativity, and comfort resembling "Starbucks' classrooms." The physicality of the spaces sends the message that students and learning matter. Since there are two universities located in town, students and professors frequent the school providing various forms of support and engaging events.

$\mathrm{SA}$ is progressive in that they practice restorative justice unlike the other schools. Students I interviewed described this process as very meaningful to them especially in comparison with the empty, interrogation-like procedures they experienced at their previous schools. They have counselors and teachers who genuinely support students in such ways to ensure their success, and it was surprising to hear students talk about their teachers caring and 
being invested in their success. Almost all the students at SA credit these caring relationships for their feelings of safety and/or motivation for attending school considering the countless negative experiences they have had with schools and teachers. The downside of attending SA, especially when contrasted with Academy Prep, is that they do not receive the same level of academic opportunity or preparation for college due to limited resources.

\section{Safe Alternative Participants' Stories}

In this section, I share the students' stories told from the students' perspectives and in their own words as much as possible because, "In a system that actively tries to eradicate or contain the voices of those impacted, self-representation is not just a significant methodological issue for academic research, it is a human right," (Meiners, 2007, p. 11). Karlene Faith claims the most basic of human rights is to "speak in one's own voice" and only someone who has had the lived experience can do so (Meiners, 2007). The length and depth of the portraits I provide of students vary due to the length, depth, and content of the stories they shared. The longest interviews lasted for three hours while the shortest interviews lasted only twenty minutes. In the case of the shorter interviews, I did not get a great sense of who students were other than basic demographic information because they simply did not have much to say about bullying. Students who had experienced bullying, obviously had more to say, plus it seemed that when they were bullied, they were then able to notice when others were bullied thus having more to share. There are two sets of SA students who I interviewed together because they were best friends and felt more comfortable telling their stories with each other present. These stories will be told together because in many cases they finished one another's stories and sentences and shook their heads in agreement. Separating their stories would mean losing meaning. 


\section{Derrick}

Derrick is an eighteen-year-old, large, African American male with a very grounded presence. He is wise beyond his nineteen years perhaps due to the intensity of his life experiences. His father died when he was in junior high, and he attended ten funerals within a year's time. He is a gifted storyteller with a strong sense of irony adding humor to the somewhat tragic stories he shared of friends who went to great lengths to change and hide who they were to stop being bullied. Throughout the weaving of his stories, it became clear that he knew himself well. He referred to himself as a "big guy" and having had earned the nickname "cheeseburger" within in his neighborhood. He said early on, he "owned" the label of being a big and so “cheeseburger" almost sounded like a term of affection used among his friends and acquaintances. He described himself as thick-skinned growing up and not as sensitive as others he knew when people brought attention to their body size. What he did find problematic though, was being called a bully by his principal in junior high while he was suffering due to the death of his father and the attended over ten funerals in one year. He was aware he could easily take this anger out on others, and to avoid doing so, he avoided interacting with peers to prevent fights.

Derrick demonstrated deep caring and sensitivity towards his friends as he conveyed their stories of having been bullied, one for his body size and another for being gay. He expressed bafflement over students bullying other students who had holes in their shoes and called people "real heartless" when they bullied people with disabilities. He named caring by his teachers at SA for being the reason why he is completing school. These caring relationships became an incentive for him to model stellar behavior for younger students in the program. 


\section{$\operatorname{Max}$}

Max is a tall, thin, eighteen-year-old male. He resists categories and labels but when he does use them he self-identifies as male, gay, multiracial (Puerto Rican, Black, and white), and as possessing feminine and masculine sides that he expresses based on his mood. His extremely outgoing personality and strong social skills are captivating and highlighted by a rich vocabulary and awareness of social issues. He was bullied extensively in junior high. He was almost never called by his name, and instead called "faggot," "that gay kid," or some variation of his name with "gay" mixed into it before, as he put it, "I even knew what I was". He did not fit in with the girls because he was not a girl, and he did not fit in with the boys because he did not like what they liked. While some teachers were very supportive, others would not make eye contact with him. More troubling to him, was the fact that personal information about him that he either shared with some teachers or they knew about in some other way, was then shared with other teachers. He explained the difference between teachers needing to know certain information about students versus being made aware of information as a form of gossip.

He was well-received when he gave up trying to conform to stereotypes around masculinity and "came out" in high school, however, in his senior year of high school, ironically after making a conscious effort to put his all into school achievement, he was bullied by his teachers who taught classes for students with various cognitive related disabilities. He has ADD, and his concentration and effort were greatly hindered when teachers began a surveillance campaign against him involving a great deal of interruptions. He was pulled out of the classroom and to the side, constantly being asked if he was okay. He was also harassed over biased dress codes. While he was not allowed to wear a shirt that revealed his stomach at all, many girls were allowed to wear shorts that showed part of their buttocks. The administration did not appreciate 
his resistance or his mom in the background shaking her head in agreement. Finally, he was "offered" the opportunity to attend the alternative school which he readily accepted. He said one of the biggest differences between his old school and SA was that the teachers and administrators only get involved with behavior when it is about ensuring students' success.

\section{Aniah}

Aniah is a tall, sixteen-year-old, Black woman who is very expressive. Due to her expressive, warm nature, she seemed like a natural teacher or a performing artist. She has been told repeatedly that, "Aniah helps people get through situations." She cares very much about her friends, and her caring is evident in the stories she shares. She was bullied extensively in her early elementary years before she "hit her glow up" or "approached her cuteness" mainly because the way she dressed did not conform to gender expectations for girls. She explained that her mom dressed her like a boy, and she was called "a boy," "gay," and "ugly," and this was very traumatic for her. Although her second-grade teacher tried to stop the bullying, it happened in so many spaces besides the classroom, that she could not stop it all together. She experienced great inner conflict over not wanting to hurt others or break the school rules by defending herself. However, by the fifth grade, she learned how to defend herself and was determined to never be bullied again. Protecting herself from bullying, hurt her too though because she got in trouble for fighting.

\section{Colton}

Colton is an eighteen-year-old, large, white male who explained that he had learning problems and some degree autism due to a difficult birth. Sensitivity and caring were present in his stories. Unlike most of the other students, he attended a school about twenty minutes out of town in a more rural, farming area. He was bullied daily for as long as he could remember 
because of his disabilities, low family income, his weight, his mom's skin disease, and because his dad was not doing well. In the school-district he attended, there was great disparity in family incomes. Although the teachers in elementary school tried to interrupt bullying, he was often called "retard" and "stupid," told he "wouldn't have anything nice in this life," and asked if he "was too poor" to afford various things. Being bullied for disabilities is a common theme that came up with many students, and Colton shared that he defended a girl with Down Syndrome and was her only friend. Colton expressed, "So I don't like it when people make fun of people with problems or even laugh cause I know how it feels and I know how other people feel when they get made fun of." He was pushed out of his home school three times. After the first time, "I went back in the $9^{\text {th }}$ grade and I got kicked out like a week after. My mom did a picketing right in front of the school saying 'stop bullying' and it was on the news. A lot people were like 'Oh your mom's so stupid for doing that."' He has been brought up on criminal charges related to defending himself against bullying, and if he has anymore charges, now that he is 18 , he will go to jail.

\section{Jesus}

Jesus is an eighteen-year-old, Mexican male, small in stature with very fair skin. He said he was not bullied but provided examples of being made fun of for being short. He mostly shared examples of others being bullied. The overall reasons for students being bullied included disabilities, slut shaming, and body shaming. He came across as sensitive and caring as he shared stories and instances of intervening on the behalf of others when they were bullied, including his two younger sisters after the administration would not do anything. He shared a story about a girl with a disability who was bullied: 
There was a girl with a Turner Syndrome in my school, she was just a normal person. She would fidget a lot with her hands and shake, and like, people were constantly, like, "can you take a picture with me," like trying to make her feel included but it was as a joke. They would be like "come here, like let's be friends" but they weren't genuine. They would take a picture of her and then you'd see it in their story like with different captions like "this idiot" or something like. I'm like really, like we were seniors in high school, like this has been going on since junior high.

There was anger in his voice as he described with detail similar stories of students being bullied especially when it came to his little sisters.

\section{Brittany and Michelle}

Brittany and Michelle are best friends and are inseparable. Brittany is a white young woman, and Michelle identified as African American and white. Both women come across as timid and meek which is understandable based on their experiences and because they were about to discuss extraordinarily painful, personal experiences. They knew the same stories and completed one another's sentences. They both experienced extreme bullying and serve as supports for another. They are classified as "digital students" which means that they only come to school once a week or as needed. This is in part because of the tremendous bullying they each experienced, some of which they continue to experience at SA.

Brittany is at SA because she was bullied by her former friend/boyfriend who in junior high and high school "called her names," "pushed her into lockers," "hit her," and threatened her until she stopped going to school. Michelle attempted suicide nine times and cut herself due to being bullied and the lack of help in interrupting the bullying at school. She has a long history of being bullied at every grade level. Some of her earliest bullying memories had to do with being 
made fun of because her mom cleaned houses for a living and because of her weight. She was told by the school administrators, she had "too many issues" and had to transfer to SA after an incident where she was attacked in the school cafeteria.

\section{Kayla and Maya}

Kayla and Maya are both young, Black women who described being pushed out of their home school. Their stories were co-constructed as they knew many of the same stories, but not necessarily what either of them thought about them in relation to school. Maya, who was quieter, verified Kayla's stories throughout with a soft but firm, "Mmm hmmm” and headshaking.

Kayla shared that she began her junior year of high school being pursued by a girl who kept trying to fight her. This eventually erupted into her defending herself, and because of that, she was sent to SA. Kayla said, "The only thing about alternative is you would get a better education at the other school. They have more like real world stuff, more electives, Spanish, cooking class, their [SA] money isn't good."

Maya has not experienced bullying. She described herself as very quiet and always keeping to herself, and "I didn't really experience getting bullied but I seen it around like plenty of times in school. I don't know why, just the type of person I am...like I know I look mean, but in reality, I'm like real nice. I stay to myself a lot too, that's probably why. It's just me and her [referring to Kelsey]. I don't hold my tongue for nobody. I don't know. I'm not going to say I'd pick on somebody but if I don't like something that somebody's doing I will let you know. I'm very blunt. I don't know that you would call that a bully though.”

Maya explained that she had poor attendance, and after she had her baby, she really tried to catch up and she did. She made this distinction between her former school and SA, "They [former school] have their students who they know they're going to give them the extra help to 
get there (laughing) and then it's like 'These kids, whatever' you know.” Kelsey added, with Maya agreeing, "Connecting [SA] with their kids, knowing what they have going on like literally they have conversations with you, check in on you, all the little programs that they do." Then they shared more about the caring they experienced at SA: "Like they have people come in from the outside, like you, like have you come in talk to us about stuff, like they really do care. They have like this little Christmas party (both saying at the same time) for the kids who go here with children and stuff like that. They gave him [her son] like two gifts. It was just real nice. They wouldn't have done nothing like that at my old school. I know they wouldn't have done nothing like that because of all the kids they have there. Exactly. They're [SA] understanding, they're very understanding, again, they connect with their kids (laughing). They know all about what's going on with you they really do. That's why I like this school. They care about their kids."

\section{Precious}

Precious is a sixteen-year-old, Black woman who styles hair for work. Her hair and makeup were different each time I saw her, and it showed that she was into fashion. When she is not at school or working, she helps her mom care for her new baby brother. She described strong bonds among her and her friends that served as protection against bullying. She experienced bullying when she first attended a high school in this town from another town because of the clothes she wore, the difference in fashion, and because of the boys she was dating. Eventually this was worked out, and she became friends with this group of girls. She was kicked out of her school for almost fighting. She described a scenario where her and her friends were almost fighting another group of girls, and there were teachers between them trying to stop it. She did not think this was fair because no one was actually hit, and the other girls were only suspended. 
Precious said that although she has been called a bully quite often, she did not agree with this label because she did not start fights. She expressed much frustration over the way her former school handled bullying, and shared, "I feel as I told them when I was there, it sucks cause they don't get on task with everything. It takes them time to do it so like one day me and my mom had to go up there and was arguing with them in the office cause when I first got there, when I first moved up here, I was getting bullied." In other words, she was being bullied, but the school was not responsive. She further explained that her previous school had a process of having students write their sides of the stories alone in a room, but the students never got together and discussed it. SA, on the other hand, had a "circle" where all parties involved discussed their perspectives and the problem was resolved rather than repeating.

She had very strong feelings about the presence of "real cops" in a school setting, and said, "When there's cops, honestly...because I feel that a school should not have cops at all...I know like securities they gonna be everywhere, that's supposed to be in a school. If a cop in your school you know something happened in your school. There's gotta be bullies here because you don't know nobody here yet. But if there's cops in schools, then you should know somebody is bullying here, there's something going on here and it's more than what you think it is."

\section{Terriana}

Terriana is a quiet, young Black woman who is attending a prominent university in a nearby state for culinary school in the fall. She explained that she suffers from social anxiety, and that it did not help her anxiety when she was bullied at her former high school. She said that her counselor tried to help her, but ultimately, she ended up "choosing" to attend SA because no one at her school could prevent her from being bullied. For Terriana, the bullying mostly took the form of name calling. She was made fun of for having gained weight, and it was suggested 
she slept with a lot of guys and ate too much. Her principal would frequently tell her to go home for the day, to take a break from the bullying. Her grades started to fail, so when her counselor, after a long process, suggested she attend SA, her and her mom felt it was the best option. Terriana was adamant that she did not believe in violence, she just was not that kind of person, and so fighting back was not an option for her.

She talked about witnessing other students getting bullied, mainly students with disabilities or who were gay or gender non-conforming. One student wore ear muffs to block out noise and experienced relentless bullying. She was called "slow" and "dumb" and eventually dropped out of school. A girl who was on the football team was called "gay," although she was not. A boy who was formerly on the football team and gay, was not harassed while he was on the team, but when he was kicked off the team for his grades, then he too was harassed for being gay. She too pointed out a difference between caring at her former school and SA, and said, "At my old school, they pass you on" when it comes to bullying. She also mentioned that counselors at SA spoke and met with students who were bullied to provide support, and she believed it helps.

\section{Robert}

Robert is a large, white, young man. He shared a story about his friend at his former school being bullied. He, himself, had not been bullied, but he considered defending others who were being bullied as part of his job, and said, "I like to bully bullies," and he was, "willing to take a bullet for others." What he shared about bullying was more broad than other students' stories. Robert explained that adults are bullies that use different words or cuss words, but typically when one hears the word bully, they think of a 10-year-old. He added, "People like to say the current president is an asshole. That word can easily be replaced with bully." He 
provided more examples of adults calling children "brats," "little pieces of shit," or "snot nosed," and identified this behavior as bullying. Further he said, "But adults can be bullied all the time," and named homeless people and addicts as being bullied frequently. He described pranks as "an adult version of a bully" specifically referring to reality shows that depict cheating on partners as pranks.

\section{Academy Preparatory}

AP is set up a typical high school in the Midwest except for the fact that the students have more freedom to roam and make choices within the confines of school. The students are given the choice to leave at lunch. The school is known for its exclusiveness, and seems more like a private school than a public school. The school prides itself on its high ranking in the state for achievement. One student explained that freshman are required to read a book called Race, and it provides a historical perspective of race and domination. Many of the students reiterated that the school was accepting of everyone, functioned like a family, and had very little bullying compared with other high schools in the area. Students reported that they frequently talk about politics in class, and were so passionate about politics, that there were even bullying related incidents during the 2017 presidential election. It serves as a laboratory learning space for the affiliated university and for college students who are training to become teachers. College students are frequently present in the building both tutoring and serving as student teachers. Four of the eight students I interviewed, came from the elementary school also affiliated with the university. Many of the students are children of professors at the university and/or from wealthy families who work at a local corporation. AP must meet a "diversity quota," however, when someone with ties to the people with power want to their children or an acquaintance's children to attend, these children are accepted into the school in a behind-the-scenes manner. 
Two of the eight students interviewed at AP have been bullied. They are both white and experienced the bullying at other schools in elementary and junior high. Most of the students said there really is not bullying at AP because they have such a strict policy against it.

\section{Academy Preparatory Participants' Stories}

\section{Hope}

Hope is a tall, thin, eighteen-year-old, white woman. She is upbeat and talkative. The bullying she spoke of occurred at a private Catholic school in town. Overall the bullying was due to a perceived difference of any kind, popularity, low SES, but really it came down to what she considered very random: "Literally anything. Like if you had, like if everyone liked Under Armor, and you wore an Adidas pair of sneakers, like they would just not talk to you. Like, you were considered weird if you didn't go to mass every weekend." Student enrollment dropped significantly due to bullying, and she explained, “They always have these seminars like don't bully each other like that sort of thing but it was never taken seriously by the students we always just kind of made fun of it because they didn't think it was like a real thing which really bothered me because I was like because people from six grade to seventh grade we lost like 10 kids and in a class of like 50 kids shrinking down to a class of 40 is like a lot so when it's that small of a little class losing 10 kids is a lot. I'm like why do you think these kids left?"

The bullying that affected her the most in her life was when her younger brother was bullied. Even though she herself had been bullied to such a degree that she left her school, she explained that she was just like "“F' you if someone doesn't like me” compared to her brother, and some of her friends, who internalized it. Her family did not know her brother was being bullied because he did not talk about it. He was smaller in stature than other boys his age and he liked technology which made him a target. She believes the bullying went on since he was in 
kindergarten and culminated one evening at the affiliated Catholic high school's football game with boys surrounding him and taking turns punching him. When their parents reported it to the elementary school principal, they responded that there was nothing they could do about it because it did not happen on school grounds. Hope's response to this was: "I'm like what do you mean it didn't happen on school grounds? It happened on the high school's property. It's a sister school to our school. Like what do you mean it didn't happen? It happened at a school event. It was a football game. They just always kind of brushed it off. Like no it's not a problem." That same weekend, Hope's parents pulled her brother from the school and enrolled him in a local public school where he did not encounter further bullying. After finishing elementary and junior high at public school, he, too, enrolled in AP. She said the bullying has had lasting effects on her brother as he is skittish around people and slow to open up because he is afraid he might be bullied again.

Similar to her brother, Hope was able to choose her school to opt out of the bullying environment, “Alright well I don't want to deal with these people in high school,' so I asked my mom if I could not go to the Catholic high school. We applied to AP and if I didn't get into AP I would go to public school. I just didn't want to go to school with those kids cause it's such a negative vibe all the time. I still talk to my old friends who went there with me and they say it's still the same."

She called telling adults in the school "a lost cause" after her brother's experience. Her youngest brother attends the same elementary school and told the principal he was being made fun of because kids thought he dyed his hair. She told him to stop dyeing his hair even though he had not been and did not address the bullying. Hope added, "People are always like, 'tell an adult, tell an adult' but the adults don't care. They just want to stay out of it. So a lot of the adults 
already know but they're like let it go but then that's like when people end up cutting themselves or committing suicide or depression or stuff like that."

Her friend Barbara experienced extreme bullying as well. A group of girls would pretend to be her friend, but taunt her by talking about hanging out in front of her and not invite her and sending her text messages that no one liked her. They called her a "lesbian" and "emo" because she liked bands such as Green Day and started rumors that she wanted to kill herself and that she cut herself. She actually had been suicidal at times due to the bullying. Later in high school, a public high school as she did not attend Catholic high school, she came out as Bi. Hope explained that being gay or lesbian was one of the worst things one could be according to their religion and values. Hope touched on the irony of this because the religion was supposed to be about love and modeling the accepting behavior of Jesus, but the religion mixed with schooling became a space where students were not accepted and bullied because of it.

\section{Tim}

Tim is a tall, thin eighteen-year-old, white, male who is entering the military soon after he graduates. He came across as very controlled, careful with his word choice, and respectful in a military sense. He has studied psychology and sociology and has thought extensively about bullying. He was bullied severely from second or third grade until he was a freshman in high school mainly because he was smaller than other boys, and because when his parents divorced, he became quiet and withdrawn. He did not begin talking about his having been bullied until an hour into our conversation. His voice and demeanor changed a bit when talking about it which most likely indicated it was painful to talk about. Tim seemed to have compartmentalized and reckoned his own experience of having been bullied with his current understanding of bullying. He explained a pop-psychology perspective of the cause of bullying. From this perspective, if 
students learn how to not be victims, they will not be bullied. This perspective is consistent with notions around mental toughness (a term he used) that some people in the military share. When he shared this perspective on bullying prevention, I referred back to an experience he shared earlier in the interview about when he went to a principal for help when he was being bullied. The principal responded to his plea for help by explaining to him that some students have a "bad home life" and to just ignore it. I asked, "What can a student do in that case?" He responded, "I don't know."

The turning point for him in his own having been bullied occurred when he was on the track team as a freshman. The coaches took a strong stance against bullying by telling the team members that they would be kicked off the team after one offense which is quicker than the school's policy of several warnings. He described feeling safe at school for the first time.

Interestingly, he had analyzed the bullying discourse at AP, and shared that what was formerly called bullying was now referred to as hazing. He believed the purpose of reframing bullying in this was to make families feel like their children were safe and this was just a normal part of schooling. He also pointed out that because AP has such a strong focus on academic achievement, some of the teachers behaved as bullies when they chastised students publicly for not having better test scores. Somewhat contradicting his critique of AP, he described AP as being a family and protecting and upholding its image, and that these sentiments were expressed at all-school assemblies especially when a former student was involved in a fatal car accident and another student committed suicide.

\section{Heather}

Heather is a large, eighteen-year-old, white woman with bright, red hair who came to AP from the university-affiliated elementary school. She witnessed and experienced little bullying in 
her life. She spoke in a very chipper, upbeat tone and manner and was eager to focus on positive aspects of schooling downplaying conflict. When asked if she had been bullied, she had this to say:

Umm, well there was this one girl who actually goes to this high school with me now, she would bully us or other people, but she had some like anger problems. Like one time she hit a boy with a baseball bat...like a metal one... a lot. And she hit my arm once so hard during a game of tag, it was like intentional, I had a handprint on my arm for like a week or so.

Just ah, the last day of school, at the old school, she pulled my hair so hard she pulled some of it out, as I was messing around with my friend she took my phone. We were like play fighting, I was trying to get it back and so that girl yelled and grabbed and pulled my hair and like I had to go to the nurse cause like, I'm like, "Umm what's going on" and the police got called, it was a huge mess (laughing). She had to take anger management classes over the summer. She got like 3 school suspensions and now she's kind of like a friendly acquaintance of mine (laughing). Because she got a lot of help and stuff.

When asked about LGBTQ students being bullied, she responded, "We have an alliance group, so we're really accepting." She also pointed out that she was large, but she was not bullied and nobody said anything about her size. One short-lived incident happened when another girl told her no one wanted her to come to the homecoming dance. Heather's mom, who knew the principal, immediately called the principal. Multiple meetings with notetaking were held, and it ended there. She said that she believed girls were bullied more than boys and that it usually took the form of social media "mean girl" type bullying. Heather was emphatic about the positive 
environment at AP. The social connections between her mom and the principal protected her from being bullied to some degree.

\section{Ashley}

Ashley is an eighteen-year-old, white woman who seemed to have a very active social life and a thorough understanding of the social milieu at AP as she described in great detail the social interactions on various levels. She spoke of political cliques and bullying around political alliances like Hope did. She explained that there is "always a lot of drama going on and rumors being spread" and "a lot of times it's a lot of people ganging up on one person like a group of people that don't like a singular person and then they'll gang up on them," but there are also many groups that do not like each other and are constantly fighting but not face-to-face. She also described a subtle, less apparent style of bullying among girls that frequently took the form of slights that were based in what that particular girl is most insecure about, "They just go for what they know you hate about yourself and then they'll like, I think it was yesterday, she went at one of her [one of Ashley's best friends] insecurities and my friend was like texting me and calling me during her chem class and she was like 'I'm going to cry, I'm going to cry, I can't do this' and I'm like, 'You got it. I'll talk to her about it later.'” She explained though that this mostly does not happen at school or in person because "we have zero tolerance policy for anything so if you do it over the phone, you can't really have any backlash if they don't have proof so Snapchat is always a thing people use." Ashley felt that "the teachers just kind of just let the students try to deal with it themselves but if it gets too extreme then they'll step in and try to stop it but there's really no way that they can stop it because they can't monitor phones or text or everything they're doing. So I mean they help to an extent but not completely to get rid of it." 
Many of the students at AP, including Ashley, would at times state that it was a bully-free zone. Almost all of students described a climate that was very open, accepting, and nondiscriminatory towards students of color and LGBTQ students. Ashley shared that she heard, but was not sure, that a young, Black woman was attacked in the bathroom after the presidential election. She named specific statements made about LGBTQ students that were not made to their face but perhaps within ear range, "I would hear about like the transgender and his girlfriend they would just be like 'ewww, I don't want to see two girls making out' or something like, 'I don't want to see that' or 'that's disgusting, why would you ever kiss that thing?' stuff like that would go on. Or if someone's gay, they'll like automatically feel uncomfortable around them because they're gay." She explained that it seemed like more people were homophobic than racist, and it was "really just a handful of people like that."

\section{Cameron}

Cameron is a tall, thin, white, eighteen-year-old male who is a senior at AP. He is on the swimming team and is in band. He had not experienced bullying in lifetime. The only bullying he mentioned was having witnessed the type of bullying that went on among girls similar to what Ashley described, “I don't know if this would be considered bullying, it's more like gossip but it's really mean stuff. Especially when it's not face-to-face bullying because they like pretend to be friends and then they talk to their other friends about it. Social media is a breeding ground for it because you can be secret, you can be unidentifiable. Like starting rumors, posting it on snap chat — because it goes away. Administration has gotten involved with this. People have been banned from school field trips. Girls called 'ho' but she's not. People were saying she made out with this guy in the elevator and she did this with somebody. It hurts her and it hurts her reputation." He spoke with great empathy and a bit of confusion when describing these bullying 
incidents among girls. Other than sharing about what he had witnessed among girls and bullying, his responses were very brief as was the interview. His responses added to the data showing that students who had not experienced bullying tended not to be aware of it.

\section{Gill}

Gill was the youngest student I interviewed. He is fourteen, a freshman, and a white male. He is tall and somewhat large. He lives about twenty-five minutes out of town in a rural area, and for elementary and junior high school, he attended a mix of Catholic schools and a home-school/community-school based in the Apostolic Christian religion. He loved the bigger environment of AP and seemed very social as he was in several clubs and many students were greeting him. He confided that he had bullied students when he was younger at different periods in his life mostly for nonconforming to ideals around masculinity: high-voice, non-athletic, not seeming masculine enough, or being interested in technology. He explained that after selfreflection, he knew what he did was wrong, and that now he knew more "how to be around people." He was somewhat careful in his language when talking about the LGBTQ community and Black Lives Matter. He was very clear that any type of dissent against either of these groups was considered quite intolerable with the "social movements."

He explained that his family is highly accepting of everyone, but he contradicted this sentiment when he said, in a somewhat irritated tone, that we're no longer able to say anything negative about people of color or gay/lesbian/transgender people. He spoke of a book called Race that all freshmen at AP are required to read and confided that he secretly found it a compelling read. His main takeaway from the book is that there will always be a dominating group, and that this is just the way it is. 


\section{Richey}

Richey is an eighteen-year-old, tall, lanky African American male who plans on attending one of several prestigious universities in the fall. He comes across as a student who is very involved in academic life and focused on high-achievement. He responded to questions with oneword-answers in Standard English, varied intonation, and with a slight lisp. Based his responses, he did not seem to have a wide and varied social group, but referenced several friends and getting along with everyone. Richey attended the university-affiliated elementary and junior high school and had witnessed no bullying except for some of the same types of bullying among girls that other students at AP described. He almost seemed surprised by some of the questions asked indicated by his response of emphatic, "No," when asked about specific bullying scenarios. This was a very brief interview with short responses, but important to the overall picture of the data showing that some students of color at AP were protected by class privilege from bullying and being marginalized through its discourses.

\section{Larry}

Larry is an eighteen-year-old male who identified as Eskimo-Inuit but mostly white. Finding a time to interview was difficult because he has a strict workout routine which was apparent by his build. He mentioned that he used to weigh 300 pounds but had lost a lot of weight. Even though he had been called fat a lot, he said it did not bother him at all and he did not care what others thought. He came across as very laid back and confident. His stories about bullying centered around YouTube videos he had watched, his little brother who has Autism, and punching a bully in the face and being suspended. He really did not have much to say about bullying. What he did share was not detailed or in depth except for the following story. 
Larry described a scenario of a male at AP who constantly harassed girls and described him as a "real perv." This same student came up in Hope and Ashley's stories. Larry was suspended for punching this student. Members of the senior class made and wore \#FreeLarry shirts when he was suspended because many of the students were tired of the student's behavior. More specifically, the student he punched had taken his chair and refused to get up. Larry said if it was any of student, he would have just sat somewhere else. He viewed the suspension as a mini-vacation and seemed to take the experience lightly.

In this chapter, I described the school settings and climates. I then provided a profile of each student that pertained to our interview, my impressions, and what they shared. The students at SA had much more to share about bullying because they had either been bullied or been framed as a bully. The students at AP, overall, expressed less experiences with bullying and had less to say about it. In Chapter 5, I analyze school policy on bullying and discipline and the interview data. 


\section{CHAPTER V: DATA ANALYSIS POLICY AND INTERVIEWS}

\section{Overview}

In this chapter I analyze the schools' policies on bullying and student interview data using discourse analysis. First, I discuss discourse analysis. Next, I review local schools' policies on bullying as an extension of their discipline policies. I analyzed AP's bullying policy and the bullying policies of the main two high schools most of the students interviewed at SA were expelled from or left. I include brief mention of local newspaper articles reporting the institution of new bullying interventions because these articles are part of the bullying discourse in that they help to create a perception of how schools handle bullying. Finally, I analyze student interview data and connect the data back to the policies.

\section{Discourse Analysis}

Critical Discourse Analysis emerged as a way to explain how language use is represented by, reflected in, and constructed systematically by the social world, and "focuses on how language as a cultural tool mediates relationships of power and privilege in social interactions, institutions, and bodies of knowledge" (Rogers, Malancharuvil-Berkes, Mosley, Hui, \& Joseph, 2005, p. 367). As Critical Discourse Analysis (CDA) emerged within the field of education, it sought to answer questions of not only a linguistic nature, but critical linguistics in relation to society. The evolution of CDA, particularly in relation to societal issues occurred side-by-side revolutions and the movements of the 1970s. Sociologists and cultural scholars began to look at the ways social structures were reproduced particularly in educational institutions, and rituals, interactions, and classroom traditions became a point of focus to understand this (Rogers, et al., 2005). 
While CDA (with capital letters) is primarily associated with Fairclough, I used "critically orientated forms of discourse analysis" (Rogers et al., 2005, p. 367) more in line with the work of James Gee (2004) with an emphasis on "treat[ing] social practices in terms of their implications for things like status, solidarity, distribution of social goods, and power" (Rogers et al., 2005, p. 367). Defined in such a way, it follows that language is never neutral as it is entangled in and used to navigate sociopolitical, economic, racial, gender, and many other cultural constructs (Rogers, et al., 2005). I used discourse analysis to interpret my data because I am examining the ways bullying is spoken of and communicated, its rules, policies, effects, and the ways it might privilege some identity groups while harming others. I also look at the underlying constructs that shape worldviews on race, privilege, and which students are viewed as bullies/victims. I will use it as a tool to "uncover[s] the order in social life" (Gee, 2014, p. 28) or "seeing, interactive communication through the lens of socially meaningful identities" (Gee, 2014, p. 25).

I argue that to truly understand what is occurring within the bullying discourse, the social nature of relationships, hierarchies, and the "rules" for how they work (Gee, 2014) need clarification. Embedded within these socially-orientated relationships that occur in school settings are identities. Gee (2014) explains that when discourses are enacted (language plus context), they are enacted from these "socially significant identities." I aim to deconstruct first what discourses exist around bullying and then to reconstruct possibilities for discourses aligned with equity.

\section{Policies Serving an Imagined White Norm}

To analyze this data, I read bullying, harassment, and discipline policies in student handbooks. I read them for all grade levels, but analyzed the high schools' policies because those 
were the most recent settings for the students, and they were all fairly similar to the grade schools' and junior highs' policies. Initially, I intended to only examine bullying policies, but reflecting upon that so much of the students' at SAs stories were about what happened to them through discipline and then noticing in the handbooks that there were no aligned consequences for bullying within with the bullying policy, I realized discipline was an integral part of the discourse. Bullying and discipline are not separate for some students but actually shapes much of the outcomes for them.

I conducted an internet search to identify local news concerning the school's bullying policies and found announcements/descriptions of when new bullying policies were being implemented. I include this in my analysis because the public perception of how bullying is handled and what the nature of the problem is, is an important aspect of the bullying discourse (Walton, 2015). When the problem is framed as being students who need to be managed, then the status quo continues unchallenged and undisrupted. Then I tie the policies and perceptions created around them back to colorblindness and intersectionality, and the ways policies fail because it is the actors writing and enacting them, as well as the effect of the policies, that make the written policy or formal discourse meaningful or not.

\section{The Discourses Surrounding the Policies}

There have been many changes in bullying policies over the past four years. Most relevant to this research, in 2015 , the state board of education required that schools include in their bullying policies, clauses related to cyber bullying, actual or perceived race, and many other protected groups. It is important to note that the students I interviewed have been affected by bullying policies prior to these changes as they reflect on their K-12 experiences while zero- 
tolerance was heavily used, but most of the students at SA have also experienced the effects of the ways bullying was handled after the laws and policies shifted.

As mentioned, to determine what discourses exist around bullying, I reviewed AP's bullying policies as well as the policies of the two high schools most of students at SA formerly attended. The two main high schools', students at SA formerly attended, bullying policies include the language required by the state about race. AP's bullying policy is separate from their policy on harassment and discipline, but includes this language in their "threatening and intimidating behavior section" and in their harassment section.

Harassment and bullying behaviors overlap, but the laws around them are different. While schools are supposed to know the difference, and ensure those populations are protected, whether they clearly understand the difference and follow through is unknown as, "Policies vary in scope, definitions, mandates, for training, and procedures for reporting, investigating, and intervening. And districts vary in how they implement these policies" (AERA, 2013). In many cases bullying and harassment are used interchangeably by the students and in some cases, it is difficult to tell the difference between the two. So, in analyzing bullying policies, harassment and disciplinary policies must be considered because harassment and bullying overlap and discipline is how bullying and harassment are managed. Bullying is so intricately tied to discipline that it cannot be separated when it comes to results and effects on students.

Bullying is perceived in so many different ways by students, school personnel, and the laws and policies guiding them. There is at least one study that suggests African American youth conceptualize bullying differently than some of the definitions used in measurement, and so they may underreport victimization (AERA, 2103). Many of the students at SA, and especially the students of color, asked how I defined bullying or what I meant by it upon asking them the 
interview questions. Every student interviewed, at some point during the interview, made comments to the effect, "I don't know if you consider that bullying." The men of color, said they had not been bullied; however, they told some stories of being teased repeatedly and threatened. The white male who had been bullied extensively, did not talk about it until an hour into the interview, managing to answer all of the questions about bullying without mentioning his own extensive bullying history. In other words, it is unknown if the data reflected in the literature is skewed by varying definitions used in measurement and underreporting.

\section{Creating Perceptions of Schools_-The Spinning of Stories}

As mentioned, because of state requirements, the school districts in the town shifted the language of their policies to include language about race, sexuality, perceived sexuality, homelessness, and cyberbullying. They also added bullying and cyberbullying hotlines so students and their parents could anonymously report bullying without the students being further targeted for reporting the bullying. There was in fact several articles published in the local newspaper about these changes, and in doing so announcing to the public that their children's schools are safe but have become safer. I provide quotes from these articles to show how they shape public perception around student safety as well as the perception that school personnel understand what is going on with bullying and are concerned. The opening line of one of the article reads:

Local education leaders say their districts will not have much difficulty complying with a new state law that puts more teeth in public schools' anti-bullying policies.

This sentiment is followed by an even stronger claim by the assistant superintendent: 
We have an aggressive policy already because we don't tolerate bullying in our schools, but we will have to review the requirements of the new law to see if it all matches. We think it will.

These statements almost come across as arrogant and ignorant at the same time in that they say they already have a policy in place that surpasses what the newest legislation is requiring before they even review it. They assure the public that they already have a strong handle on bullying before even being mandated to add new provisions and protections. Furthermore, the statement “we don't tolerate bullying" implies that overall bullying has been handled and is not a problem. In the following quote, a member of the school staff claims that school personnel understand and can see bullying from the students' perspectives and are addressing the issues: While an elementary school child likely would tell a teacher or adult if he or she were bullied, a middle school or high school student likely would not. Sometimes older students choose not to speak up for fear of being labeled a 'rat' or targeted for retaliation. Again, this communicates to the public they understand the risks involved, how children feel, and that they are taking these extra measures to address these issues.

The article also quotes the governor which sends an even stronger message that this is important and really happening. The governor was quoted as saying, "The law will protect students inside and outside of the classroom." This is another "feel good" statement that implies that all of the cyberbullying is being taken care of and it will no longer be a problem for students. The governor goes on to add:

Every student in Illinois deserves to go to a school where they feel comfortable and safe. This new law is for all students who have been bullied but didn't know where to turn. Our schools will now set comprehensive anti-bullying standards for all districts so we can 
help students succeed inside and outside the classroom [because] The policy must include a definition of bullying, procedures for the reporting of bullying, parental notification, investigation of reports of bullying and actions that can be taken to address bullying.

Contrasting the statement about success with the actual rates of school failure and disproportionate discipline rates among students of color, the statement seems absurd. The district goes on to explain that they use a positive behavior incentive program called PBIS which has been shown to not prevent disproportionate discipline of students of color unless it is coupled with cultural competence (Skiba, 2014). These statements about policies imply fairness (Meiners, 2007). The article closes with a board member cheering on this new-found solution and praising of anti-bullying campaigns in schools:

I am elated this is happening and it's something I wanted to see happen for a long time. There is a of attention being paid to bullying right now and this is a great idea. The service provides schools an exclusive telephone number that accepts both text messages and voice calls, both anonymously. It also includes anti-bullying posters featuring the hotline number and behavior tips. Each student will get a card, about the size of a credit card, bearing the hotline number to carry in their wallet.

Students can now report bullying using their cell phones which the article says they are more comfortable doing, and then staff can make the reported spaces bullying is happening in safer by increasing school personnel. Students whose families can afford to give them cell phones are protected in this way, and another company profits from providing a bully prevention program.

The article in the local paper about the other main district reads more realistically as it uses phrases like "potential to help," "the law has provided us with a broader way to address issues," and "proactive approach" towards bullying. The superintendent references "restorative 
discipline" as having been helpful in reducing office referrals not just in relation to bullying but all discipline. While restorative justice practices are one of the methods suggested in the literature to reduce bullying, it depends on how it is implemented. If implemented in such a way to stop bullying or a different way to discipline students, it would not be effective in the way it is intended to be, such as in building relationships and mutual respect. Plus, if there are still social hierarchies in the schools, then it might just be another panacea that schools could say they are applying. Regardless, the superintendent's statement implies that it is being used on a regular basis and even subtly addresses the issue of disproportionate discipline. This article was published two years ago. At the beginning of this school year, there was a restorative justice inservice held for the principals in the district to begin using restorative justice practices, and now, three years later, these practices are not institutionalized or widespread. Maybe there were pilot programs going on that the superintendent is referring to, but the article suggests they are using a method to help prevent discipline referrals and it is fully integrated. After speaking with teachers in the district, it is not. This article, like the other article, creates a perception of being on top of the bullying problem.

Reading these articles in the paper might make a parent whose child had not been a victim of bullying, who trust their child's school, and the authorities in it, feel very good about their child's safety at school. On the other hand, a parent whose child had been bullied at school, who has had experiences of the school not following through, might react with feelings of disbelief, mistrust, and anger. Either way, the message is that the schools are taking steps towards preventing bullying and students will be safer. After all, the schools are implementing these policies, they have been published in the newspaper, and even the governor has spoken. If taken a step further and the parents read the bullying policies in the student handbooks, they 
might react by feeling even better about their child's safety, or outrage depending on their background and experiences. Most likely, both sets of parents would believe it was their child's right to be safe at school.

\section{What the Policies Say-Words and Rules}

Here I present the most inclusively written of the bullying policies of the three high schools. I will show how the language falls short of its implied purpose of protecting all students. The language written into a policy is meaningless if the effects of the policy are not what the policy states and intends it will do for all student populations.

Bullying, intimidation and harassment diminish a student's ability to learn and a school's ability to educate. Preventing students from engaging in these disruptive behaviors and providing all students equal access to a safe, non-hostile learning environment are important District goals. Bullying on the basis of actual or perceived race, color, national origin, military status, unfavorable discharge status from the military service, sex, sexual orientation, gender identity, gender-related identity or expression, ancestry, age, religion, physical or mental disability, order of protection status, status of being homeless, or actual or potential marital or parental status, including pregnancy, association with a person or group with one or more of the aforementioned actual or perceived characteristics, or any other distinguishing characteristic, including among others body type, body image, or personal reputation, is prohibited.

The discourse in this policy suggests that these formerly unmentioned groups will now be protected because they are now named in the policy. Listing the names of groups or the categories of people without understanding of or mention of the discriminatory processes these groups face, in part by the teachers and administrators the institution employees, makes it a 
colorblind policy. There is no mention that the district's employees discipline students of color at higher rates, and that students of color are also overrepresented in special education (as determined by the district's criteria) which is another group that is bullied and so increasing their chances of being bullied even more. The policy avoids speaking to the systemic, institutional oppression of its students. While the school districts have implemented the required changes to their policies as mandated by the state in recent years, what ultimately matters are the actual effects and outcomes of the policy. In other words, almost anything can be written down and become law, i.e., desegregation, but it does not mean the implied intention will be achieved. As Omi and Winant (1993) point out "far from intervening in racial conflicts, the state is itself increasingly the preeminent site of racial conflict" (p. 82) meaning the laws and policies and the institutions through which they are filtered are "inherently racist" and a way of maintaining racial hierarchies. It is not what is in the explicitly stated in public policy that matters most, but the way it is enacted and the results on the affected parties.

\section{White washing bullying through discipline}

As of 2015, schools have been required to collect students' demographic data along with their discipline data because of the attention that has been brought to students of color being disproportionately disciplined. That is not written into the discipline policy, and so the policy fails to address one of the most problematic features of its process. It claims fairness and equality, yet it does not mention what has been central to it being unfair. The issue of disproportionate discipline of students of color is not openly being addressed or acknowledged making it a colorblind policy. What will be done to address it if it is not even mentioned?

Furthermore, when the policy is filtered through the many layers of the educational system in place, it looks quite different than what is stated in the school handbook and the 
implied meaning and intent. There exist countless ways school bullying policies could be understood, enacted, and filtered through federal requirements, state laws and policies, the regional climate, the district climate and policies, the school climate and policies, the student populations, the administrative beliefs and values, the teachers, and the students (see Figure 1 on page 28). Ultimately, the meaning given to the policy is subjective (Meiners, 2007) just like discipline policies and their enactment.

Since discipline is the main way bullying is processed and managed, I share below key pieces of the discipline policies from the high schools. The language used in the discipline policies are vague and have many assumptions built into them:

...there is an absolute obligation and responsibility to follow verbal and written instructions from any faculty member and to properly identify oneself to any staff member in regard to all aspects of student behavior and conduct at school and school activities. Willful and deliberate refusal to do so is insubordination and may result in a disciplinary consequence.

I am not sure how this statement could be more ambiguous concerning both the behavioral expectation and the impending threat. Essentially it is saying, "If you do anything I do not want you to do, or do not do anything I instruct you to do, anything could happen to you." While they also provide an itemized list of examples of behavior with potential punishments, statements like these, leave much open to interpretation and the consequences for students are open ended. The statement is colorblind because it does not address or consider any of the additional challenges students of color face due to being racialized by society and in schools. It also does not consider the many varying cultural frames and lived experiences people of color, or cultural perspectives 
of any other groups marginalized through discipline or guidelines for interpretation.

"Instructions" are filtered through many personal lenses and can be made to mean and refer to almost anything. The school personnel are demanding students blindly follow authority and accept disciplinary consequences which is extremely problematic considering students of color are disproportionately disciplined. It leaves no room for students of color to resist unjust systems.

The below statement similarly threatens disciplinary action for highly subjective behavior:

Students are responsible at all times for their language and gestures. Profane or obscene language is always unacceptable. Students responsible for improper language and gestures directed toward any teacher, staff member, or students are to be reported to the appropriate Assistant Principal immediately for appropriate disciplinary action. Students will be subject to a disciplinary consequence for using obscene or otherwise offensive language or gestures toward a staff member. Disciplinary consequences will also be assigned for incidents not directed toward a staff member.

In this clause, the rules and consequences become even more vague. What exactly are profane and obscene gestures? Obscene is definitionally connected to moral principles and profane relates to disrespect and ideas around sacredness and so even has religious undertones. There is an assumption that a "we" exists with a shared and common understanding. The policy goes on to invoke the word "improper" as a descriptor of language which is even more obscure and subjective. What is not considered or included in the policy is what has led to disproportionate discipline in the first place which the research suggests is most likely some combination of the following: teacher/administrator bias, biased curriculum and pedagogy, and hegemonically 
defined behavioral expectations. What also is not addressed is how these vague policies couched in whiteness, effect students who have been marginalized in countless other ways.

To link discipline back to bullying, in the above examples language use and not following instructions are worked into and throughout the bullying discourse and written into the discipline policies. Furthermore, expulsion from school falls under the category of "gross misconduct" but this could mean many different things to many different people. The following is an example from AP's handbook:

Students may be disciplined for gross disobedience or misconduct, including but not limited to, any of the following acts or behaviors which occur at school, at any school related or school-sponsored activity, or which substantially impacts the school:

a. Refusal to obey the policies, rules, and regulations of the Laboratory School or administrative staff;

b. Refusal to obey reasonable written or oral instructions of any member of the administrative staff, teaching staff, non-certificated supervisory personnel, or bus driver; c. Behavior, which interrupts the orderly process of school affairs;

d. Conduct, which is or may be physically injurious to persons or property; e. Repeated minor incidents of misbehavior, which other disciplinary measures have failed to deter;

f. Repeated minor incidents of misbehavior that violate or attempt to violate Lab School policy, rule, or regulation;

g. Behavior, which constitutes gross disrespect for the property or rights of other students, teaching staff, administrative staff, and non-certificated staff; 
h. Being in possession of selling, using, or threatening to use any weapon, dangerous object, or instrument capable of inflicting or intended to inflict bodily harm, or creating in an individual reasonable fear for bodily harm and/or the emotional/mental disruption of a person's daily life or educational environment.

The language in this policy, like the others, is highly subjective and ambiguous. Schools are a place where oppositional knowledge is not allowed (Hill-Collins, 1998), and where does this leave students of color and other students who are marginalized? "Behavior, which interrupts the orderly process of school affairs" leaves no room for students to resist being treated poorly, abused, bullied, or harassed because it is all interpreted and played out through the eyes and hands of those holding the power. There is a huge assumption of "we all know what this means," but with exploited student populations, biased school personnel, and the record of disproportionate discipline of students of color, it could come to mean anything the person with power to enact punishment interprets it to mean. Even among a group of white people from similar middle-class backgrounds and cultural frames, for who the policies are meant to address, words like "reasonable" are up for interpretation.

\section{The problem with policy}

Beginning in the 2017-2018 school year, the top twenty-percent (the schools who are disproportionately disciplining students of color at the highest rates comparatively) will have to come up with a plan to address this. Most likely restorative justice practices will be a part of their plan, like the superintendent in the newspaper reported, they implemented two years ago. The following outline of restorative justice is taken from one of the high school handbooks:

Restorative measures means a continuum of school-based alternatives to exclusionary discipline, such as suspensions and expulsions, that: (i) are adapted to the particular needs 
of the school and community, (ii) contribute to maintaining school safety, (iii) protect the integrity of a positive and productive learning climate, (iv) teach students the personal and interpersonal skills they will need to be successful in school and society, (v) serve to build and restore relationships among students, families, schools, and communities, and (vi) reduce the likelihood of future disruption by balancing accountability with an understanding of students' behavioral health needs in order to keep students in school. Even if restorative justice practices were fully integrated and being used in schools, as it is written in this policy, it still has inherently built into so many different meanings depending on who is reading it and who has the power to enact it. In this way, it is not inclusive and could potentially serve to maintain the status quo when white administrators are in charge. Plus, like any other type of cultural change that tries to make its way through schools, if it will ever be enacted and enacted with integrity depends on many variables. If it conflicts with the values of the principal and teachers, and in what ways will they resist it? If they do not buy into it, they will not institute it with fidelity, rendering it a meaningless string of words because it is not being practiced with integrity and not doing what it is intended to do.

Gee (2014) distinguishes between language with context, power, and meaning and language that is just words. He explains this difference as, "the role of doing and being and being in language" and "the role of saying and communicating" (p. 5) by comparing language to a child's card game. The point of his illustration is that language gets its meaning from "the game" or the practices. So, in the case of bullying policies, the written policy can say literally say anything, but the meaning is what matters (pgs. 4-5). Meaning, Gee (2014) explains, is derived from the practice or what actually happens. The layers of meaning involved in the bullying 
discourse are many because schools exist, function, and are filtered through hegemonic systems of white supremacy (see Figure 1, page 28).

In the analysis of policy, it became clear that policies themselves are inherently racist, whitewashed, and serving an imagined white norm designed by white administrators and policymakers. Not only are the policies racist, but they are very ambiguous so as to change to serve the authority or the one with the power to enact the policy in countless ways and "as needed." The perception created for the public, or the propaganda around bullying in schools, very much highlighted how "under control" and on top of the "bullying problem" they were. Newspaper articles announced measures schools were taking and unless one lived the experience in schools, they might not have a reason to question what was printed in the newspaper about schools, where the experts are in charge. Finally, new measures, such as restorative justice, are being pushed as a way to counter bullying, and while it sounds like an answer, again, it goes back to who is implementing it and what their level of fidelity in implementing is. Next, I share the words of the students themselves - their stories and discuss policies as lived experiences.

\section{Student interviews: What policies do and their lived meaning}

The meaning or what actually happens (Gee, 2014) is described by the students through their lived experiences. Some of the students' stories are conveyed through the portrayals of students in the methodology section, but here I focus on the themes as related to the original inquiry of this research. In analyzing this data, first I transcribed the interviews verbatim, and

then I created four tables separated by students of color at SA, white students at SA, students of color at AP, and white students at AP with answers to each question per student. Not all of the interviews flowed sequentially in the order of the questions, and this meant sifting through the data to identify when students spoke to the question. This process gave me a sense of themes, 
and I wrote analytic memos. I had over 50 potential themes when analyzing the data just through the lens of what students shared as significant about bullying. Refocusing the themes through the lens of the initial research questions, I created a table divided into the following categories: students of color who were bullied, white students who were bullied, students identified as a bully, students identified as a bully for defending themselves, and students who ended up at SA related to bullying.

Nine of the students interviewed at SA are students of color and three are white. One student interviewed at AP is African American, one is of Inuit Eskimo descent but identified as "mostly white," and the other six are white. Six students of color at SA said they had been bullied and five of them are female. One is a gay, male who is also nongender conforming at times. Two white students at AP had been bullied — one male and one female. The table below displays students demographically and by school, who was bullied, who was identified as a bully, and who ended up at SA due to bullying related incidents. I include their names (pseudonyms) to show how these categories overlap. 
Table 1

\section{Student Data}

\begin{tabular}{|c|c|c|c|c|}
\hline $\begin{array}{l}\text { Students of color } \\
\text { who were bullied }\end{array}$ & $\begin{array}{l}\text { White students } \\
\text { who were } \\
\text { bullied }\end{array}$ & $\begin{array}{l}\text { Students } \\
\text { identified as } \\
\text { a bully }\end{array}$ & $\begin{array}{l}\text { Students } \\
\text { identified as a } \\
\text { bully but } \\
\text { were } \\
\text { defending } \\
\text { themselves }\end{array}$ & $\begin{array}{l}\text { Students who ended } \\
\text { up at SA related to } \\
\text { bullying either as } \\
\text { having been bullied } \\
\text { or through } \\
\text { punishment related } \\
\text { to bullying }\end{array}$ \\
\hline $\begin{array}{l}\text { Aniah-Black female } \\
\text { at SA }\end{array}$ & $\begin{array}{l}\text { Colton-white } \\
\text { male at SA }\end{array}$ & $\begin{array}{l}\text { Gill-white } \\
\text { AP }\end{array}$ & Aniah & Aniah \\
\hline $\begin{array}{l}\text { Kayla-Black female } \\
\text { at SA }\end{array}$ & $\begin{array}{l}\text { Brittany-white } \\
\text { female at SA }\end{array}$ & & Kayla & Kayla \\
\hline $\begin{array}{l}\text { Terriana-Black } \\
\text { female at SA }\end{array}$ & $\begin{array}{l}\text { Hope-white } \\
\text { female at AP }\end{array}$ & & Terriana & Terriana \\
\hline $\begin{array}{l}\text { Michelle-Biracial } \\
\text { female at SA }\end{array}$ & $\begin{array}{l}\text { Tim-white male } \\
\text { at AP }\end{array}$ & & Precious & Precious \\
\hline $\begin{array}{l}\text { Precious-Black } \\
\text { female at SA }\end{array}$ & & & Derrick & Derrick \\
\hline $\begin{array}{l}\text { Max-Multiracial } \\
\text { male at SA }\end{array}$ & & & Jesus & Max \\
\hline $\begin{array}{l}\text { Derrick-Black male } \\
\text { at SA }\end{array}$ & & & Colton & Jesus \\
\hline \multirow{3}{*}{$\begin{array}{l}\text { Jesus-Mexican male } \\
\text { at SA }\end{array}$} & & & & Colton \\
\hline & & & & Brittany \\
\hline & & & & Michelle \\
\hline
\end{tabular}

Ten of the twelve students attending SA ended up there related to bullying either by being framed as a bully, for defending themselves (and friends) from being bullied, or because 
they were bullied. All 12 of the students I interviewed at SA had a great deal to share about bullying while only two of the eight students interviewed at AP had anything to share about bullying including stories about others. This is significant because students who had not experienced bullying of some kind seemed oblivious to it and had little to share. It is also significant because only two white students at AP had stories about having been bullied indicating it is more of a problem for students of color and students from working-class backgrounds. There was only one white male at AP who said he bullied students when he was younger, and it had nothing to do with self-defense.

\section{Central themes}

Four themes became apparent through this process. The themes have to do with what types of students are marginalized and in what ways they are marginalized through the bullying discourse, the consequences of the marginalization they experienced up to this point in their lives and the ways marginalization through bullying intersects with other forms of marginalization, and the hidden system that simultaneously orchestrates and maintains this marginalizing process. In the following sections, I provide an overview of the themes and then explain them more thoroughly providing examples from the data.

Consequences of being unprotected. The first theme is that teachers and administrators do not protect and interrupt the bullying of students or at least not effectively enough to make it stop. This was the case for all of the students who reported having been bullied; however, the consequences for the students of color and white students from low-income backgrounds are much graver because they had fewer choices around school choice. By this I mean, they simply could not switch schools like the student with class privilege could. Because of the way racism and classism intersect, lack of school choice was evident with more students of color than with 
white students. Furthermore, students of color and students from low-income or working-class backgrounds are already marginalized in ways related to race and income level in greater society and in schools. Students of color and from working class backgrounds are overrepresented in special education meaning they had labels of "disabled" which other students are aware of because of their placement in classrooms or being pulled out for services. This makes them a target. Students of color are already disproportionately disciplined. Some students of color reported that when they are viewed as not a "good student," they were protected less. This is addressed later in the "ideal student" theme. Not being protected played out in several different ways. Students reported that teachers and administrators witnessed bullying but did not stop it, or sometimes when students reported bullying, the teachers and administrators were unresponsive. Terriana talks about how being bullied without successful intervention played out for a classmate with disabilities:

Umm, there was this girl in my class, she had a thing where she had to wear earmuffs because sounds, the sounds messed with her. So people would make fun of her because of that and call her slow, or dumb, or retard and it just bothered me. It was most of the class. They would do every time they'd see her, yeah. It got to the point where she just dropped out of school.

When I asked how the administration handled it, she responded:

They really didn't. They just told her to ignore them or to ask to step out of the class if she needs a break or they told the bullies to leave her alone. They were just like, (raised voice) "Leave her alone!" And they were like, "Okay, okay." But they didn’t really do anything about it, and that's why she ended dropping out of school. 
Terriana said she did not feel comfortable going to administration for help when she was bullied because:

I tried and they just suggested me going to study hall or me going home early, stuff like that. I told my counselor at the time and my principal, my counselor tried everything. She - there would be days when I wanted to go home or leave, and she'd be like, "No get your books and stay here to do your work." She would motivate me to stay at school, but my principal would just say, "Hey, just go home early, take a break and come back tomorrow and try it again." He's the type of principal who doesn't really deal with conflict. Like, he like a typical principal, he doesn't want to really deal with anything except like sports or the gym or it's like one of those TV principals in real life so, yeah.

Terriana is at SA because:

It [being bullied] wasn't helping my anxiety at all so I just left cause I'm not a violent person. I've never been in a fight my entire life. So normal people are just like, "Well if they hit you, hit them back, if they do stuff, hit them," and I'm just like, "Well I'm not that type of person," so instead of me just being violent I just went to a different school that's better for me anyway because of anxiety and me being stressed out with school making my grades fail, so my mom just said it would be better for me to go to a different school where's there's less people and I can focus on my education and stuff instead of focusing on getting bullied.

Ultimately, her counselor's solution after many meetings with her principal who she said, "You could tell that he wasn't really paying attention," was to transfer her to SA. Although she was able to "choose" to attend a different school, it is a school with lower academic expectations and that carries stigma. 
Aniah was bullied for many years in elementary school. She described feeling this way about it:

I was an emotional wreck. Like as a little kid, I um, I really thought that I was what people saw, so like you know, um, I was like really timid, I was like quiet. It made me feel like, oh my gosh, I was being backed up into a little corner. Oh my gosh I don't know what to say. At that time, I wasn't good at comebacks...so it really kind of damaged me emotionally.

In the following story demonstrates non-responsiveness on the part of the teachers and administrators:

So there was a time, remember I told you, in $5^{\text {th }}$ grade, I had kind of outgrown being bullied, I had friends and stuff like that? And I joined band. I was playing the flute and there was another boy and his name was Nathaniel and he played this big old trumpet horn type looking thing and he was walking around with it, and he did, he looked like a nerd doing it, but he was my friend (with an affectionate tone) and so we were standing outside. We were waiting for the schools to open up the doors and there was this boy and he was talking about Nathaniel and I'm like "Stop. That's not cool, that's not cool," and he's like, "But he's such a nerd," and he just kept going on and I don't know what happened but I hauled off and smacked him in the face with my flute and I was like, "Man I feel so bad," and I was like, "Well he was being a bully," and Nathaniel, Nathaniel he was just like, I was like, oh my gosh, you could see it on his face. He was trying to ignore the guy who was insulting him. That kind of thing, "just ignore it, just ignore it," (in a rushed, quiet tone) and he wouldn't stop so I smacked him in the face 
with my flute, oh my gosh, he couldn't believe I did it, I couldn't believe I did it. But it's like, "You're a bully," (in a high pitched expressive tone) "and I know a bully when I see one," and so I just kind of hauled off and smacked him with my flute, but I was like you know (fades off).

I asked her if she thought of telling the teachers and administrators, and she responded:

No! Because they were right there at the doors! We had huge doors. There's two big doors and there was an administrator and a teacher at both doors. So, we were standing in the corner right by the teacher and he was listening to everything this guy was saying but he wasn't saying ANYTHING (strong emphasis, louder)!

The boy who was bullying got a detention, and Aniah was suspended because she "took a violent measure." For contrast sake, the following is a story Aniah shared about a girl who did not fight back because she did not want to get into trouble:

But there was an overall rule at my former school that whoever throws the first punch is usually suspended longer. So, when people get into altercations they be like, "You hit me first and then I hit you." So, it seems like whoever started the actual fight that's who would be in the most trouble, even if the victim was defending themselves and fought back, you would still be in trouble. So, I saw a fight where this one girl, um, she didn't, she didn't hit back at all. She actually goes here. She was in a fight and the girl was like hitting her and was dragging her everywhere and she just would not hit her back because she didn't want to get in trouble. She was like, "I do sports. You know, I do this, I do that and I need to be here so I'm not going to fight her back." So, people were calling her like a punk and calling her a wuss for not hitting her back but she just didn't want to have to deal with the drama of getting in trouble. So, she like literally let herself get beat up. I 
was like she didn't get in trouble because she didn't hit her back in any type of way. She just kind of sat there.

There are not many viable options for students and especially for students of color. As research has suggested, teacher bias may be a reason why students of color are disproportionately disciplined. Who receives the benefit of the doubt in the above scenario if there is unconscious bias?

By fifth grade, Aniah had successfully learned to protect herself from being bullied by fighting back and had established a reputation so students would not bully her. Later, in junior high, she had developed such a stance of self-protection from having been bullied and witnessed others being bullied, she was fighting and getting in trouble regularly. She was missing classes to be proactive about maintaining her safety through fights. However, when she realized she was failing P.E., her favorite class, she knew she had to change her behavior. She realized through the support of her family and counseling by her Pastor's wife that her anger was based on the trauma she experienced in grade school that she was repeatedly reminded of by students in junior high coupled with the fear of the bullying repeating itself. Before leaving her school and attending SA, she conveyed that she felt good about preventing a new student from a possible bullying situation because she made sure people who were beginning to pick on her, left her alone. These are the consequences of going unprotected for Aniah.

Colton communicated his attempt to seek help from teachers and administrators. He was bullied on a daily basis for as long as he could remember due to coming from a low-income background, his disabilities, his size, and for his parents' physical conditions. He said that students frequently brought weapons to school such as knives. Colton directly asked for protection but it he did not receive it: 
First, I would tell the teachers and the principal, but like I said the other day they really didn't do anything, so I just had to take it into my own hands. Beat um up. It's weird cause a lot of the people that bullied me were a lot smaller than me. Because I'm so much bigger than them, I can't be that much on them but I have a problem with fighting - anger problems cause it runs in my dad's side of the family so if I fight, I keep fighting until someone pulls me off of him. I black out and don't stop.

He was sent to SA because "a kid who was making fun of me, I smashed his head on top of a fence.” He added, “The administration did not act like they cared. I'd tell them every day and they'd say 'leave it alone' and didn't do anything about it.' He explained later, maybe as part of his autism, he had difficulty stopping once he began fighting back. These instances of being bullied and harassed and defending himself have resulted in him having criminal charges against him, and the possibility of being imprisoned if he is brought up on anymore charges. He explained that he was not the only student bullied for having disabilities. He frequently defended a girl with Down Syndrome. Their elementary school playground extended into three park areas where students would "force her to do drugs and force her to steal, cuss, take her clothes off. I made sure no one touched her in anyway. In grade school I was still a big kid so people were kind of scared of me too." This bullying also occurred in school bathrooms.

Brittany who was bullied and harassed by a former boyfriend/friend at school explained the non-responsive behavior and the consequences for her:

I had lots and lots of meetings at school, was put on medications, teachers basically called me a liar and didn't really do anything so I transferred. The teachers said there was no proof that he did it when there were teachers that saw him do it. They took his side over mine. 
This went on for two years and eventually Brittany would not leave her bed. Her mom took her to counseling, and that is when she was put on medications because she had shut down, would not talk to anyone, and as she put it, "I had a hard time with people last year".

Sometimes when teachers and administrators do respond, it may be in a way that minimizes the students' experience or it is not enough to stop the bullying. Tim was told by the administration:

To ignore it. Don't give them the attention. That's kind of the era they tried to push bullying out with if you don't give them the attention then they won't do it anymore, maybe they bully because they have a worse home life than you. It becomes, if you bully them back, automatically you become the worse bully no matter what.

Michelle, who was bullied at every grade level because her mom cleaned houses and for her weight, responded by cutting herself and attempting suicide nine times. She repeated like a mantra, “They never do anything. They [school administrators/teachers] don't stop it." She was told she "had too many issues" and was sent to SA after she was attacked in the school cafeteria where cameras recorded the incident. Michelle did not fight back, but was still sent to SA while the girl who attacked her received a two-day suspension.

Kalya shared a story about the beginning of her junior year in which she resolved to do well in school, but was being bullied. Like other students, the teachers and administration were unresponsive:

Like every day, she wanted to fight me for some reason, I don't know, she like just don't have it all in. I got suspended within the first 3 weeks of school cause me and her, cause I had fought her cause every day she try to bump into me, every day she try to say something to me just cause she was with her friends thinking it was funny. I was tellin' 
my momma, we had got into an altercation to where my teacher had seen her bump into me and she was like, "Stop," and I went to the principal and everything and they talked to her and her mom but she kept on, then I finally just fought her. Got sent here.

She expressed emphatically the exchange between her and the administration:

They brusin' it off, brushin' it off. Then when they seen what all happened everyone was just like, “Wow." When I had told them this was comin,' like I literally said in front of the dean, "I'm going to fight her." Even my mom was like, "Why is she even going to alternative? She told you all."

Their mutual friend was continually called "gay" and "a girl" by the same girl Kayla defended herself against. This bullying culminated in the girl who was bullying their gay friend being spat on, and he responded by breaking her nose. He, too, is at SA for defending himself.

Based on what Maya observed over the years, she backed up Kayla's stories:

I don't think [teachers/administrators] they pay too much attention to it unless it gets to like where it's just terrible. Then that's when they really want to start to care. They say school is safe for the kids but the worse things happen to you at school.

Kayla followed with, "I do feel that way too." Maya is at SA because, "They just don't care, like that's why I came here. Like I didn't even come here for behavior problems, I came here because I had to get caught up on my credits and [my high school] wasn't trying to help." Max echoed Maya's observation about teachers and administrators not responding by noting the interest convergence present when they do respond:

Some cases are more important than other cases. They're more important because if they weren't resolved and they weren't taken care of then that would become a bigger issue. And that's when bigger people would have to get involved. Higher level. And that's when 
parents have to get involved. And that's when it becomes hate crimes or the police have to get involved. It depends on the kind of bullying because if it's a small kind of bullying it's you know taken care of, it's a small problem, but if it's something that for instance if I was being bullied for like how I was dressing or something like that, it would be taken as small, but if I got to the point where someone is going to because my sexuality that's when it turns into a sexual hate crime, and that's when it becomes a real issue and that's when we really have to deal with this issue or it's going to become something big. It's going to make their jobs easier.

Most of the students mentioned there were usually a few teachers present in their schools who really tried to intervene, but the intervention was ineffective- the bullying persisted. When the students protected themselves, a criminalization process ensued which further marginalized students.

Consequences of students protecting or defending themselves. The second theme is that teachers and administrators punished students of color and white students from low-income backgrounds for defending themselves against physical attacks or protecting themselves when they were bullied verbally to prevent further bullying. When they were punished, it left them with few options other than to suffer the consequences of the punishment which was typically suspension and expulsion criminalizing the students. The two white students who attend AP, who were bullied, either did not defend themselves or did not get into trouble for it. Not all of the students of color defended themselves, but they still ended up at SA.

The number of stories the students at SA shared about caring for others, viewing others in humane ways, and the depth of the caring expressed ran parallel and in stark contrast to their stories of being in trouble. Which as it turns out, and is discussed in other themes at greater 
length, is not the perception teachers had of them or most likely, the common perception held by greater society. While they expressed great compassion for others, in part due to the various forms of marginalization they experienced, they are not viewed in this light. As highlighted in many places throughout this research, the literature supports a more realistic, humane, and assetbased view of marginalized people. This is one of the effects of marginalization and particularly multiple marginalization - they are portrayed in a dehumanized way and it is part of what maintains and continues the marginalization.

Who is the bully? The following account is Tim's assessment of the dilemma many of the students described. It is important to point out that Tim is a white male, and what he experienced is without the added layers of marginalization. Many of the students were faced with potential consequences when considering protecting themselves. If they did not protect themselves, they would continue to get bullied:

What constitutes self-defense and what constitutes wrongful action....and that's a big thing administrations have trouble discerning. Each side has her own friends vouching for them, and you get such mixed convoluted stories, and both people lined up with negative action and punishment being taken against them and so one party will always feel like they're the ones being discriminated against. Because they're just standing up for themselves they might then start seeing themselves as the bully and they go around question[ing] themselves, 'Am I really a bully? Is this really what happens when I stand up for myself? Should I keep doing this?'

Tim highlights how punishment and self-defense is not well understood or managed in school settings. It usually comes down to one student's or a group of students' words against another 
and who the administration believes leaving the already marginalized students, the less favored students, to fend for themselves.

In many cases, when the students of color and white students from low-income backgrounds defended or protected themselves or their friends, they were called a bully or it was insinuated. Derrick, a Black male, explained why his assistant principal called him a bully: because he (emphasis on he) thought I need to be nicer to kids. Me, my personality, like, me growing up, like me losing my dad, me going through a bunch of funerals at a young age, like I went through 10 funerals before I even hit junior high school. Imagine that. I went to my class (slowly, with emphasis), did my work, and came home.

This resulted in him being labeled a bully due to his "unfriendly" ways and being told by the principal to "grow up." He adamantly resisted the label of "bully" because, to him, a bully was someone who sought out fights and picked on others. He described bullies as those who picked on people with disabilities as "real heartless" and expressed confusion and disapproval over people bullying others with less money. He gave the example of students being made fun of because they had holes in their shoes, and said as if directly to them, "You've got it [money]. So, what's the purpose of this bro?"

Colton, who was called a "retard," "stupid," and made fun of for not having much money, explained how he was labeled a bully for defending himself and the outcomes:

The only reason I got called a bully was because I would beat the crap of kids who were bullying me. That caused me to have no friends. Everybody to hate me. Make up rumors about me.

Aniah said that she was identified as a bully, but she disagreed with this label because: 
you know how I said I was getting into a lot of fights? But I would never start the fights but they thought because I was always fighting I was considered a bully and after a while it kind of died out, "Nyia's not crazy. She's just not fighting," but in the beginning because I was getting into fight, after fight after fight, they'd be like, "Is something wrong with Nyia?" But usually I wasn't the one to initiate a fight.

When I asked her if she thought she was a bully now, she responded:

No! Most definitely not! Because I try my best, bullies tear people down, so whether I'm your friend or whether I'm your associate or acquaintance whatever you want to call it, I try to build people up even if I'm feeling terrible, I try to come in here and be like smiling and it be so hard. And there's people in my class, there was this one girl yesterday or the day before, sometime this week, she was just crying but she had on a blanky so you couldn't really see her but you could kind of hear her muffled cry, and so I you know, try to make her feel a little better cause you know me and her don't really talk but even though we don't really talk, I feel like that's no reason not to encourage her and let her know that whatever her situation, she didn't even have to tell it, whatever her situation is, you know "It's going to work out." (high encouraging voice) "It's just a right now type of thing," so I try my best to encourage people. I don't know if I'm good at it. People say, [I am]. I just like being there for people because I know for a long time people weren't really there for me. So, I try to be there for people.

Since Black girls and women are perceived as not needing protection, they had to fight but when they did, they were "punished for survival and self-defense" (Ritchie, 2017, p. xv) mimicking greater society and the legal system. When they refused to play out femininity as Black women and girls in ways that were acceptable to white people (Ritchie, 2017), they were punished. 
Kayla had this to say when I asked if she was ever called a bully, referring to her pleading with the administration over daily bullying by a peer who she eventually fought:

I'm pretty sure they were thinking I was like a bully at that school picking on her even though I told them what was happening, they acted like it happened out of nowhere.

Being called a bully is a form of punishment in and of itself because it creates a perception of the student as a person who seeks to hurt others unprovoked — a criminal. The perceptions and reputations of students among the school faculty have deleterious consequences for students as seen in the next theme - the ideal student and the social construction of difference.

Consequences of difference, normativity, and hegemony. The third theme emerged around difference, normativity, and ultimately hegemony. There are several ways this played out in school settings within and around the bullying discourse. The perception of difference of students by other students made the "different" students a target for bullying. Normativity also played out as a dichotomy around worthy/deserving and unworthy/undeserving students from the teachers' perspectives evident it the ways students were treated. The way hegemony played out in the bullying discourse was it awarded the students who were willing and able manage a desirable social identity or "brand" themselves as "normal" or "ideal student" reaped the benefits of the privileges related to those social identities. These social identities are the most advantageous as they offer students protection and educational opportunities.

Almost every student interviewed said students were bullied for being different or standing out in some way, but it depended upon the context and a student could be bullied for the exact opposite characteristic or label the next day. For example, students could be bullied for talking too much, for talking too little, for being fat, or too thin. Terriana expressed how arbitrary this can be: 
Umm, I was really quiet, really my whole life if you want to get technical, and people nowadays pick on you for anything so being quiet would be seen as, "She doesn't like anybody so let's pick on her," or if I was too loud "She's annoying, let's pick on her," so I just excluded myself from everything.

Hope also highlighted the arbitrary nature of bullying at the Catholic elementary school she attended with students from wealthy backgrounds. Being different meant not wearing a specific brand of socks and style within that brand, not attending church services enough, not conforming enough to traditional gender norms, and not being included in a socially constructed "popular" groups where the rules were unclear and changed rapidly. There was little to no racial or ethnic diversity present among the student body, and no students with disabilities in this school setting, so the rules of difference change depending on the setting when compared with schools with a more diverse student body. At the other schools, what counted as different ranged from body type to severe disabilities, and included sexuality, perceived sexuality, family income level, language, gender nonconformity or interpretations of it, being viewed as introverted or quiet, being seen as a loner, and many other variations on these themes. In other words, students who are already marginalized are bullied. To avoid being bullied, students ultimately had to "fit in" and blend in without disappearing socially because that would make a student a target too. Not being bullied meant maintaining a special blend and balance of being similar enough to the rest of the student body and what was most valued by those with the most social power. Max explained how being perceived as different made him a target in junior high and early years of high school:

many students in junior high—name calling, pushing down stairs, gossip, rumors, making up lies, rarely ever called by my name. I was either "faggot," that "gay kid," I was known 
as "that gay kid," or [version of his name with gay added in] and I wasn't even out of the closet. I didn't even know who I was. I knew I was different. I felt like I was pressured and bullied into conforming to a certain way in junior high. I was forced to dress like all the other guys but I was still bullied because I didn't like sports. I didn't fit in with the girls because I was a guy. I wouldn't do guy things. I wasn't into the stereotypical guy things. Girls wouldn't talk to me because I was a guy.

\section{The "ideal" student}

I include "the ideal student" in the category of difference, normativity, and hegemony and coupled with the "being different theme" because they are both based in normativity, expectations, and are dictated by hegemonic rules. In school settings, how does the whole notion of being different and not conforming manifest and emerge? Who reinforces it? The "ideal" student was a student who the teachers deemed worthy of protection and help, in terms of protection in disputes among students and academic assistance.

Kayla explained, as many students at SA did, that the "ideal student" (good grades, good behavior) was protected more than students like her, as she put it, "I was coming from alternative and I'm telling them so they probably thinking, 'You have previous this so,' they really didn't pay that much attention to me until they seen what I was capable." What she was conveying was that teachers viewed her in a poor light and were less apt to react to her until it became something serious. The idea behind the "ideal student" can be understood further through the lens of whiteness which Ladson-Billings (2000, p. 207) explains as:

The creation of a racial hierarchy with White and Black as polar opposites has positioned all people in American society (King, 1994) and reified "whiteness" in ways that suggest 
that the closer one is able to align oneself to whiteness, the more socially and culturally acceptable one is perceived to be.

Aniah explained that students were protected:

based on your credibility as a student, I think they do it sometimes based on that.

Like a good student. If you're a good student, their more apt to protect you but if you, but if you're a student that's been in trouble before, if you're a student that's always getting detentions and they know your face and they see someone doing something to you that may be considered bullying, they won't really mess with you. Like they'll leave you to the wolves. Rather than if you're someone whose good, you're always there, you're always doing your work, they're more apt to you know, "She puts in work so you know we're going to shield her from everyone else."

Max explained favoritism and the notion of the ideal student in the following way:

I was different. I feel like they favored other students but then I was never the favorite. I felt as if I stood alone. The other kids that were cookie-cutter that we're all kind of the same. They had good grades. They were athletic. They were all into the same things, same hobbies, and all the teachers loved them and they got along with the students perfectly, but when it came to the different crowd, and the kids that were different they didn't care.

Terriana suggested another way favoritism played out was through group membership. Students who belonged to the most valued groups in schools were protected more, "If you play something that's important then you don't get bullied but if you do something that's not really important like chorus." The example Max provides adds clarity to Terriana's statement: 
The ones that I've grown up with, the ones that finally get their senior year football, act like the gods. And are treated as if their gods. If you're not a football player you don't get as much attention.

Max continued to talk about the ways football is funded more than theater, and the message that sends to students who do not want to be part of mainstream activities, who want to be different, and want to have more than one-dimensional identities.

Consequences of the ways schools are complicit in bullying. Students described schools' complicity in bullying in these ways: presence of police, sending conflicting and confusing messages by holding bullying assemblies and then not being responsive, teachers modeling bullying and bullying students, pitting students against one another, inconsistent punishment, and by providing unsafe, dangerous spaces.

Tim describes a culture where bullying is acceptable and normalized at AP:

freshmen are bullied and it is seen as hazing, and it's just become part of the culture. If something happens to them especially on a sports' team, it's just brushed off until something greater happens to them. We've had two full school meetings about bullying/hazing and how it's not tolerated. In the meetings, it's talked about how it affects the image of the school and the staff in it. Because administration are the ones that try to keep the school image clean. The teachers are the ones who say this is how you will be punished.

Changing the terminology frames it differently for students by making them think hazing is something that happens to everyone, and that they are not being picked on or targeted. What Tim also alluded to was the administrative interest in portraying a certain image of the school which can be accomplished by downplaying bulling, reframing bullying, and pressuring 
students to conform and "behave" almost as a form of loyalty and pride. Where does that leave the students who are bullied, the students who do not feel included, who reject the culture of the school, or for whatever reason do not want to invest in that collective identity? Tim further reflected upon bullying on an institutional level. He said the staff did not want to use the word bully anymore because of the harsh connotations associated with it and instead have tried to replace it with the word hazing because it sounds "lighter" and has a "joking" feel to it. The word hazing normalizes and minimizes the experience, effects, and behaviors implying it is a rite of passage that happens to everyone. This alternative framing of bullying and even change of terms, can mean the school has less reporting of bullying incidents to account for. When framed as just par for the course for students in this way, students as less apt to report it. He explained that some of the parents have resisted this change in terminology because they want bullying to be taken seriously.

Another way Tim cites, as a way schools are complicit, is through teachers modeling bullying to increase academic competitiveness. He explained:

We're seen as the prep school. I think it was last year or two years ago, we were ranked, we are at 55th in the whole nation for academics and that's something we're prided on. It was something the administration prided on and is also something that whenever something went bad in class like the test average was down, the teacher would say, "You guys are 55th in the nation. Like why does this happen?" It's almost in a sense then that the staff are kind of bullies. That's based on a whole because the school has already set high expectations, and if one class doesn't meet it...in the mindset of the teacher, that could drag the rest of the school down with it. 
Maya and Kayla in the following dialogue show how schools are complicit in bullying too through teachers bullying students:

$\mathrm{K}$ : You could be like having a bad, like a really bad day and a teacher can make it like 10 times worse. Like say you got into it with your parents last night and you go to school and you're not in the mood and you don't want to do nothing, like just that day. They call on you and embarrass you in the class. Some teachers are like, are really something else, like will stop their whole lesson just to focus on you. Seriously.

M: like you could be putting your head down, and they stop what they're doing, they like, "What are you doing? Pick your head up." "Leave me alone," you say something like that. "No you guys, see this is what you don't do."

K: Stuff like that, they do stuff like that, seriously. That stuff happens very often actually. And they do this like when they get a school teacher evaluation and the principal will come sit in the class and M: and everything's so peachy and so perfect $\mathrm{K}$ : and I'll be straight telling them M: straight telling them, you not acting like this when they not here Another example Maya provided is a way a teacher targeted one student to try to get students to comply, making that student a target for future bullying:

I know this time we be in class and this boy be having his head down and the teacher be like, "We're not going to play Kahoot" or something like that, "Because so-in-so doesn't want to put his stuff away," and didn't do good so then you have everybody in the class mad at you. And then that will cause people to mess with you cause they wanted to play 
the game and they can't. All because of the teacher. Why are you worried about this one student? You have 29 other students that (laughing) you could've worried about.

Kayla provides a counter example of teachers who show caring:

I think the teachers that pull you to the side after class and are like, "Are you okay? What's going on?" care. But the ones that just like want to do the most, like during class...the ones who just focus on you [during class], I feel like they don't have good intentions.

Max felt that some teachers bully by gossiping about students:

I couldn't trust many teachers in junior high because things I would tell them personally, they would go and tell other staff members, and I would find out because other staff members would bring it up and everything...to myself how did you learn that? Because I didn't tell you that. I told another teacher that personally. So why are they going around telling other staff members? My personal information and things I told you in private. That's not even things that other staff members need to know. It was what they wanted them to know and there's a big difference between the two. There's a big difference between what teachers need to know about a student and things teachers want to gossip and know about students, and there's a lot of it in the schools. And that's a big problem. Yet another angle of teacher bullying was through being picked on. Max describes an extremely hierarchical environment with one person in power that is almost predatory:

I feel like they can tell when you're down. It's not every staff member but it was two in particular. I felt like they could sense when you're down and they would keep kicking you, keep kicking you, keep kicking you. And then when you're at your lowest they act like it's your fault. And then they make you build yourself up so they can take you down 
again. It's that same process and I wasn't letting them kick me down anymore my senior year. And that's when they would get angry. They had to take it up a notch. Bullying by the staff. I feel like some adults don't like my spirit, the way I shine. I have a very positive outlook.

Max also touched upon talked about respect. Usually in schools it is spoken of in one directionstudent to teacher. Max captures how this usually plays out and how he feels about it:

They have no respect. They want to be treated with respect and be treated like adults but they don't treat you with respect. I was 18. I was a young adult and the way they're talking to me and other young adults was as if we were small, as if we were little, as if we were meaningless, as if we were just, they were just up there. They were high and mighty and we were just little students. We don't have to respect you but you have to respect us. Respect is important in the discussion of bullying because ultimately it comes down to humanizing practices and treatment, inclusiveness, non-hierarchical environments, and shared power.

Another way school complicity plays out is through overt and covert messages about bullying. Maya talks about her lived experience of being immersed in bullying dogma but the behaviors of school personnel not matching. She had this to share about schools being complicit in bullying:

I've seen plenty of bullying papers in my little life too. Like plenty of bullying papers, like posters, like anti-bullying, like conversations and stuff. They talk about it a lot in schools but then they do nothing. Yeah. It doesn't really matter. You know? And then like teachers talk about it, like it'll be like no bullying in that class but what about when I 
go into these hallways. There's only so many. And then like the hall monitors, like that's not a person you'd run to.

Aniah also expressed extreme confusion over having monthly assemblies and anti-bullying signs up everywhere and then the teachers not intervening to interrupt bullying.

Yeah if they kind of like put out a zero tolerance (emphasis) and actually acted on it, and they made sure they didn't condone bullying. They put the signs up everywhere. Like this is no-bullying school but bullying was everywhere. If they had acted on that more, you know, not letting students treat each other a certain type of way, it wouldn’t happen. I kind felt like, to be honest, it kind of confused me cause I'm like, "Okay, you know, so maybe they aren't bullying maybe they're just poking fun because this is a no-bullying school." So, I was kind of confused for a minute like, "Maybe they aren't bullying me because they say this is bullying," (in a high, confused tone) "but they're doing it and nobody's doing anything so maybe this isn't bullying," but it most definitely was bullying (in a strong, determined voice).

She first understood that what was happening to her was bullying from the monthly assemblies the school held on bullying. Labeling this behavior as bullying, did not lessen the harassment or hurt she experienced. She explained:

That's another reason I didn't talk to teachers cause, "You guys say you don't condone it and you hear it, so I don't know what are you going to do about it if I actually do tell you, are you actually going to help me or are you're just going to like leave me?"

When I asked specifically about the ways she thought schools were complicit, she said: By not doing anything. I think that's the worst thing because it makes the students, it gives off the impression that you don't care and if you don't care, it's almost like 
condoning it, almost like saying, "Go ahead, do what you want." So, I feel like that probably the biggest way that they like contribute to the whole bullying thing. For Colton, the biggest contributing factor that made schools complicit was the nonresponsiveness or inability to stop bullying. He makes the distinction between his home school and the school he attends now:

My home school, they really don't do anything, it's not fair between the kids that do get bullied and the kids that are picking on people. But the school I go to now, if someone tells someone to shut up or even act like they're going to hit them, they stop it right then. Most of the kids weren't protected, they'd bring knives to schools or bats to protect themselves.

Brittany described a false impression schools create for parents when students are new to the school. When I asked Brittany how schools were complicit in bullying she responded: What doesn't make sense to me is when you go to a new school and you're talking to the principal and they say, "Your kid's gonna like it here. We have a no bullying policy," but it's not really true. I think it's just something they have to say cause in my opinion, they don't do anything about it. I don't know if it's cause they don't know how to react to it or help us but, counselors, I feel like they're just there to help you change your classes or something. They don't actually talk to you.

Precious felt very strongly that when she entered her new school and saw police presence, this sent the message that "something could happen to you here," as she explained:

they have REAL LIVE COPS! These are not no security guards, cause at my old schools just security guards, I never heard no, seen no, yeah I seen cop when they was coming in to do, to talk to your class about stuff about what you should not do in the world, okay 
that's supposed to happen, but if it's like real cops in your school on the daily, all day like from 8-3:30 or 8-2:30, then there's bullies in your school or something going on in your school. So, I feel as there should not be no cops in schools. But if there's cops in schools, then you should know bullying is here, there's something going on here and it's more than what you think it is.

I asked Precious questions about what the presence of "real cops" meant to her. It was obvious from her tone and expressions it was terrifying. Connecting her emphatic statement to the literature, Precious most likely has heard stories of Black girls and young women being assaulted in schools by police officers. Being a Black, young woman adds the additional threat of being assaulted and/or sexually assaulted by police officers (Ritchie, 2017).

Hill-Collins (1998) reflects on an experience of teaching second grade and the curriculum touted an experience of safety and reliability around public service workers such as fireman and police officers. Knowing this was not the experience of students of color, Hill-Collins openly discussed with her students the lack of assistance and sometimes threat these public servants posed to her students' communities. Derrick explained how a budding friendship was based in this shared distrust:

I met him [his good friend] in the summer, even then he was like, man, the first thing out of his mouth was like "I don't like the police," and I was like, me just meeting this kid I was like, “Okay, cool, neither do I. We already bond on something so I mean that's cool." So, then over the years, I like go to school with him and nowadays, and back then, he's always telling me, "Man FUCK that principal," every school he went to, "Fuck that principal. I don't like him. I don't like any of the teachers. Fuck all these classes.” He just didn't like it. He was always that kid that just didn't like it. I don't know if that's how he 
was when he was younger but when I met him, "Fuck the police. Fuck the teachers. Administration.”

The imposing threat police presence in school poses is an additional marginalizing factor for students who have had negative experiences with these authorities. A similar threat and marginalizing process occurs when students have these experiences with teachers and administrators as expressed by Derrick's friend. For Precious, it came down to, "You can't be weak in here. You gotta be tough because you don't know what's coming your way yet."

Individual students. One of the research questions was about whether students would either explicitly name race in relation to bullying or through the use of coded language. None of the students spoke about bullying and race. In fact, most students said each racial group was bullied about the same, or because most of the students in their school were white, white students were bullied most frequently. Two students said students of color were bullied more frequently. Race was brought up by students not directly related to bullying, but since the topic of the interview was bullying, and it was one of the research questions, I include the data here.

Derrick, who is Black, described unfair disciplinary procedures unrelated to bullying. He and his best friend, who is white, threw food in the lunch room and Derrick was suspended for longer than his friend. This made him question whether differential treatment based on race was still occurring these days. He described conversations with his mom and his family about this. He struggled with believing that racial discrimination still occurred, stating that he knew it had been the case for his mom, as she had explained various experiences she has had.

Robert, who is white, talked about Black students needing Black teachers to keep them "in line," and he mentioned a form of bullying he found at SA that he never saw in his ruralschool environment with all white students. He did not explicitly state that Black students were 
saying these things, but since he was one of the few white students present, I assumed this was who he was talking about. Plus, having been at an all-white school was a big difference between his home school and SA. He said that students often, in a very direct fashion would tell other students that they smelled, did not have the right shoes, and called others "gay" and "fag." He said that the teachers let it go unless it went into the territory of "making fun of someone who just lost a loved one." Since he was the only student who reported this, I was not sure how to interpret it because most of the students (all but three) reported feeling safe at SA. I wondered about "white niceness" versus more direct forms of dialogue, but again, since I did not have other examples to compare it too, I did not want to be too presumptuous but, at the same time, wanted to note it.

The last case of a student who talked about race was Gill from AP. Overall, the students I interviewed at AP repeated "we accept everybody here" types of sentiments, as it is one of the espoused values of AP. They prided themselves on being what a school "should be" and accepting of diversity is one of those qualities. However, when speaking with Ashley from AP, she gave a behind-the-scenes perspective of whispering voices denouncing students that were gay, transgender, and people of color. Gill is a freshman while most of the other students are seniors. He was schooled in a community homeschool co-op that was based in an Apostolic Christian belief system. He said there were a few students of color in his home school who were adopted. This "accepting" new, environment at AP was new to him, and he said he loved it. He further described, "Since I've been at AP, my filter has gotten a lot tighter." He rolled his eyes when mentioning Black Lives Matter and uttered, "Uhhh, there's a lot of that at my school, uhhhhhhh." He went on to explain: 
I feel like there's an extent to which umm, eeeh—this is going to sound racist—umm, a white person, like I make fun of my white friends all the time, whether or not because they're white or not, but then when it comes to — and people don't care about that, but if I were to say something mean or something to an African American, people would be pouncing on me left and right. Because of racial awareness.

He had similar views on gay students:

bullying a homosexual doesn't fly now a days with all the people gender identification, all the social standards, like you have to accept everyone for who they are. However, though, (stumbling over words) don't take this to mean this because I don't mean thisI'm just going to say this---ehhh (uncomfortable noise) the gay epidemic. I don't mean to say it in a negative way. It's the only word that came to mind. I feel like that wasn't a big thing - that everyone needs to be treated equal which they should (emphasis in tone)

For Gill, it was about having the socially acceptable response:

And again with the BLM movement and all this stuff, same with the homosexual movement. It's just not tolerated period. People notice it more. But back in second grade this wasn't nearly as big of an issue. We already thought he (student they bullied) was like gay, and of course now, you can't say—no matter what your personal beliefs areyou can’t make fun of gays no matter what your belief systems are.

Maybe the data would have looked different if younger, less cultivated AP students were interviewed. Gill's perspectives could be based on the conservative, Christian background he was raised in, but he contradicted himself when he talked about his family being very accepting and, and at the same time, he obviously was struggling with accepting all of his peers. 
In summary, there were four main themes that emerged from the data related to consequences for the students: going unprotected, the consequences for students when they protected themselves because they were unprotected, the ways normativity and hegemony led to bullying, and the ways schools are complicit in bullying. The main consequences for students of color and white students from low-income backgrounds were: they were pushed out of mainstream schooling which led to less educational opportunity in stigmatized school setting; they were traumatized through bullying; they were punished and then criminalized for protecting themselves and framed as the bully; they felt chronically unsafe; and at least one attempted suicide as a result of being bullied and feeling helpless because they did not receive protection. When students were not perceived as being part of the most valued groups, they went unprotected. A dichotomy existed around worthy/unworthy and deserving/undeserving students. Students were punished when their achievement or behavior was inconsistent with school norms, and some students explained that "good students" or "ideal students" were protected and teachers displayed favoritism towards them. Schools were also complicit in bullying when students begged for protection but teachers and administrators were unresponsive, when they did not provide safe spaces, and when teachers, themselves, modeled bullying of students.

In Chapter 6, I present my findings. I discuss the ways whiteness informs normativity in school settings connected to the ways some students are treated as if they matter while others do not, the ways some students are multiply-marginalized, particularly how Black girls and young women are marginalized and hurt, and then I revisit the embeddedness of white supremacy in policy. I share implications having to do with new and upcoming policy meant to interrupt bullying, but how new policies will only be as effective as those who enact it. I reflect upon different ways of approaching this research, provide recommendations on a grand scale plus 
recommendations for practitioners and administrators, and suggest focal points for future research based on these findings. 


\section{CHAPTER VI: FINDINGS}

\section{Bullying Discourse and Race}

My overarching research question sought to inquire into the ways the bullying discourse was connected to race and to identify racialized discourses in schools. More specifically, I wanted to discover which students were marginalized through the bullying discourse, in what ways, and what were the consequences of the marginalization process. I also wanted to know which students were protected, and did students talk about race in relation to bullying either explicitly or in coded language. Referring to the review of the literature on bullying and schooling, it was suggested by many researchers (Walton, 2005; Jacobson, 2010, Shujaa, 1993) that the institutional culture of schools provided a ripe environment for bullying to thrive, and two of the strategies schools used to deflect attention away from their responsibility was through bullying propaganda in the form of bully prevention and intervention programs, and blaming individual students through a pathologizing process. Analyzing the students' lived experiences and the school policies informing the procedures related to bullying through the lens of discourse analysis, the meaning of the discourse is revealed (Gee, 2014) through what happens in real life beyond written policy. In the next sections, I discuss the findings in terms of these inquiries, but in such a way to form a comprehensive picture.

The following display provides a graphic organizer showing the ways whiteness informs school policy and discourse and the effects on students. 


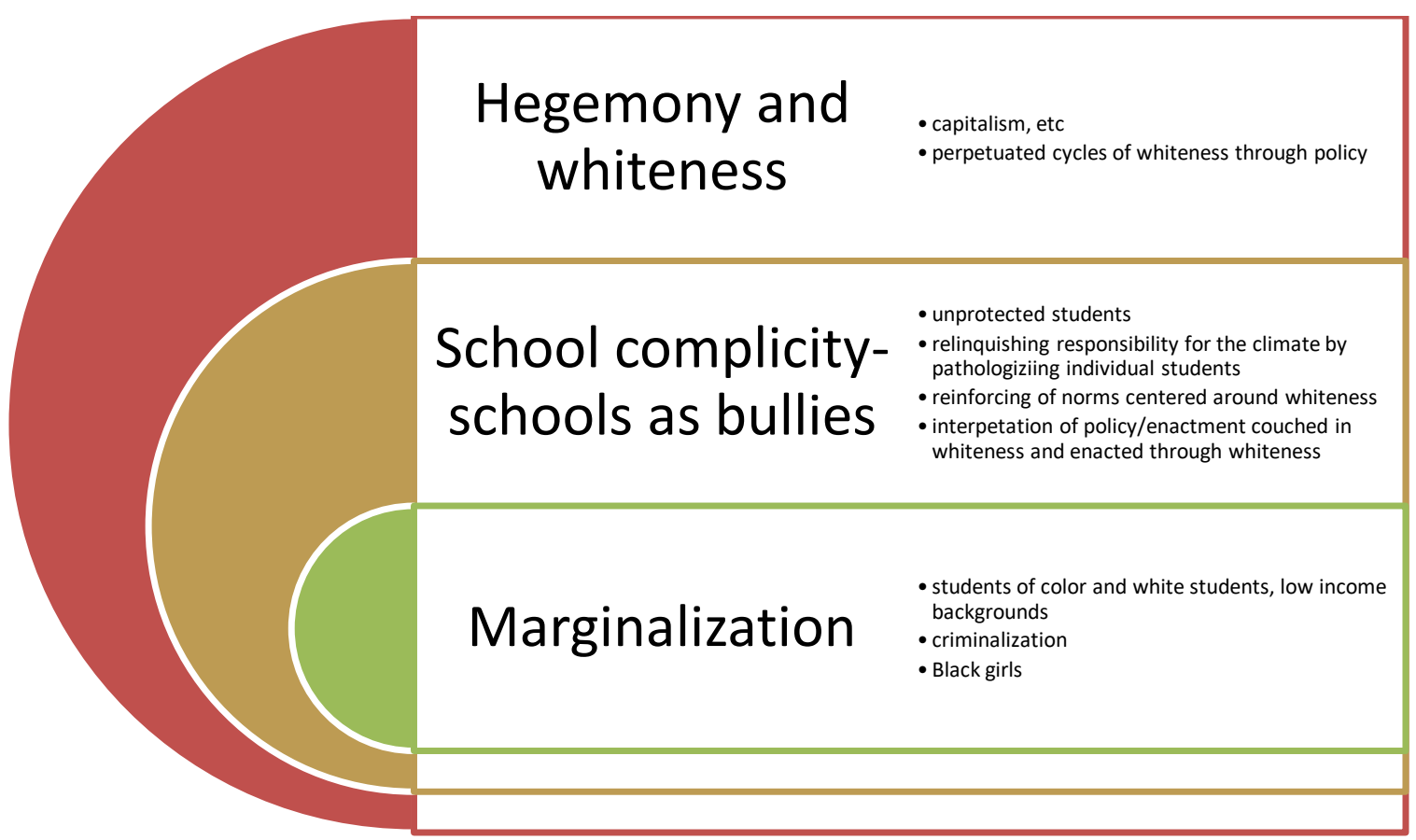

Figure 2. School policy and whiteness

\section{Overall Findings}

Ultimately, the policies did not do what they explicitly stated they intended to do. If they are created within whiteness, then it follows they will be steeped in white liberalism and colorblind rhetoric, which they are. The policies also supported the notion that bullying is a problem of individual school children, and the school's role is to prevent and manage it, but they only did that for some students. The propaganda and hype around bullying such as anti-bullying campaigns in schools and articles in the newspapers get buy-in and support from parents and the community, but this is deceptive because as some researchers suggest (Walton, 2005; Derber \& Magrass, 2016; Jacobson, 2010), bullying is a systemic problem and by blaming the most vulnerable, the already marginalized, the students with the least institutional power, marginalization and inequities continue and the status quo remains intact. The dominating class continues dominating, and students of color and white students from low-income backgrounds 
experience the fallout, and are victimized because the dominating groups have the most power to tell their story and shape perceptions around what the cause of bullying is.

Bullying in the school systems mirrors the criminal justice systems and is an extension of the criminalizing process of discipline. Rewards are attached to morally-defined laws and policies and punishments and consequences are given for going against them by standing up for oneself, protecting oneself, resisting surveillance and unjust systems. Moral definitions, meaning, and interpretations of both the laws themselves and the judgement of behaviors are based in the interests of dominating groups who have accumulated the most power. Those with the most power commit crimes behind the scenes that are covered up by the multiple privilege they hold.

\section{Multiple Marginalization}

Students from low-income backgrounds are marginalized in society and in schools. A limitation of this study was that I was unable to speak with more students of color from AP to isolate race from class, however, the fact that most of the students attending SA are students of color and the students interviewed did not have other choices suggests that race plays a strong role in limiting their educational choices. The two white students from middle or high-income homes at AP who were bullied, and could choose to attend AP because they had not been marginalized in multiple ways or criminalized. For example, Hope's younger brother was severely bullied for years at the same Catholic school Hope attended. The same weekend their parents found out, they enrolled him in a different school the following Monday. SA was the only option for the students who attended. The privileged social identity groups that Hope, Hope's brother, and Tim belonged to are privileged in such a way to provide them with educational choice. 
Through the lens of intersectionality (Crenshaw, 1991), each social identity group students belong to or are perceived to belong to that is marginalized in schools and by society, the effects of marginalization increase. Students from low-income backgrounds are more likely to be bullied, and because of the ways race and class intersect, meaning that students of color are more likely to be bullied. Their families are multiply-marginalized through housing discrimination which determines the quality of the school they can attend. Employment discrimination limits how much money people of color have access to to buy a house in a neighborhood with better teachers, resources, and educational opportunities. Students of color are further marginalized by being placed in special education and lower educational tracks, having teachers with lower expectations and biased perceptions around academic ability and behavior, and the overall racialized experience in schools with faulty curriculum that renders them invisible or pathological. Students with disabilities and females are two groups identified by students as being targets for bullying.

Students of color and white students from low-income backgrounds cited many incidents and many ways that they were not protected. The consequences of not being protected led some to protect themselves which led to being labeled as a bully and punishment. Punishment is ultimately what pushed them out of mainstream schooling and resulted in fewer educational opportunities. Once they were labeled as such, they were not seen as an "ideal student" which meant additional lack of protection because teachers tended to protect and favor the "ideal student." When students had a record of behavioral infractions or poor grades, they were not the favored students who everyone knew the teachers were going to help. Put another way, the marginality both precedes the marginalization/criminalization through bullying in schools and then increases and builds on it. 
Outlaw emotions. There was a palatable feeling of helplessness present as some students told their stories about bullying and the trajectory that led them to SA. Almost all the students resisted being bullied or being framed as a bully, but they did not have the institutional power to change the outcome. They described having been bullied, teachers observing bullying and not responding, being confronted with overt messages of anti-bullying mixed with covert messages of condoning it, asking for help and not receiving it, following the protocol around bullying, and having to defend themselves and the punishments that followed. Some students expressed and named feelings such as sadness over feeling they had to fight because it conflicted with their values, frustration over not being listened to and responded to, fears around being hurt, embarrassment about what they were bullied over, conflicting feelings around what to do, and in others, emotions were evident in their tone and facial expressions as they described what had happened.

Students of color are multiply-marginalized when they push back against a racist system and unjust treatment that sets them up to be treated in these ways, so in this way they have a much heavier load to bear emotionally. Meiners (2007, p. 29) cites Jagger (1989) who described "outlaw emotions" as "distinguished by their incompatibility with the dominant perceptions and values," and questions where does anger go? Meiners (2007) explains that outlaw emotions can be used as keys to identifying inequities because the dominating group do not see these inequities. Rather than using such emotions as indicators of inequity, students are punished for them.

I did not ask the students questions about how they felt about themselves nor did I spend enough time with them to form accurate perceptions about the potential ways identities around the bullying events were shaped. Some students clearly stated though that they were traumatized, 
felt helpless, felt very scared, did not trust the adults in the environment, were angry over being called a bully, felt bad about themselves because of the bullying, and a few avoid people now because of bullying experiences. Their body language and tone of voice, as mentioned earlier, indicated a definite range of emotions about the events. Voices changed, bodies tensed or chests caved, wide-eyed vacant expressions associated with trauma spread across faces, speech slowed, shrugging of shoulders, and sometimes laughter, too much laughter, at the events they named. It is possible that their experiences of seeking help, being victimized and traumatized through bullying, and being labeled in negative ways could support identities around powerlessness. Depending upon the level of self-determination and familial support present, they may have internalized messages such as "I'm not worth the trouble," "I'm not a 'good' student," or "I deserve this punishment." Another way these messages and experiences could have been internalized are as "identities of inadequacy" based on the experience of over and over again being powerless in the situations described and being punished. The adults in charge have more power and in many ways, decide students' fates. Students are faced with decisions around seeming disrespectful and being kicked out of school and receiving an education and a degree, many stated very emphatically that they wanted.

Based on the teachers' judgment of the type of student you are, they decide when and if the student is allowed to use the bathroom or drink water. In many ways, if the students do not conform - are not viewed as an "ideal student," they become a ruled, lorded over commodity in schools, and this dehumanization has been normalized. Less extreme examples of this control are whether students are granted the "privilege" of getting to play and move their bodies. Social exclusion and isolation is another form of punishment in schools, denying students of another basic human need. In this militaristic socialization process, students are forced into the dilemma 
of either giving themselves up through conformity, allowing themselves to broken, or, if they have enough resilience and support to resist this pressure, not internalize its messages, but then they lose out on educational opportunities, are possibly criminalized, and have less access in life without diplomas.

White-middle class students are trained, from a very young age, in the art of blindly being led by the ever-dangling carrot. This is what "good behavior" in schools amounts to. Playing the game so someday they too can have material things and this kind of power. Who can blame them? What are the alternatives offered or shown to them? Some day they hate their job, have all kinds of stress, and are disconnected from themselves. Worse of all, they do not think for themselves and they do not even know it. They "behave" to support a dream they have been sold, that is not their own, about living a life full of stuff-because that is what it means to be successful and a good citizen. The ideal citizen can look like, "You're not poor, you're a U.S. citizen, you're white." As long as they are living a life as a good citizen with all kinds of internalized unconscious checks and balances reinforced by external moral, judgments that eventually become internalized that keep them in place, then they feel okay. Going outside the lines is associated with feeling bad. It may feel slightly worse than the everyday conforming to the good citizen because it could mean degrees of public humiliation or create anxiety because by this point the punishment is internalized. As long as the crimes committed, the digressions from the "moral-driven life" are well-hidden, even from oneself, and capital is accruing, they are "good citizens." Bullying is an extension of the schooling model with strict rules, moral codes, inclusion, and tangible rewards. The rewards establish power and dominance because it puts the dominating group in the position of giving the rewards and granting some people permission. It is another form of colorblind racism, just another way it has been rearranged. 


\section{Threat, Black women, and marginalization}

There was quite a different level of threat present in the stories told by the students at SA compared to the stories of the AP students. White girls and women from middle and high-income backgrounds are granted and experience a level of safety, i.e., the benefit of the doubt, police protection, absence of verbal abuse, etc. just for being white and the status associated with it that Black girls and women are not granted, i.e., police victimization and murder, assault and sexual assault by police, verbal abuse, and surveillance, etc. Students of color and students from lowincome backgrounds have already been living with the effects of marginalization and its accompanying lack of safety, and, along with this, the real threat of mental and physical violence. They have been treated as "other" in school settings or "grateful ambassadors" and "unwelcome intruders" (Collins, 1998, p. 5). "Black children's formal belonging as American citizens did not ensure first-class treatment" (Hill-Collins, 1998, p. 5), and they don't have the same power as the dominating groups. Based on their lived experiences, they have already been marginalized and have the need to push back against further marginalization. An experience that white students of middle and wealthy income-levels have not had. Patricia Hill-Collins (1998, p. 4) shares her personal experience as a Black, female in high school which may capture the level of threat the girls of color experienced in their school settings:

Although my classmates [white girls] also journey to school, their power afforded them a degree of entitlement that I could only imagine. Even though they traveled through my neighborhood, the combination of being White, middle-class, and female guaranteed them protection and safe passage. Because they were assured that they would attend college, they relaxed into high school routines and focused on choosing their colleges with a casualness and a confidence that astounded me. They showed little interest in the 
community in which they were physically located, over which they clearly held dominion but to which they neither belonged nor felt accountable. A few used their privilege to become assertive and questioning. Some even stopped to look around. Most, however, simply occupied the territory.

Hill-Collins (1998), in the sharing of her experience, captures space privilege in school settings — entitlement afforded the white girls in terms of safety and protection, comfort in belongingness and being welcomed, acceptability of and allowing the white girls to assert themselves, the knowledge/norm that the school personnel and greater society held expectations for white girls to be in lucrative educational tracks associated with high expectations, and being able to freely "tour" the neighborhoods in which they attended school. Black girls face being gendered, racialized, and classed in school settings that are mostly white. While not explicitly stated in this way by the young women I interviewed, the sense of threat or lack of safety is embedded within the stories they told, the ways they expressed their stories with emotional undertones, and their overall perceptions of bullying and the complicit roll schools play in bullying. Their stories demonstrate the privilege or lack of privilege as lived.

The Black women in this study, compared to the white women, had to contest with more persistent bullying and in more violent forms, both psychological and physical, and were subject to punishment to the degree that they were pushed out of school. Their pushout stories and criminalization in schools are consistent with national trends for Black girls (Morris, 2016). There are three parts to marginalization for Black women and girls: resistance, gender, and caring. The marginalization of Black girls and young women in schools is much more complex and runs much deeper than the points I will touch upon here (Morris, 2016). Many Black girls and young women are aware of differential treatment when it is happening, bias by white 
teachers, and by society in general and resist it. Yosso (2005) refers to this as resistant capital and defines it as oppositional behavior challenging injustice. Teachers may interpret this resistance, that is part of survival for people of color in a racist society, as affronts having to do with disrespect. Referring back to the bullying and discipline policies, they exist in the eye of the beholder and can be acted upon by the actors with the power to do so. Gender bias in the form of expectations for girls and women to behave in subservient and docile (Collins, 2004) ways may exacerbate racial bias, and so girls involved in these behaviors, such as resistance, are more at risk for being unduly punished. These traditional white, middle-class standards of femininity demand that women are passive, agreeable, quiet, suppress their opinions and emotions, and behave "respectably" (Winkle Wagner, 2009). In Girlhood Interrupted: The Erasure of Black Girls' Childhood, authors Epstein, Blake, and Gonzalez (2017) show that white teachers view Black girls and young women as needing less protection and nurturing and treat them more like adults. Many of the women of color I interviewed, spoke in depth about the lack of caring on the teachers' part and provided contrastive examples of teachers that did have their best interest in mind. They also spoke of teachers bullying students which could be a way white teachers punished Black girls when they did not play out white femininity, resisted racism, or simply expressed themselves. Gregory and Weinstein (2008) cite that Black students were more oppositional with teachers when the teachers communicated low expectations and demonstrated lack of caring. There is much research that speaks similarly of the importance of caring studentteacher relationships which were a hallmark of schools facilitated by Black teachers and administrators and key to student success (Ladson-Billings, 1994; Siddle Walker, 1993). 


\section{Hegemony, Whiteness, and Policy}

Policy is what happens: the actors, the actions, and the effects. The difference between the formal and informal policies is what Ball (2008), who is considered the leading educational policy scholar internationally, refers to as "little-p policies' that nevertheless influence beliefs and practices" (Gillborn, 2013, p. 130) and "include multiple sites or contexts (where policy is

produced, contested, (re) shaped) and forms of discourse (including texts and ways of speaking about particular issues and possibilities for action). This perspective, therefore, includes the widest possible spectrum of 'policy."'

When schools fail to incorporate into their enacted policies, student identity and the ways these identities are further shaped by schools, depending on the status associated with these identities, some students are further marginalized through fewer educational opportunities and a criminalization process. "Race, ethnicity, sexual orientation, age, ability, socioeconomic status, and gender are interrelated" (Meiners, 2007, p. 22), and do matter in shaping student identities in school settings and then providing or not providing educational opportunities for students which then lead to access to resources in greater society.

The rhetoric in the bullying policy reflects the law, but in revisiting Bonilla-Silva's (2006) framework of colorblindness and Crenshaw's (1991) theory of intersectionality, it falls apart or does not hold up in a way that protects and supports students of color. The policies ignore the real or actual needs of students of color. They do not emphasize outcome but rather intent. What is most important about the language in the policy statements on bullying and discipline is no matter what is stated as a school district's policy, is it is filtered through the lens of the school and the individuals. We have these policies that in some cases are very explicit, detailed, and inclusive. They address race, sexuality, and perceptions of gender, but in what ways 
do they hide principles of liberalism and inequality embedded in rhetoric of logic and morals? All students receive the "same" punishment for behavioral infractions. They all have the "same opportunity" and "choices" to behave or break the rules. These policies are very "practical," "clear cut," and "treat everyone the same." It would not be "fair" to do anything else. They “assume a unitary conception of 'every child', just as they assume a particular view of 'parents' and 'commonsense' - one based firmly on Rightest principles of market competition" (Gillborn, 1995, p. 33). To address the ways students of color are being marginalized would be like affirmative action and what some people refer to as a form of "reverse racism." Ladson-Billings (2000, p. 207) explains why and how this is so highly problematic:

By the time the landmark Brown v. Board of Education (1954) decision was rendered, many African Americans were arguing from a position of sameness (Tate, LadsonBillings, \& Grant, 1993). That is, they were asserting that African American children were alike and deserved the same educational opportunities. This rhetoric of "equality means sameness" tended to ignore the distinctive qualities of African American culture and suggested that if schools were to make schooling experiences identical for African Americans, we somehow could achieve identical results. However, because African American learners do not begin at the same place as middle-class White students either economically or socially, and because what may be valued in African American culture (Boykin \& Tom, 1985) differs from what may be valued in schools, applying the same ‘remedy' may actually increase the educational disparities.

Not only is it problematic in that it makes it extremely difficult for African Americans to succeed or even remain in these spaces, it is beyond dehumanizing because, "For them [African 
Americans], the offer of acceptance in return for assimilation carries a primal insult: it asks them to join in something that has made them invisible" (Steele, 1992, p. 4).

In these and other ways, the policies are colorblind and wrapped in white liberalism. They are focused on serving an imagined norm, but not on serving the students who are already faced with biased treatment by teachers who underestimate their intelligence and misjudge their character, and that result in negative consequences based on both. Further, policies do not consider the biased curriculum that may not be engaging because it does not portray students of color in a positive light and does not utilize styles of relating that are familiar or engaging. The policies to do not account for disproportionate discipline practices or what is behind this momentous disparity. They do not consider that being a person of color in this country is associated with poverty because of systemic racism. All of these practices are normalized within school systems. They are solidified in policy and backed by the law. Enactment of policies and laws in schools are similar to the ways the U.S. justice system operates with all its colorblind laws, policies, punishments, systems of surveillance, and bias among the enforcers of policies and laws. Further, there are advantages for people with money to pay for an attorney, advantages for having personal connections and associations with people in positions of power, while there are risks associated with simply coming in contact with police officers for people of color, and once involved in the criminal justice system, there are life-long consequences for having a criminal record.

Gillborn (1998) explains how policy in England, but it also applies to the U.S., developed from the same system that created policy that marginalizes people of color and reproduces more such policy. This quote reflects, in part, the merry-go-round rhetoric involved in the bullying discourse: 
This sanitized (white-washed) version of history envisions policy as a rational process of change, with each step building incrementally on its predecessor in a more-or-less linear and evolutionary fashion. But such an approach is contrary to the reality of race and politics in England where virtually every major public policy meant to improve equity has arisen directly from resistance and protest by Black and other minoritized communities. (p. 717)

There is an assumption when there are newly developed policies on bullying, that they are going to improve the climate and protect all students especially when they include language about protecting vulnerable and previously unprotected populations. The history of public policy concerning race shows this is not the case. They tend to be superficial and do not do much in practice. Most gains have been made by people of color resisting policies that marginalize them although the rhetoric and implied implications of the policies is that they will protect them. Grant (1982) describes this as: "The sorting and filtering processes take place in schools beneath a rhetoric of equal opportunity, so that students placed in low tracks and trained for low-status adult roles come to think that they 'merit' such 'outcomes."' (pgs. 1-2).

\section{Institutionalized bullying}

Schools are places where economic, political, and social forces that drive white supremacy come together. Schools focus on finding solutions that rest on students changing their behavior without considering the sociopolitical environment of schools, social oppression, or political factors. As mentioned earlier, school reforms can be covert ways ensuring the same structures that support the status quo remain in place (Shujaa, 1993). Much of the socialization that occurs with bullying happens at the level of deep culture, standardizing and normalizing whiteness in hidden ways. Bullying policies and school districts' messages claim fairness and 
safety while providing the environment for violent spaces. Some students are victimized, exploited, or "used up" as for-profit organizations sell their anti-bullying programs and schools share how efficacious the new programs will be with the public, neglecting the militaristic discipline practices, hierarchies, and the competition for scarce resources (Noddings, 1992; Walton, 2005a). The scarcity consciousness intrinsic to neoliberalism, is so natural seeming, that it can be difficult to identify, but it is based in competition, comparison, and groups of individuals being better than or worse than others. In schools, students are taught to believe and are indoctrinated into a reality where worth depends on being better than someone else, and policies and reforms tend to serve the groups with the most privilege.

In Bully Nation, authors Derber and Magrass (2016) discuss at great length C. Wright Mills' theory the Sociological Imagination. The theory maintains that Americans are taught to intentionally view personal problems as separate from politics, institutional practices and norms, and ways of interacting on an international level. This theory aligns with ideas of whiteness in the way that it has no actors, things are "just the way they are," based in "commonsense," and beyond reach. Derber and Magrass (2016) describe further that Mills believed that while America claims it is a democracy, it is run by elites through political and military means. However, they assert that personal problems are actually quite related to "societal values; power hierarchies; and the values and interests of economic, political, and military systems" (p. 8). Controlling the public discourse ultimately controls ways of thinking, and "the psychological way of framing the bullying conversation serves the power and profit interests of dominant institutions: further, the elites work hard to ensure that any conversation about bullying does not become a critical analysis of our corporate, militarized society" (p. 9). Mills further argues that the same type of bullying exists for adults in all levels of government and corporate America as 
it does for children in schools. It comes down to the categories and the status associated with the categories that are created in school and society as part of capitalism. Children imitate the ways adults use power in bullying (Derber and Magrass, 2016), as seen in the interview data from this study when some of the students described teachers as bullies.

The adults are not free actors either, as they are bullied into adopting and enacting the cultural values of the institution. They are also bullied into roles where they have to perform to standard or be discarded. All of these systems work together in a cohesive manner much like whiteness, and most likely they are one in the same system as Mills also discusses racial hierarchies and the invisibility of the system. Derber and Magrass (2016) dedicate a chapter to race and militarized bullying, and point out that "race has been integral to militarized bullying since the founding of the nation, employed both her and in other lands. Racial militarized bullying is part of the DNA of US militarized capitalism" (p. 103).

Audre Lorde (1984) in her essay, Uses of the Erotic, captures the essence of Mills' theory and what has happened to students of color and white students from low-income backgrounds: The principal horror of any system which defines the good in terms of profit rather than in terms of human need, or which defines human need to the exclusion of the psychic and emotional components of that need - the principal horror of such a system is that it robs our work of its erotic value, its erotic power and life appeal and fulfillment. Such a system reduces work to a travesty of necessities, a duty by which we earn bread or oblivion for ourselves and those we love. But this is tantamount to blinding a painter and then telling her to improve her work, and to enjoy the act of painting. It is not only next to impossible, it is also profoundly cruel. (p. 55) 


\section{Implications}

To further obfuscate the bullying discourse, beginning in the 2017-2018 school year, schools will be required to publicly post data related to discipline disaggregated by race due to overwhelming reports of disproportionate discipline of students of color. The data collection began in 2015, so the schools are aware of the pressure to not have data showing that students of color are disproportionately disciplined. This could have many implications. One possibility is that "bullying" serves as a more definitive discipline "category" to place students in rather than the overused "other" category and becomes another way to criminalize students of color, another way for white supremacy to shapeshift and disguise itself.

In this way, bullying serves as an additional way to criminalize students of color and has actually become a pushback against equity measures to collect data on disproportionate discipline of students of color because it all depends on the subjective perspective of those executing power. The students interviewed clearly unveil and deconstruct how educational systems that promise to be safe have failed them by not providing protection. As one student put it, "Schools are the places where the worst things happen to you." The students highlight the ways they worked hard to prevent violence, sought the protection of teachers and administrators, navigated within the system to circumvent potential violence, and followed the rules to achieve academically, but were left without recourse due to the centralized and hegemonized power structures in place. In the sharing of their stories, lies how the bullying discourse plays out in schools regardless of formal, explicitly stated zero-tolerance policies, how it favors some students and marginalizes others, how students had to protect themselves and their friends, and the roles teachers and administrators played in all of this. The way it plays out for wealthy and middle-class white students is different than how it plays out for students of color and white 
students from low-income backgrounds, and this demonstrates the power of marginalization.

Building from my methodological description of epistemologies that marginalize, I placed in the forefront students' experiences of pushing back against schools where oppression was structural, where not being heard or responded to by administrators was prevalent when they tried to prevent bullying occurrences from happening, and fought to keep themselves and their friends safe and were often met by indifference or punishment that greatly limited their educational opportunities. Many were forced to choose between educational opportunities and safety. Their practices of resistance, enactment of familial capital, and efforts to bring humanity and caring into educational discourses based in "science" that aims to shape bodies as "bad, dangerous, disabled, behavior disordered" (Meiners, 2007, p. 20) are characteristic of their stories. The stories the students share reveal the performance or acting out of policies, and most importantly, show the distinction between espoused and enacted policy.

\section{Heuristic Moments}

The most significant awakening I had based on this research is the meaningless and unworthiness of policies for students of color, particularly Black girls and women. Due to my white and class privilege, I believed that if the right policy was in place, and schools were accountable, students of color could be given a fair deal. My personal experience of having been mostly protected as a white girl/woman in ways that Black girls and women have not been, shaped my ignorance concerning the potential efficacy of these policies. This awareness was pealed back in layers. As I came to the end of this research project, I understood on a much deeper level, the degree of privilege I was afforded as a white female. The words I wrote describing the conceptual framework concerning intersectionality have taken on new life and meaning for me, which I added to the analysis of the data. 
It was not until I was reading the newspaper articles and the actual policies in place on bullying in the schools, while contrasting them with trauma described by bullied students from the same school districts, that I realized there is no new policy that could be put in place that would actually protect all students. If it were so, desegregation would have played out differently. School policy and publicized declarations by school authorities in the newspapers about bullying state that all students are protected. As mentioned, one district even listed typically marginalized student groups. While having previously written about the power of whiteness and the ways it morphs and shapeshifts to serve white people, in this research I saw firsthand, or secondhand through students' stories, how it happens. Schools on the one hand, put forth public statements about the safety of all students, and students, on the other hand, explained how they tried in so many ways to protect themselves and their friends, to be protected by the adults in their environment, and to avoid breaking school rules. However, they were not only the victims of abuse in this system, but then blamed for this humongous institutional failure.

The second most significant realization I had was just how unimaginably horrible bullying can be. Reading about it is different from hearing it from students who have lived it and whose friends have experienced it. The horrors some of the students were subjected left me speechless. I do not believe the general public has any idea that this degree of abuse occurs in schools or they would probably have restraining orders against them. It reminds me of the covered-up violence in prisons and the ways it is normalized, joked about, and inmates are said to deserve it. I also now have a better understanding of how students are criminalized in schools because I have step-by-step details of the identity shaping, the punishments, the pushout, the blaming, the scapegoating, and lack of choice on the students' part—essentially, the way power is abused in schools and truly favors those with class and white privilege. 


\section{Different Approaches}

Based on my experiences throughout this research process and what I have learned, there are a few methodological approaches I would consider rearranging because I believe I could highlight various aspects of the data in a better way. Realizing the extent to which some students are bullied, I could have focused solely on the students at SA and their stories. There were many more stories that I did not hear, and I could have gone more in depth into contextualizing how intersectionality of identity played out for those students, especially those of Black young women, and the ways they were adultified, offered less protection and less nurturing, and then connected it to the literature on criminalization of Black girls.

I do, however, consider it valuable that there was a comparison of the two schools because it demonstrated the way class privilege protects students which really showed the many facets involved in intersecting identities and being multiply-marginalized or privileged. The missing piece in the AP students' stories is those of students of color who were not vested in whiteness, not protected by class privilege, or who were activists. I became aware through some of the students' stories at AP, that much more was going on racially than I was hearing about in my interviews. If I had conducted fieldwork in AP, I possibly could have been able to identify those students and interview them to show the way race alone is a marginalizing factor. I also believe I could have captured a more holistic picture of bullying that was occurring at AP, but not necessarily being called bullying or even identified as bullying, because the students described being adept at hiding it through social media to avoid repercussions from the administration. Although it was hidden to some degree through social media, some of the students described emotional responses to the bullying in classrooms and hallways. Other 
students explained that bullying played out as whispers heard by those it was directed against, namely for gay, lesbian, or transgender students.

\section{Recommendations}

The ideal would be for students of color and any other groups who have been historically marginalized or marginalized by society to attend schools outside of mainstream systems. As Angela Davis puts it, in her forward in a book about the intersection of racialized and gendered violence: the unifying theme is the impossibility of eradicating racist violence without radical transformation of the social, economic, political, and cultural contexts that produce it (Ritchie, 2017). Ideally, students of color would have the option to attend schools run by and curriculum taught by and developed by people informed by scholars of color because white people in power have a stronghold on institutional power. There would have to be enough interest convergence present to shift this. Ultimately, for schools to be spaces for all students to thrive, there would have to be a willingness to change the culture that creates and maintains bullying.

So as not to reproduce economic and racial inequity through education, student voices from marginalized groups would be considered as part of what schooling means. Even though it is critical to understand how bullying discourses are constructed, influence policies, and in what ways they affect various student populations, especially those not belonging to the dominating

culture, it is not enough. While knowledge was gained through this research that could challenge colorblind policies providing students of color with equitable educational opportunities and experiences, policies are not enough. This study includes a different view of whiteness as it plays out in the bullying discourse and the ways it further marginalizes students of color and white students from working class backgrounds. 
Further, policy reforms based on the research of scholars of color rather than positivist research paradigms that neglect to tell the stories of colorblind policy are needed. Epistemologies and methodologies used in relation to bullying have been grounded in positivist paradigms which support the practice of whiteness. Qualitative, constructivist research is needed to look at the real-lived experiences of groups of students affected by the bullying discourse, and discourse analysis is helpful in deconstructing mainstream narratives. As stated earlier, the limitation with policy though is who is enacting it.

As schools stand now, one of the most important steps for practitioners and school leaders who decide to work against bullying in their classrooms and schools, is to dismantle social hierarchies, pitting students against one another, ensuring that they, the teachers, are not reinforcing norms that support hierarchies, dismantle patterns of normativity displayed among their students, diminish competitiveness among students, and, instead seek to use learning models that build relationships such as a community of learners' model. When students develop authentic relationships with one another, learn to perspective take of the worldview and lived experiences of those who are typically marginalized or dissimilar from themselves, and come to know them as peers and as real people rather than objectified "others" or a cluster of stereotypes, they may be less likely to engage in dehumanizing behavior.

Every teacher and school administrator holds much power to explicitly express valuing of all students and demonstrating the value and humanity of people from all social groups. Examples of such stances include strong statements of disapproval when dehumanizing language or behaviors are enacted in contrast to what some of the teachers did in reaction to bullying in SA students' stories. Advocating, standing up for, and acting as an accomplice by publicly expressing intolerance and fighting for the human rights of all students and teaching students to 
do so, like many of the students at SA did. Modeling for students ways to unlearn and rethink these socially constructed hierarchies offers possibilities for students to not live or reinforce these hierarchies. Positioning students who have been historically marginalized and marginalized in a human, realistic, and positive light is a way for educators to use their power and their privilege to effect humanizing social behavior. Using culture to promote racial identity as an asset is another way to shift power away from social hierarchies that are rooted in the construction of race (Hanley \& Noblit, 2009; Omi \& Winant, 1993).

Another important action is for individual teachers and administrators to examine and build their own critical consciousness, positionality, cultural competencies, and disrupt biases and deficit thinking within themselves. This can be worked towards on an individual level by learning and becoming informed about individuals' experiences from social groups they have the least knowledge of or meaningful connections with, reading the literature about the various ways students are marginalized in schools, and becoming informed about cultural expressions that differ from one's own. Epstein, Blake, and Gonzalez (2017) strongly urge, "we recommend providing individuals who have authority over children — including teachers and law enforcement officials — with training on adultification to address and counteract this manifestation of implicit bias against Black girls" (p. 1). To put their recommendation into context, it refers to their research showing that Black girls are seen as less innocent than white girls and needing less protection and nurturing, and that these perceptions by perceptions lead to violation of their human rights in schools. Incidences and stories of when Black girls are assaulted by police in schools are suppressed to "make disappear" Black girls and women who practice any resistance to racial and gender scripts enforced in schools and legal systems 
(Ritchie, 2017). These stories need to be in the forefront, and teachers and those in power need to understand the potential within them to play out bias in this heinous manner.

There are various methods for coming to understand one's implicit biases and interrupting them. One method is building relationships with students, students' families, and participating in students' communities especially if they are not one's own (Ladson-Billings, 1984). Real relationships decrease "othering," and the tendency to judge and misinterpret people with whom we do not share similar lived experiences. Acknowledging where one's blind spots are likely to get in the way of providing equity, coupled with using equity and culturally relevant accountability checklists, can aid teachers in developing deeper awareness of the actual effect they have on students rather than just their intentions.

For the practitioner or administrator who is serious about taking these action steps, creating groups and social supports around consciousness raising related to cultural competency, interrupting biases and deficit thinking are necessary. Groups like these could deepen and further growth and efficacy for individual educators, and power could be used to work against status quo systems that support bullying. An example of a consciousness raising group that could have monumental positive impact for all students, is a group devoted to dismantling whiteness in schools. In many ways, it would be beneficial for white educators to meet with other white educators to examine the ways they enact whiteness and to raise consciousness around working against it in all-white groups to avoid burdening teachers of color and subjecting them to microaggressions that will come up in talking about whiteness. Paramount to the raising of critical consciousness in the individual educator is emphasis on the effect, not the intention. 
Privileging and reinforcing ways of being "smart" (Hatt, 2011) associated with typical school or academic knowledge, which is oftentimes entrenched in behaviors conforming with school rules and norms need to be examined and deconstructed. Notions of smartness and behavioral norms in schools are taken-for-granted ways of being, knowing, and doing that are based in whiteness and other forms of privilege that marginalize students. To work against this, educators can take into consideration, and even forefront Tara Yosso's (2005) forms of cultural capital, or González, Moll, and Amanti's (2005) funds of knowledge. They can use these ways of being in the world as foundation from which to build curriculum, learning, and patterns for interaction. Flipping typical ways of defining intelligence and social norms is critical to changing the bullying dynamic because educators themselves are reinforcing bullying hierarchies without even knowing it. Unconscious acts aligned with whiteness driven by good intentions, reinforce the status quo, and are the breeding ground for the atrocities named by the students in this study who have been bullied.

Schools and school districts need to examine the ways they as institutions allow and even encourage bullying to play out rather than use a psychological model, meant for individuals, to diagnose group-level processes. There is so much literature on the ways many school practices are a breeding ground for some students to be pummeled and others held up on a pedestal of success, achievement, and goodness. Alfie Kohn (2005), in his piece called Unconditional, highlights the ways educators can think about valuing students when they are not high achievers or behave in ways that are undesirable in a school setting. The communication of valuing all students is what is needed most. Reframing what high achievement and behavior norms mean would be an even better step towards valuing and including all students. For example, asking how, why, and by whom these terms and expectations are defined is critical because defining 
them in pluralistic ways, considering all populations in our society, would lead to a more broad and realistic understanding rather than a narrow definition which maintains structures of white supremacy and other dominating groups' power.

Educators themselves often enact schooling in ways similar to what they experienced. For example, many students interviewed in this study considered it typical for teachers to publicly humiliate students, verbally praise favored students, and ignore others. These types of educator behaviors have been present in schools historically and have become normalized to some degree. It is "normal" and "acceptable" for some students to fail; it is normal to give up on some students; it is normal to blame families for their child's failure; and it is normal for schools to avoid looking for institutional patterns of discrimination. What is considered normal and established in schools, needs to be challenged through critical lenses to realistically serve all students.

Finally, teachers and administrators need to acknowledge that bullying, despite all the programming and publicized policy statements that state bullying is addressed, it is not. It is especially not being addressed for students of color, white students from working-class backgrounds, and students with disabilities. The law requires them to participate in spaces where they are abused, assaulted, and then told the abuse and assault is their fault. On top of that, those with the least institutional power, based on the identity groups to which they are associated with, are framed as criminals. They are told they are criminal like, treated as law breakers, and punished. In these ways, students are tracked for criminality, while other students are tracked for higher education. 
Beyond shaping the criminalizing identities, is the very real lived experiences students have when bullied, as a result of being bullied, and when punished for being labeled as a bully. These experiences include being pushed out of academic learning settings decreasing exposure to needed learning to be successful in school, being isolated, experiencing the stigma of being punished, and having involvement with the criminal justice system. People with the least institutional power and money are often at a terrific disadvantage to break free from the criminal justice system because they do not have money to get out, and then are typically treated as "throw away" members of society similar to the ways they have been treated as "throw away" students in the classroom.

\section{Future Research}

Because the discourses, policies, and methodologies used to understand bullying, as it is currently known and understood, is colorblind; methodologies and epistemologies that center race are needed. Furthermore, discourse analysis is needed to break down and unpack the colorblind language, silence, insinuations, and hidden and reversed meanings embedded in the discourse. Walton (2005b) calls for "dynamic conceptualizations of bullying" (p. 58) because "the tenets of empirical research are an inadequate framework from which to address the disjuncture between the persistence of bullying" (Walton, 2005b, p. 57). Walton (2005b) notes Foucault's assertion that empiricism disguises important historical, cultural, and political features that need to be part of research and by continuing to focus on empiricism, it will only further obscure the influence of historical and political factors embedded in bullying. In fact, "definitions carry the status and the hegemony of being objective truth discovered through the methodologies of science" (Walton, 2000b, p. 60). 
Constructivist and critical race methodologies will allow for more complex conceptualizations of bullying in general, and also provide ways to deconstruct traditional understanding around bullying, and the ways it has been constructed through colorblind practices and discourses. The fact that white teachers and administrators perceive students of color as misbehaving more often than white students, may indicate that even "non-violent expressions" are perceived as "a form of violence to whites" (Leonardo \& Porter, 2010, p. 145). Although Leonardo and Porter (2010) are describing the threat white people experience when even just talking about race and racism, it may be that it can be generalized to other situations as well. For teachers and administrators to be reacting in such a way, it seems that just the presence or animated presence of Black bodies, pose an imaginary threat. These methodologies will also allow for students of color to voice descriptions of experiences that speak to the effect of policies, how they have been treated in real life, and their perceptions of bullying.

With the upcoming requirement of school districts to provide equity reports on disciplinary data, maintaining a close watch on how the narratives, practices, and outcomes shift is critical. Skiba (2014) advises that those wishing to reduce disparities in discipline need to utilize interventions that forefront institutional behavior instead of the students' behavior and characteristics. Discipline policies and procedures, without a cultural shift and without measures to increase cultural competence among white educators, have shown to be ineffective in reducing discipline disparities. While schools may state they are using recommended practices such as restorative justice, this too needs to be examined because as mentioned earlier, schools can claim to be using it when they are not. Research also shows that restorative justice is only effective with cultural competence because if filtered through the lenses that view some students as deficit, and it will not have the intended outcome. Plus, equity-reporting companies are in this 
business for a profit, and so like bullying intervention/prevention companies, the students can get lost in the moneymaking endeavors that are supposed to help them.

\section{Masculinity}

Masculinity (Connell, 2005) surfaced as an important piece in this research, and while I acknowledge its role in shaping the discourse surrounding bullying and actual bullying, the focus of this dissertation is on race. I will speak briefly about it because it is relevant to how many students were bullied and perceived it to be bullying. Two male students of color shared bullying stories, some of the stories were consistent with what is considered bullying, but they did not identify with the label of having been bullied. For instance, one student who was very sensitive to others who had been bullied and quick to stand up for them, and take any school consequences for doing so, mentioned being teased throughout his life for being "small" and "short." He even gave specific examples of being teased for not being able to reach certain things, but he resisted naming how he was bullied as bullying. Another male student spoke of being given the name "cheeseburger" for being fat, and went on to explain how he "owned it" and it became his known name in the neighborhood. As males, admitting they had been bullied would also mean going against expectations around masculinity such as being capable of defending oneself and handle things on one's own.

\section{Girls and Women of Color}

Much more research is needed to unpack the ways girls and women of color are marginalized specifically through being labeled as a bully. A groundbreaking study by the Georgetown Law Center on Poverty released in July 2017, shows that Black girls are perceived as less innocent, more adult-like, in need of less nurturing, less protection, less support, and less sexually innocent (Epstein, Blake, \& Gonzalez, 2017, p. 1). Professor Priscilla Ocen is quoted as 
saying that, "White children enjoy greater legal protections rooted in the legacy of racial discrimination in this country" (p. 4). This treatment, historically, began during slavery when Black children were adultified and put to work when they were two or three years old. They were not allowed playtime. What white slave owners forced African children to do, then became a perception of who they were, and this dehumanizing legacy continues to play out in schools as described by some of the young Black women in this study. When these young women are criminalized in schools, they are also then subject to being placed in the criminal justice system, and, there too, receiving harsher punishment than white girls or women. Epstein, Blake, and Gonzalez (2017) in Girlhood Interrupted: The Erasure of Black Girls' Childhood recommend that, "Above all, further efforts must ensure that the voices of Black girls themselves remain front and center to the work" (p. 1). Even though this new research is considered groundbreaking, Linda Grant in 1982, published similar findings but not as in depth. My point being, it has been ignored for a long time.

Bringing the need for future research back to intersectionality — the analytical framework applied to this data, activist and attorney, Andrea J. Ritchie, in Invisible No More: Police Violence Against Black Women and Women of Color (2017), explains the complexity and the degree to which Black women and girls, women and girls of color, and transgender women and girls of color, through intersecting identities within a "criminal legal system" are sexually assaulted, physically assaulted, killed, and unprotected by police and other officials. While women of color, and especially Black women and girls, are stopped, brutalized, and assaulted at just about the same rates as Black men, these incidences and stories are suppressed demonstrating gendered and racialized expressions of genocide. 
Citing some of the same perceptions of Black women and girls as other researchers, Ritchie (2017) describes how incidences of police violence and assault against women of color are "made to disappear" so it can continue. There is an imperative to make the women disappear by suppressing incidences of police assault to continue the violence (Ritchie, 2017, p. 24). Ritchie (2017) asserts, "deeply entrenched" (p. 14) and "controlling narratives framing them [Black women and girls] as inherently dangerous and violent, heartless, promiscuous, unclean, drunk, and disorderly, inherently rapeable, incapable of feeling pain, and irresponsible" (p. 25) are part of what keeps this violence institutionalized. These "perceptions of officers drive interactions with Black women" (p. 11). When Black women deviate from the expected subordinated, racialized, and gendered roles of "mammy" or "jezebel," and practice resistance, they are masculinized by police and thought to not deserve protection because they are "defying the rules of gender" (p. 39) as it intersects with race, and they are "punished for survival and selfdefense" (p. xv). Ritchie, who works in spaces where women of color are most marginalized like domestic violence shelters, maintains that the voices of these women are missing and that "we need more such efforts collecting and sharing such stories" (p. xiii).

In Chapter 5, I review my findings, make recommendations based on the findings, and offer suggestions for future research. I also speak about heuristic moments - that is, learning that occurred through this research process, namely there is not a policy that can change racist systems when the policies are created within a racist system and enacted within a racist system. However, I speak to the many approaches educators can take to move away from the hierarchies that fuel bullying. There is much research needed on the ways Black girls and young women are multiply-marginalized and criminalized within school systems due to beliefs that they are not vulnerable or even really human and viewed, treated, and punished as adults. Teachers hold so 
much power to shape students' perceptions of themselves and the perceptions other students have of the student. Teacher and administrators can act on this power to develop critical consciousness and cultural competence, and work against bias and deficit thinking within themselves to ensure they are valuing and demonstrating the valuing of all students. Working against social hierarchies and ideologies of normativity and challenging the status quo, holding high expectations for all learners and never treating any student as a "throw away" student, becoming aware of the actual effect of their practice, rather than focusing on good intentionseducators have the power to provide transformative educational experiences which liberate. 


\section{REFERENCES}

AERA. (2013). Prevention of bulling in schools, colleges, and universities: Research report and recommendations. Washington, D.C.: American Educational Research Association.

Aitken, H. (Producer) \& Griffith, D. W. (Director) (1915). Birth of a nation. United States: David W. Griffith.

Allen, J. (2003). Without sanctuary. Retrieved from http://withoutsanctuary.org/movie1.html Anderson, J. D. 1988. The education of Blacks in the South, 1860-1935. Chapel Hill: University of North Carolina Press.

Ani, M. Yurugu: An African-centered critique of European cultural thought and behavior. Trenton, NJ: Africa World Press, Inc.

Ansley, F. L. (1997). White supremacy (and what we should do about it), in R. Delgado \& J. Stefancic, (Eds.), Critical white studies: Looking behind the mirror (pp. 592595). Philadelphia: Temple University Press.

Applebaum, B. (2010). Being good, being white: White complicity, white moral Responsibility, and social justice pedagogy. Lanham, MD: Lexington Books.

Ayers, R. \& Ayers, W. (2011). Teaching the taboo: Courage and imagination in the classroom. New York: Teachers College Press.

Baines, A. D. (2014). (Un)learning disability: Recognizing and changing restrictive views of student ability. New York: Teachers College Record.

Bell, D. A. (1995). Brown v Board of Education and the interest convergence dilemma. In K. Crenshaw, N. Gotanda, G. Peller, \& K. Thomas, (Eds.), Critical race theory: The key writings that formed the movement (pp. 20-29). New York: The New Press. 
Berger, P. L. \& Luckmann, T. (1996). The social construction of reality: A treatise in the sociology of knowledge. New York: Anchor.

Berlowitz, M. J., Frye, R., \& Jette, K. M. (2015). Bullying and zero-tolerance policies: The school to prison pipeline, Multicultural Learning and Teaching, 1-19. Retrieved from http://www.auburn.edu/outreach/opce/antibullying/documents/2015presentations/JetteKel li_School\%20to\%20Prison\%20Pipeline\%20Official.pdf

Blau, J. (2003). Race in the schools: Perpetuating white dominance? Boulder, CO: Lynne Rienner Publishers.

Bonilla-Silva, E. (2002). The linguistics of color blind racism: How to talk nasty about Blacks without sounding "racist." Critical Sociology, 28(1-2), 41-64.

Bonilla-Silva, E. (2006). Racism without racists: Color-blind racism and the persistence of racial inequality in the United States. Lanham, MD: Rowman \& Littlefield Publishers, Inc.

Brown, K. D. (2005). C'mon, tell me. . . . Does school ethnography really matter? Educational Researcher, 29-34.

Caplan, P. J. \& Ford, J. C. (2014). Voices of diversity: What students of diverse races/ethnicities and both sexes tell us about their college experiences and their perceptions about their institutions' progress toward diversity. APORIA, 6(3), 30-69. Retrieved from http://www.oa.uottawa.ca/journals/aporia/articles/2014_10/Caplan_Ford.pdf

Carbado, D. W., Crenshaw, K. W., Mays, V. M., \& Tomlinson, B. (2013). Intersectionality: Mapping the movements of a theory. DuBois Rev., 10(2), 303-312. 
Carter, M. (2003). Telling tales out of school: "What's the fate of a Black story in a White world of White stories?” In G. R. Lopez \& L. Parker (Eds.), Interrogating racism in qualitative research methodology (pp. 28-48). New York: Peter Lang.

Carter, P., Skiba, R., Arredondo, M., \& Pollock, M. (2014). You can't fix what you don't look at: Acknowledging race in addressing racial discipline disparities. Bloomington, IN: The Equity Project at Indiana University. Retrieved from http://www.indiana.edu/ atlantic/wp-content/uploads/2014/12/AcknowledgingRace_121514.pdf

Casella, R. (2001). "Being down": Challenging violence in urban schools. New York: Teachers College Press.

Clarke, J. H. (2012). A Great and Mighty Walk. Retrieved from http:// www.youtube.com/watch?v=njdQzyQnHeg.

Collins, P. H. (2004). Black feminist thought: Knowledge, consciousness, and the politics of empowerment (2nd ed.). New York: Routledge.

Connell, R. W. (2005). Masculinities. Oakland, CA: University of California Press.

Cornell, D. \& Limber, S. P. (2015). Law and policy on the concept of bullying at school. American Psychologist, 70(4), 333-343.

Crenshaw, K. W. (1991). Mapping the Margins: Intersectionality, identity politics, and violence against women of color. Stanford Law Review, 43(6), 1241-1299.

Crenshaw, K., Gotanda, N., Peller, G., \& Thomas, K. (Eds.). (1995). Critical race theory: The key writings that formed the movement. New York: The New Press.

Davis, A. (1981). Women, race, and class. New York: Vintage. 
Davis, A. (2016). Freedom is a constant struggle: Ferguson, Palestine, and the foundations of a movement. New York: Haymarket Books.

Darling-Hammond, L. (2010). The flat world and education. New York: Teachers College Press.

Delpit, L. (1998). The silenced dialogue: Power and pedagogy in educating other peoples' children. Harvard Educational Review, 58, 280-298.

Derber, C. \& Magrass, Y. R. (2016). Bully nation: How the American establishment creates a bullying society. Lawrence, KS: University Press of Kansas.

Fanon, F. (1967). Black skins, white masks. New York: Monthly Review Press.

Farber, J. (1969). The Student as nigger: Essay and stories. North Hollywood, CA: Contact Books.

Ferguson, A. A. (2001). Bad boys: Public schools in the making of black masculinity. Ann Arbor, MI: The University of Michigan.

Ferri, B. A. \& Bacon, J. (2011). Beyond inclusion: Disability studies in early childhood teacher education. In B. S. Fennimore \& A. L. Goodwin (Eds.), Promoting social justice for young children: Advances in theory and research, implications for practice (pp. 137146). Netherlands: Springer.

Foster, K. M. (2004). Coming to terms: A discussion of John Ogbu's cultural-ecological theory of minority academic achievement. Intercultural Education, 14(4), 369-384.

Gee, J. P. (2014). An introduction to discourse analysis: Theory and method. New York: Routledge.

Gillborn, D. (1995). Racism and antiracism in real schools: Theory, policy, and practice. Philadelphia, PA: Open University Press. 
Gillborn, D. (1998). Racism, selection, poverty and parents: New labour, old problems? Journal of Education Policy, 13(6), 717-735.

Gillborn, D. (2005). Education as an act of white supremacy: Whiteness, critical race theory and educational reform. Journal of Education Policy, 20(4), 485-505.

Gillborn, D. (2013). The policy of inequity: Using CRT to unmask white supremacy in education policy. In M. Lynn \& A. D. Dixson (Eds.), Handbook of Critical Race Theory in education (pp. 129-139). New York: Routledge.

Glesne, C. (1999). Becoming qualitative researchers: An introduction (2nd ed.). Don Mills, Ontario, Canada: Longman.

Glesne, C. (2006). Becoming qualitative researchers: An introduction ( $3^{\text {rd }}$ ed.). New York: Pearson Education, Inc.

Gordon, B. M. (1990). The necessity of African-American epistemology for educational theory and practice. Journal of Education, 172(3), 88-106.

Grant, L. (1982, September). Black females' 'place' in desegregated classrooms. Paper presented at the American Sociological Association Meeting, San Francisco, CA.

Gregory, A. \& Weinstein, S. R. (2008). The discipline gap and African Americans: Defiance or cooperation in the high school classroom. Journal of School Psychology, 46, $455-475$.

Gregory, A., Skiba, R., \& Noguera, P. A. (2010). The achievement gap and the discipline gap: Two sides of the same coin? Educational Researcher, 39(1), 59-68.

González, N., Moll, L., and Amanti, C. (2005). Funds of knowledge: Theorizing practices in households, communities, and classrooms. New Jersey: Lawrence Erlbaum Associates, Publishers. 
Hanley, M. S. \& Noblit, G. W. (2009). Cultural responsiveness, racial identity and academic success: A review of literature. Pittsburgh, PA: The Heinz Endowments. Retrieved from http://www.heinz.org/UserFiles/Library/Culture-Report_FINAL.pdf

Harris, C. L. (1993). Whiteness as property. Harvard Law Review, 106(8), 1707-1791.

Hatt, B. (2011). Smartness as a cultural practice in schools. American Educational Research Journal, 49(3), 438-460.

Hill-Collins, P. (1998). Fighting words: Black women and the search for justice. Minneapolis, Minnesota: University of Minnesota Press.

Hill-Collins, P. (2015). Intersectionality's definitional dilemmas. Annual Review Sociology, 41, 1-20. Retrieved from http://www.annualreviews.org/doi/pdf/10.1146/annurev-soc073014-112142

Hill-Collins, P. \& Bilge, S. (2016). Intersectionality. Cambridge, UK: Polity.

Hoff, P. (2013). Lecture on Schools and Hegemony. Personal Collection of P. Hoff, Illinois State University, Normal IL.

Hoff, P. T. \& Martin, K. (in press). Colonizing communities: Smartness and the ideology of domination.

Holben, D. M. \& Zirkel, P. A. (2014). School bullying litigation: An empirical analysis of the case law. Akron Law Review, 47(2), 299-328.

Jacobson, R. B. (2010). Narrating characters: The making of a school bully. Interchange, 41(3), 255-283.

Kailin, J. (2002). Antiracist education: From theory to practice. Lanham, MD: Rowman \& Littlefield. 
King, J. (1991). Dysconscious racism: Ideology, identity, and the miseducation of teachers. Journal of Negro Education, (60)2, 133-146.

King, J. (2006). If our objective is justice: Diaspora literacy, heritage knowledge, and the praxis of critical studyin' for human freedom. In A. Ball (Ed.), With more deliberate speed: Achieving equity and excellence in education--realizing the full potential of Brown v. Board of education, 105th yearbook of the national society for the study of education (pp. 337-357). Chicago: University of Chicago Press.

King, J. (2011). Who dat say (we) “Too depraved to be saved”?: Remembering Katrina/Haiti (and beyond): critical studyin' for human freedom. Harvard Educational Review, 81(2), 343-371.

King, J. E. (2015). Dysconscious racism, Afrocentric praxis, and education for human freedom: Through the years I keep on toiling, the selected work of Joyce E. King. New York: Routledge.

Kohn, A. (2005). Unconditional: Teaching the whole child requires that we accept students for who they are rather than for what they do. Educational Leadership, 20-24.

Kunjufu, J. (1998). To be popular or smart: The Black peer group. Chicago: African American Images.

Ladson-Billings, G. (1994). The dreamkeepers: Successful teachers of African American children. San Francisco: Jossey-Bass.

Ladson-Billings, G. (1995). Toward a theory of culturally relevant pedagogy. American Educational Research Journal, (32), 465-491.

Ladson-Billings, G. (2000). Fighting for our lives: Preparing teachers to teach African American students. 
Lareau, A. (1989). Home advantage: Social class and parental intervention in elementary education. London: Falmer Press.

Leonardo, Z. (2004). The color of supremacy: Beyond the discourse of 'white privilege'. Educational Philosophy, 36(2), 137-152.

Leonardo, Z., \& Boas, E. (2013). Other kids' teachers: What children of color learn from White women and what this says about race, whiteness, and gender. In M. Lynn and A. Dixson (Eds.), Handbook of critical race theory in education (pp. 313-323). New York: Routledge.

Leonardo, Z. \& Broderick, A. A. (2011). Smartness as property: A critical exploration of intersections between whiteness and disability studies. Teachers College Record, 113(10), 2206-2232.

Leonardo, Z. \& Porter, R. K. (2010). Pedagogy of fear: toward a Fanonian theory of 'safety' in race dialogue. Race Ethnicity and Education, 13(2), 139-157.

Lewis, A. E. (2001). There is no "race" in the schoolyard: Color-blind ideology in an (almost) all-White school. American Educational Research Journal, 38(4), 781-811.

Lewis, A. E. (2004). Race in the schoolyard: Negotiating the color line in classrooms and communities. Chicago: University of Chicago Press.

Lensmire, T. J. (2010). Ambivalent white racial identities: Fear and an elusive innocence. Race, Ethnicity, and Education, 13(2), 159-172.

Loewen, James W. 2005. Sundown towns: A hidden dimension of American racism. New York: New Press. 
Lorde, A. (1984). Sister outsider: Essays and speeches by Audre Lorde. Berkeley, CA: The Crossing Press.

Maxwell, J. A. (1992). A synthesis of similarity/continuity distinctions. Poster presented at the Annual meeting of the American Anthropological Association, San Francisco, CA.

Meiners, E. (2007). Right to be hostile: Schools, prisons, and the making of public enemies. NewYork: Routledge.

Mills, M. \& Keddie, A. (2010). Cultural reductionism and the media: Polarising discourses around schools, violence and masculinity in an age of terror. Oxford Review of Education, 36(4), 427-444.

Mitchell, D. M. \& Borg, T. (2013). Examining the lived experience of bullying: A review of the literature from an Australian perspective. Pastoral Care in Education, 31(2), 142155.

Morris, M. W. (2016). Pushout: The criminalization of Black girls in schools. New York: The New Press.

Moule, J. (2009). Understanding unconscious biases and unintentional racism. Phi Delta Kappan, 321-326.

Murrell, P.C., Jr. (2009). Identity, agency, and culture: Black achievement and educational attainment. In L. C. Tillman (Ed.), Handbook of African American education (pp. 89-105). Thousand Oaks: CA: Sage Publishers.

Myers, L. J. (1987). The deep structure of culture: Relevance of traditional African culture in contemporary life. Journal of Black Studies, 18 (1), 72-85.

Nash, J. (2008). Re-thinking intersectionality. Feminist Review, 89, 1-15.

Nash, J. (2014). Institutionalizing the margins. Social Text 118, 32(1), 45-65. 
Noddings, N. (1992). The challenge to care in schools: An alternative approach to education. New York: Teachers College.

Noguera, P. (2009). The trouble with black boys: And other reflections on race, equity, and the future of public education. San Francisco, CA: Jossey-Bass.

Omi, M. \& Winant, H. (1993). On the theoretical status of the concept of race. In C. McCarthy \& W. Crichlow (Eds.), Race, identity, and representation in education (pp. 310). NewYork: Routledge.

Patton, M.Q. (1990). Qualitative evaluation and research methods (2nd ed.). Newbury Park, CA: Sage.

Peshkin, A. (1998). In search of subjectivity—one's own. Educational Research, 17(7), 17-21.

Ratteray, J. D. (1994). The search for access and content in the education of AfricanAmericans. In M. Shujaa (Ed.), Too much schooling, too little education: A paradox of Black life in white societies. Trenton, NJ: African World Press, Inc.

Rigby, K. \& Bagshaw, D. (2003) Prospects of adolescent students with teachers in Addressing issues of bullying and conflict in schools. Educational Psychology, 23(5), 535-546.

Rogers, R., Malancharuvil-Berkes, E., Mosley, M., Hui, D., \& O’Garro-Joseph, G. (2005). Critical discourse analysis in education: A review of the literature. Review of Educational Research, 75(3), 365-416.

Selden, S. (2000). Eugenics and the social construction of merit, race and disability. Journal of Curriculum Studies, 32(2), 235-252.

Shujaa, M. J. (1993). Education and schooling: You can have one without the other. Urban Education, 27(4), 328-351. 
Siddle Walker, V. (1993). Interpersonal caring in the "good" segregated schooling of AfricanAmerican Children: Evidence from the Case of Caswell County Training School. Urban Review, 25(1), 63-77.

Skiba, R., Arredondo, M., \& Rausch, M. K. (2014). New and developing research on disparities in discipline. Bloomington, IN: The Equity Project at Indiana University. Retrieved from http://www.indiana.edu/ atlantic/wp-content/uploads/2014/.pdf

Smedley, A. \& Smedley, B. D. (2005) Race as biology is fiction, racism as a social problem is real: Anthropological and historical perspectives on the social construction of race. American Psychologist, 60(1), 16-26.

Smedley, A. \& Smedley, B. D. (2011). Race in North America: The origin and evolution of a worldview. Boulder, CO: Westview Press.

Smith, W. A., Yosso, T. J., \& Solórzano, D. G. (2007). Racial primes and Black misandry on historically white campuses: Toward critical race accountability in educational administration. Education Administration Quarterly, 43(5), 559-585.

Solórzano, D. \& Solórzano, R. (1995) The Chicano educational experience: A proposed framework for effective schools in Chicano communities. Educational Policy, 9, $293-314$.

Solórzano, D. G. \& Yosso, T. J. (2001). Critical race and LatCrit theory and method: Counter-storytelling. Qualitative Studies in Education, 14(4), 471-495.

Solórzano, D. G. \& Yosso, T. J. (2002). Critical race methodology: Counter-storytelling as an analytical framework for education research. Qualitative Inquiry, 8(23), $23-44$. 
Steele, C. (1992). Race and the schooling of Black Americans. Memo to the Faculty: Faculty Teaching Excellence Program, 64. Office of Academic Affairs, University of Colorado at Boulder.

Stiggins, R. (2014). Revolutionize assessment. Thousand Oaks, CA: Corwin A SAGE Company.

Tatum, B. D. (1997). Why are all the Black kids sitting together in the cafeteria? And other conversations about race. New York: Basic Books.

Thompson, A. (1998). Not the color purple. Harvard Educational Review, 68(4), 522-554.

Thompson, A. (1999). Colortalk: Whiteness and off white. Educational Studies: A Journal of American Educational Studies Association, 30(2), 141-160.

Thompson, A. (2003). Caring in context: Four feminist theories on gender in education. Curriculum and Inquiry, 33(1), 9-65.

Tierney, W. (1995). (Re)Presentation and voice. Qualitative Inquiry, 1, 379-390.

Tillman, L. (2002). Culturally sensitive research approaches: An AfricanAmerican perspective. Educational Researcher, 31(9), 3-12.

Tillman, L. C. (2006). Researching and writing from an African-American perspective: Reflective notes on three research studies. International Journal of Qualitative Studies in Education, 19(3), 265-287.

Valencia, R. R. (2010). Dismantling contemporary deficit thinking: Educational thought and practice. New York: Routledge.

Valenzuela, A. (1999). Subtractive schooling: U.S. Mexican youth and the politics of caring. Albany: State University of New York Press. 
Walton, G. (2005a). “Bullying widespread": A critical analysis of research and public discourse on bullying. Journal of School Violence, 4(1), 91-118.

Walton, G. (2005b). The notion of bullying through the lens of Foucault and critical theory. Journal of Educational Thought, 39(1), 55-73.

Watkins, W. H. (2001). The white architects of black education: Ideology and power in America,1865-1954. New York, New York: Teachers College Press.

Webb-Johnson, G. (2002). Are schools ready for Joshua? Dimensions of African American culture among students identified as having behavioral/emotional disorders. Qualitative Studies in Education, 15(6), 653-671.

Winkle-Wagner, R. (2010). Foundations of educational inequality: Cultural capital and social reproduction. ASHE Higher Education Report. 36(1), 1-115.

Wolcott, H. F. (1990). On seeking — and rejecting — validity in qualitative research. In E. W. Eisner \& A. Peshkin (Eds.), Qualitative inquiry in education: The continuing debate (pp. 121-152). New York: Teachers College Press.

Woodson, C. G. (2006). The mis-education of the negro. Drewryville, Virginia: Khalifah's Booksellers \& Associates.

Winkle-Wagner, R. (2009). Race, gender, and identity among black women in college. Baltimore: John Hopkins University Press.

Yosso, T. (2005). Whose culture has capital? A critical race theory discussion of community cultural wealth. Race Ethnicity and Education, 8(1), 69-91. 


\section{APPENDIX A: INTERVIEW QUESTIONS}

1. I'm just trying to figure out who gets identified as a bully and who doesn't. Have you ever seen bullying?

2. Do you know someone who is a bully? If so, tell me about them. How do you know they are a bully?

3. Tell me a story of someone you know who was bullied.

4. If you were ever bullied, how would you handle it?

5. How fairly do you think bullying gets handled at school by teachers and administrators?

a. Was it fair who was told they were a bully?

b. Were all kids protected fairly? Were all kids believed?

6. Have you ever been identified as a bully? Have people at school ever told you were a bully?

a. Why haven't you been identified as a bully?

b. Do you think you're a bully now?

7. What kinds of kids do you think are more likely to get bullied?

a. Have you known more boys or girls to be bullied?

b. Have you known more gay or straight kids to be bullied?

c. have you known more Black, Latino, and Asian kids to be bullied or white kids?

8. In what ways do you think schools can contribute to bullying happening?

9. Anything else you would like to add about bullying? 


\section{APPENDIX B: RECRUITMENT SCRIPT FOR STUDENTS \\ Email Communication to Students}

\section{Dear Students,}

My name is Kathleen O'Brien and I am a graduate student at ISU. I am conducting research on high school students' perceptions of bullying. Your participation would involve being interviewed by me for approximately 1 hour at school. The interview will be audio recorded. You will receive a $\$ 15$ gift card for participation regardless if you decide to withdraw from the study or stop the interview at any time. The interview will not interfere with your in-class instruction time as it will be arranged during a study period or before or after school.

If you think you might be interested in being interviewed on the topic, please read the following information about the details and consent/assent forms that need to be signed by you and/or your parents/guardian if you are under 18 .

Students 18 and over: if you would like to participate (be interviewed) please respond to this email. I will set up a time to meet with you and provide a consent form for you to sign.

Students under 18: if you would like to participate (be interviewed) please respond to this email and have your parents or guardian complete the attached permission form. If needed, hard copies of the permission forms are also available in the main office. The parental/guardian permission form must be signed and returned to me before the interview occurs.

If you have any questions, please do not hesitate to ask. Thank you for your consideration!

Sincerely,

Kathleen O'Brien

XXXXXXX@ilstu.edu

$\mathrm{XXX}-\mathrm{XXX}-\mathrm{XXX}$ 